University of Louisville

ThinkIR: The University of Louisville's Institutional Repository

Electronic Theses and Dissertations

$5-2017$

\title{
The sounds behind language : three musical settings of Beckett's not I by Heinz Holliger, Paul Rhys, and Agata Zubel.
}

Trevor Roy DeJarnett

University of Louisville

Follow this and additional works at: https://ir.library.louisville.edu/etd

Part of the Musicology Commons

\section{Recommended Citation}

DeJarnett, Trevor Roy, "The sounds behind language : three musical settings of Beckett's not I by Heinz Holliger, Paul Rhys, and Agata Zubel." (2017). Electronic Theses and Dissertations. Paper 2670.

https://doi.org/10.18297/etd/2670

This Master's Thesis is brought to you for free and open access by ThinkIR: The University of Louisville's Institutional Repository. It has been accepted for inclusion in Electronic Theses and Dissertations by an authorized administrator of ThinkIR: The University of Louisville's Institutional Repository. This title appears here courtesy of the author, who has retained all other copyrights. For more information, please contact thinkir@louisville.edu. 
THE SOUNDS BEHIND LANGUAGE:

THREE MUSICAL SETTINGS OF BECKETT'S NOT I

BY HEINZ HOLLIGER, PAUL RHYS, AND AGATA ZUBEL

By

Trevor Roy DeJarnett

B.M.Ed., University of Louisville, 2012

\author{
A Thesis \\ Submitted to the Faculty of the \\ School of Music of the University of Lousiville \\ in Partial Fulfillment of the Requirements \\ for the Degree of
}

Master of Music

in Music History and Literature

Department of Music History

University of Louisville

Louisville, Kentucky

May 2017 
Copyright 2017 by Trevor Roy DeJarnett

All rights reserved 

THE SOUNDS BEHIND LANGUAGE:

THREE MUSICAL SETTINGS OF BECKETT'S NOT I BY HEINZ HOLLIGER, PAUL RHYS, AND AGATA ZUBEL

$$
\text { By }
$$

Trevor DeJarnett

B.M.Ed., University of Louisville, 2012

A Thesis Approved on

April 14, 2017

by the following Thesis Committee:

Dr. Caroline Ehman

Thesis Director

Dr. Devin Burke

Committee Member

Dr. Krzysztof Wolek

Committee Member 


\section{DEDICATION}

This thesis is dedicated to my trumpet instructor,

the late Dr. Michael Tunnell,

who always demanded my best in every musical pursuit. 


\section{ACKNOWLEDGEMENTS}

I would like to thank my thesis advisor, Dr. Caroline Ehman, for her commitment to my success in this endeavor. I would also like to thank Matt Ertz of the University of Louisville Dwight Anderson Music Library for all his insight into research materials and helping me find several hidden gems. Additionally, I would like to thank my other committee members, Dr. Devin Burke and Dr. Krzyzstof Wolek, for their dedication to serving on my committee and their invaluable input.

I would also like to thank several people and organizations that provided me with study materials that were an integral part of my work. First, Dr. Paul Rhys and Agata Zubel were both willing to answer my questions about their work over email. Dr. Rhys also provided me with access to his unpublished score manuscript and a live recording of the work. I would also like to thank Schott Music for sending me the unpublished recording of Heinz Holliger's Not I. I am especially indebted to Dr. Heidy Zimmermann, the curator of the Heinz Holliger collection at the Paul Sacher Foundation who provided me with the manuscript of Holliger's unpublished score.

Most importantly, I would like to thank my wife, Brittany, who made every sacrifice to ensure my success in this undertaking, including letting my books and materials overtake a significant portion of our household for several months. 


\section{ABSTRACT \\ THE SOUNDS BEHIND LANGUAGE \\ Trevor Roy DeJarnett}

April 14, 2017

Samuel Beckett's literary and dramatic works have served as sources of inspiration in the last five decades for multiple composers such as Morton Feldman and György Kurtág. Beckett's late minimalist monologue Not I (1972) is the basis for recent compositions by Heinz Holliger, Paul Rhys, and Agata Zubel. While scholars have discussed similarities between Beckett's style and individual musical works, a comprehensive study of multiple compositions based on the same work by Samuel Beckett has not yet been completed. Each of these compositions reflects various aspects of Beckett's late dramatic style such as his use of rhythm, depiction of internal voices, and exploration of speech production. These musical works highlight aural features of Beckett's Not I uniquely through the medium of music. This study will reveal how these musical works emphasize the sonic content of Beckett's Not I in a significant manner. 


\section{TABLE OF CONTENTS}

\begin{tabular}{|c|c|}
\hline & PAGE \\
\hline ACKNOWLEDGMENTS.. & \\
\hline 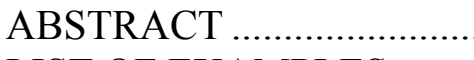 & $\ldots \ldots \mathrm{V}$ \\
\hline LIST OF EXAMPLES ... & ......ix \\
\hline
\end{tabular}

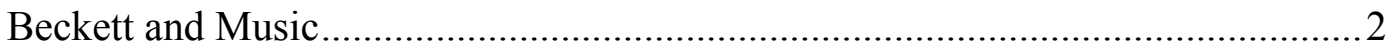

Beckett's Not I in Academic Criticism ........................................................ 3

CHAPTER 1: BECKETT'S LATE DRAMATIC STYLE IN NOT I .......................... 8

Beckett's Monologue Not I: Dconstruction of Narrative and Character ................ 8

The Sound of MOUTH's Monologue ....................................................... 12

Large-Scale and Small-Scale Forms ........................................................ 13

MOUTH's Character: "Theatereality”, and Voices ............................................. 17

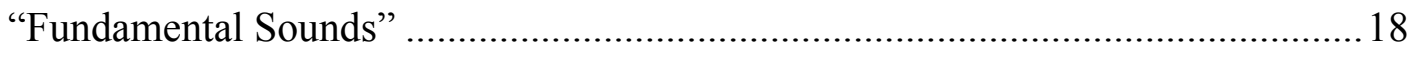

Short Composer Biographies ................................................................. 19

CHAPTER 2: "VISCERAL INTENSITY” IN RHYS'S NOT I FOR PIANO SOLO....22

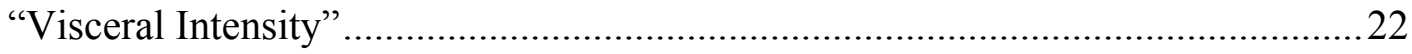

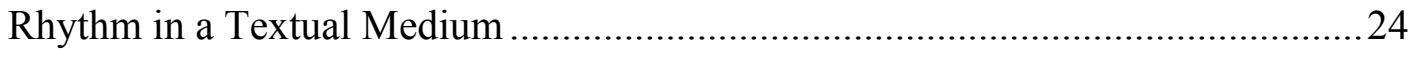

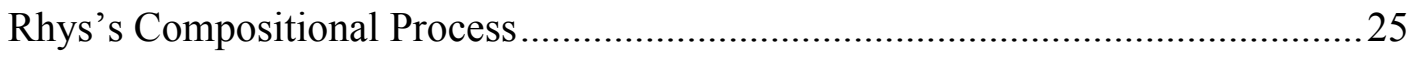

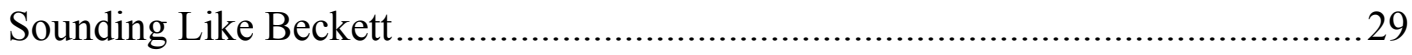

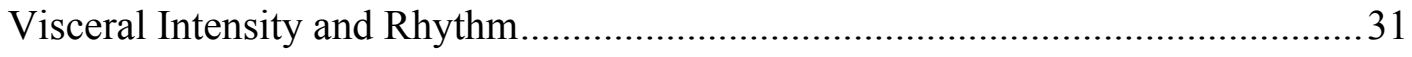




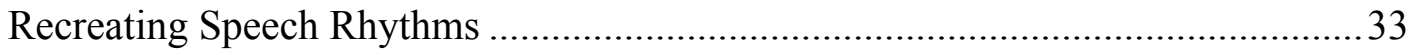

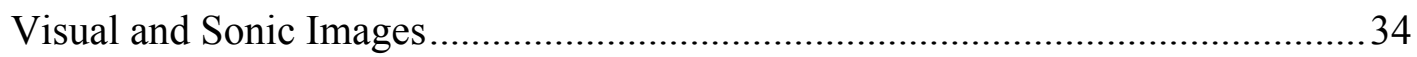

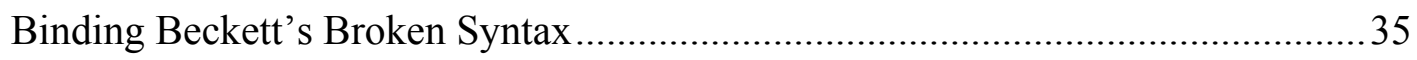

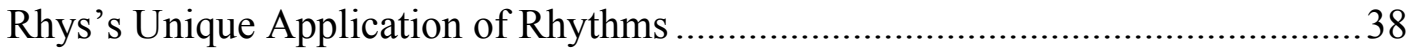

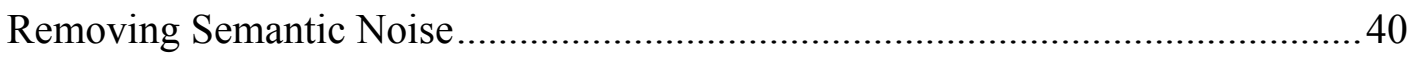

CHAPTER 3: REINTRODUCING THE INTERMEDIARY VOICE: AUDIENCE AS TYMPANUM IN HOLLIGER'S NOT I ...............................................................42

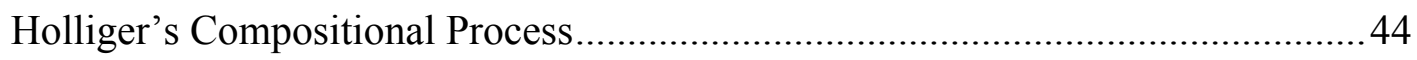

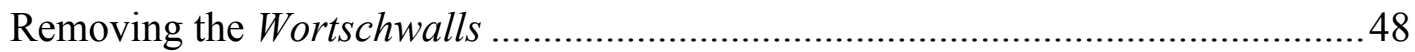

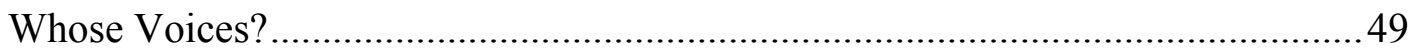

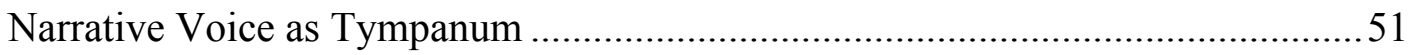

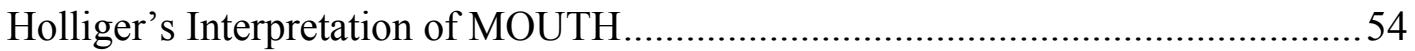

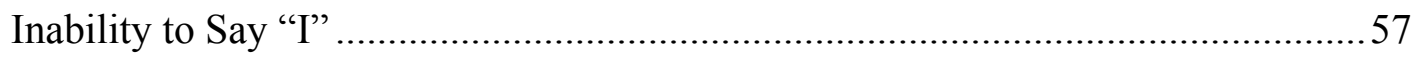

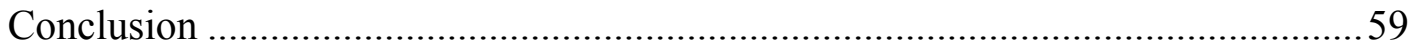

CHAPTER 4: REINSTATING MOUTH AS HUMAN IN ZUBEL'S NOT I................61

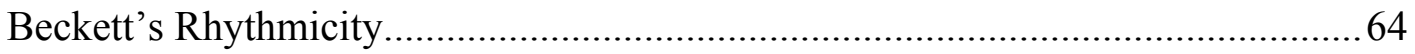

Rhythmic Pitched Section: Compositional Process .................................................66

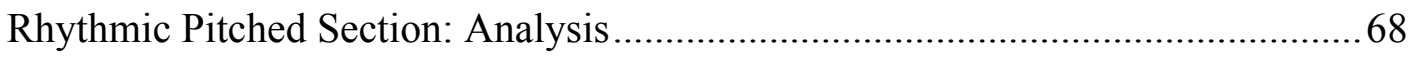

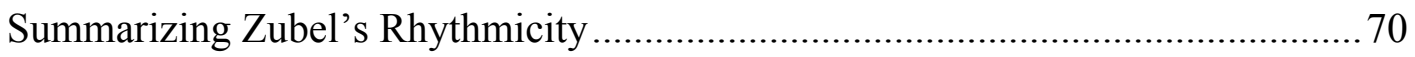

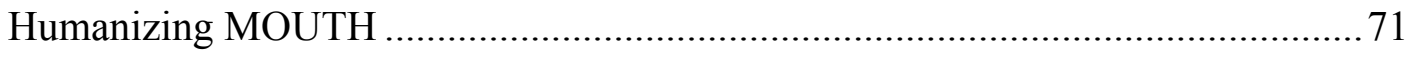

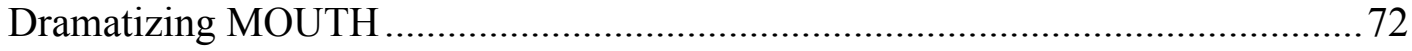

Speech Production and Beckett's "Fundamental Sounds" .....................................75

Fragmenting the Text ........................................................................................

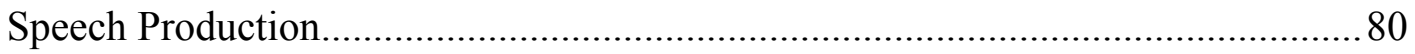


"Theatereality"

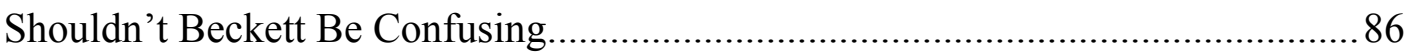

CHAPTER 5: THE “THINGS” BEHIND LANGUAGE ....................................... 89

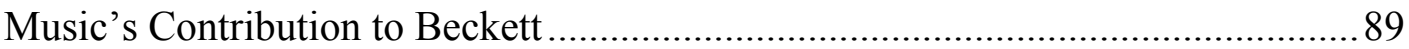

Removing Words to Expose Rhythmic Patterning ..............................................91

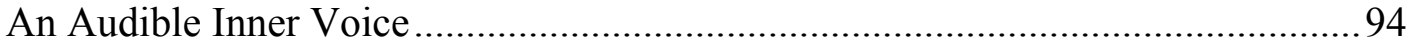

Fragmenting Words with Articulation ...................................................... 97

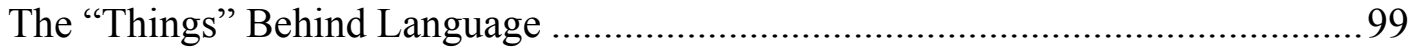

Areas of Further Research..................................................................... 101

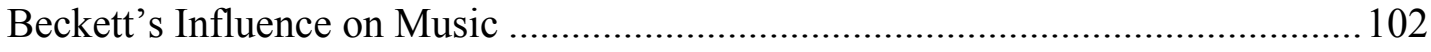

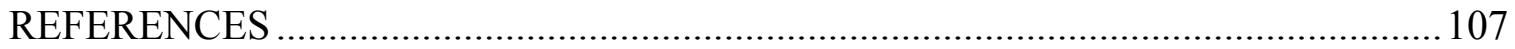

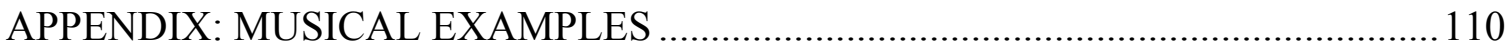

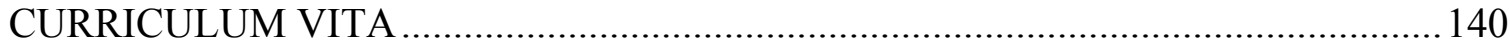




\section{LIST OF EXAMPLES}

EXAMPLE

PAGE

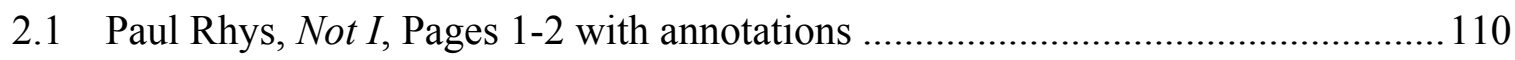

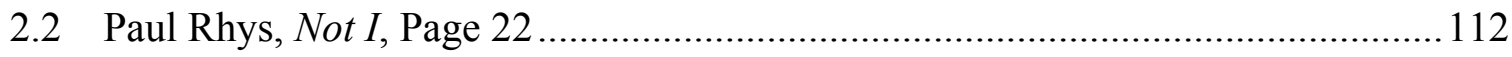

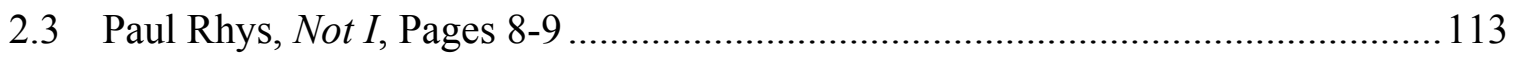

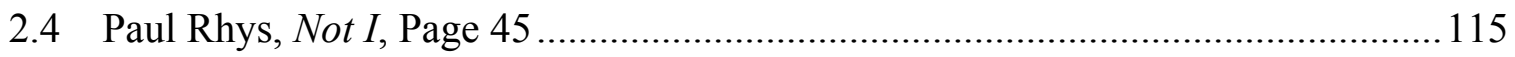

2.5 Samuel Beckett, Not I, Annotated excerpt …............................................. 116

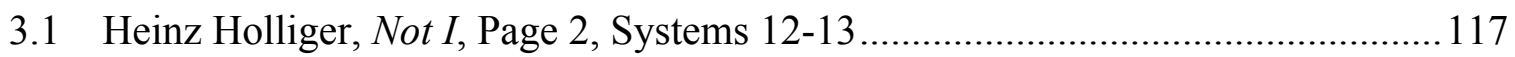

3.2 Heinz Holliger, Not I, Page 2, Systems 20-21 ................................................ 118

3.3 Heinz Holliger, Not I, Page 2, System 15, Entrance of tape ............................... 119

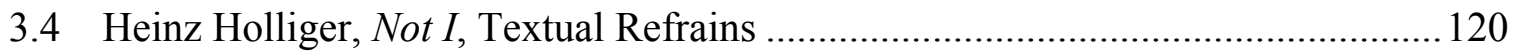

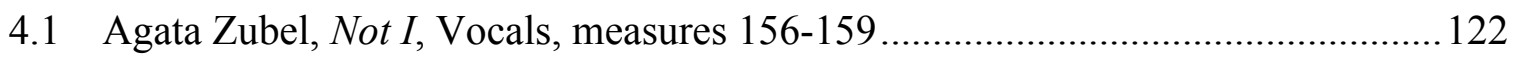

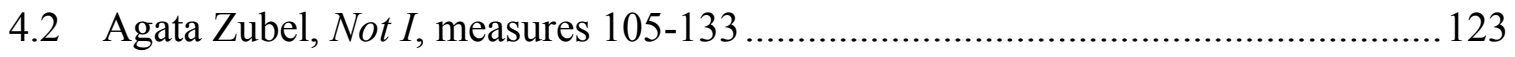

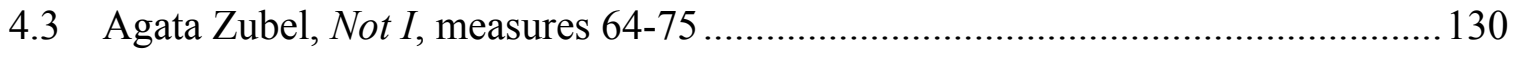

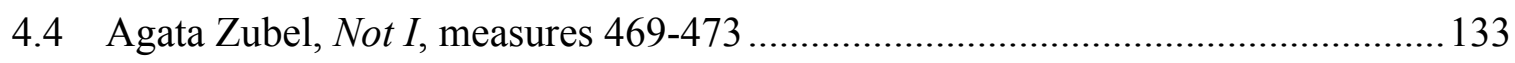

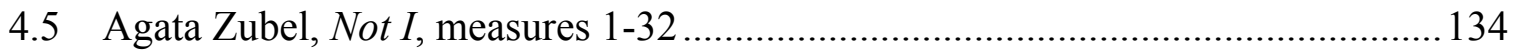

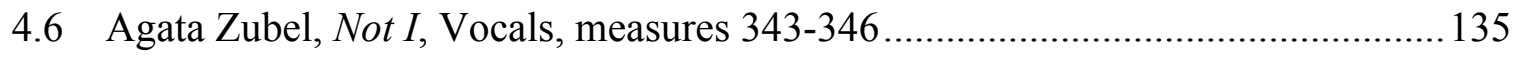

4.7 Agata Zubel, Not I, Comparison of multiple vocal styles ................................ 136

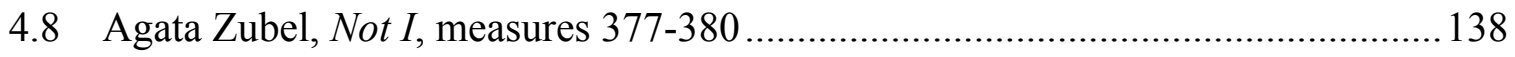




\section{INTRODUCTION}

The dramatic works of the Irish playwright and novelist Samuel Beckett have provoked audience members and academics to a wide range of responses regarding Beckett's deconstruction of narrative, rejection of standard dramatic elements, and unusual staging. Multiple modern composers, such as Morton Feldman and György Kúrtag, have been inspired to compose works based on various Beckett texts. These compositions, in turn, have led to academic interest in studying the relationship between each composition and the related Beckett work. Mary Bryden published the first collection of essays solely focused on the relationship between Beckett and music in 1998; similar collections of essays have since followed. ${ }^{1}$

The academic literature on compositions based on Beckett texts has been limited mostly to either one individual composer or even just one specific composition. ${ }^{2}$ While this approach is obviously valid, recent compositions have provided a valuable opportunity to analyze multiple composers' interpretations of the same dramatic text. A particularly intriguing case is Beckett's late dramatic work Not I that has been set in its entirety by three different composers: Heinz Holliger, Paul Rhys, and Agata Zubel. This

\footnotetext{
${ }^{1}$ See: Mary Bryden, ed., Samuel Beckett and Music, (Oxford: Clarendon Press, 1998); Lois Oppenheim, ed., Samuel Beckett and the Arts: Music Visual Arts, and Non-Print Media, (New York: Garland Publishing, 1999); Sara Jane Bailes and Nicholas Till, eds., Beckett and Musicality, (Burlington, VT: Ashgate, 2014).

${ }^{2}$ The only exception I have found to this is “...dire cela, sans savoir quoi...:” Samuel Beckett in der Musik von György Kurtág und Heinz Holliger by Michael Kunkel.
} 
study will reveal how these three different compositions, although based on the same work, reflect different aspects of Beckett's late dramatic style.

\section{Beckett and Music}

The academic fascination with Beckett and musicality is a natural outgrowth from Beckett's late dramatic style. Beckett is much more fascinated with how the words in his drama sound than what his words mean. While I will elaborate on the implications of Beckett's focus on sound throughout this study, two quotes from the playwright himself will be most effective for now.

My work is a matter of fundamental sounds (no joke intended), and I accept responsibility for nothing else. ${ }^{3}$

It is indeed becoming more and more difficult, even senseless, for me to write an [sic] official English. And more and more my own language appears to me like a veil that must be torn apart in order to get at the things (or the Nothingness) behind it...As we cannot eliminate language all at once, we should at least leave nothing undone that might contribute to its falling into disrepute. To bore one hole after another in it, until what lurks behind it - be it something or nothing - begins to seep through; I cannot imagine a higher goal for a writer today. ${ }^{4}$

Beckett's works cannot be approached with the expectation that language will operate in a typical manner. As these quotes demonstrate, Beckett has no interest in expanding the semantic function of language but in finding "what lurks behind it."

With Beckett's focus on sound, music seems a natural parallel to Beckett's artistic goals. However, critics like Eric Prieto have expressed a legitimate concern that using musical terms and descriptors for Beckett's work seems like an end goal in itself in some

\footnotetext{
${ }^{3}$ Keir Elam, "Not I: Beckett's Mouth and the Ars(e) Rhetorica," in Beckett at 80/Beckett in Context, ed. Enoch Brater (New York: Oxford University Press, 1986), 124.

${ }^{4}$ Samuel Beckett, Disjecta, ed. Ruby Cohn (New York: Grove Press, 1984), 171-172.
} 
Beckett criticism. ${ }^{5}$ Prieto goes on to cite musical terms like "counterpoint" and "leitmotif" that have made the rounds in Beckett scholarship without truly revealing much about Beckett's art. Therefore, I consider it necessary to assure my reader that this study will not be a scavenger hunt for basic stylistic parallels between Beckett's Not I and the three compositions. I do not feel inclined to produce more evidence to convince the reader that Beckett's works contain musical qualities. I also do not feel responsible for defending Rhyz, Holliger, and Zubel as composers that were able to properly reflect Beckett's style. Instead, I intend to discuss how each musical work significantly reflects on Beckett's late dramatic style in a manner only possible in music. Through these compositions, features of Beckett's style are highlighted in a manner not possible in the original dramatic work alone.

\section{Beckett's Not I in Academic Criticism}

Beckett's play Not I has received a large amount of academic attention in the areas of dramatic and literary criticism as an important source for examining Beckett's later dramaturgical aesthetics. Not I is even grouped into what R. Thomas Simone terms the "other trilogy" in his essay about three dramas from the 1970s in Beckett's oeuvre with similar aesthetics. ${ }^{6}$ Bestowing this title on the play (in a frequently cited article of Beckett criticism) demonstrates the prestige of the play as the term is reminiscent of the trilogy of novels that is most frequently discussed regarding Beckett. ${ }^{7}$

\footnotetext{
${ }^{5}$ Eric Prieto, Listening In (Lincoln, NE: University of Nebraska Press, 2002), 163-164.

${ }^{6}$ R. Simone, "Beckett's Other Trilogy: Not I, Footfalls, and Rockaby," in 'Make Sense who May:' Essays on Samuel Beckett's Later Works, ed. Robin Davis and Lance St. J. Butler. Irish Literary Studies 30 (Gerrards Cross: Collin Smythe), 56-65. As the title of this article suggest, Footfalls and Rockaby are the other members of this trilogy.

${ }^{7}$ This trilogy of novels consists of Molloy, The Unnamable, and Mallone Dies.
} 
Not I belongs to a group of works that James Knowlson and John Pilling summarize as "the short plays of the 70s." ${ }^{\prime 8}$ The short monologue involves an actress, MOUTH, who delivers a dizzyingly rapid outpouring of words for about twelve minutes. To make Not I even more striking, the entire stage is left in darkness save the actress's mouth, which is illuminated by a spotlight. The only other character on stage is AUDITOR who never speaks, but simply raises his/her arms on a few occasions as detailed in the script.

Chapter 1 will include a lengthier description of Beckett's Not I along with a discussion of pertinent characteristics of Beckett's late dramatic style. This chapter will prepare the reader for the more nuanced readings of Beckett's style in the following chapters. Each composer's work will be given a dedicated chapter. Each chapter will start with a brief introduction to the composer's work and their specific approach to the drama Not I. At least one study from the area of literary criticism will be utilized in each chapter as a starting point for a deeper discussion of each composition's relationship to Beckett's style. Like much of Beckett criticism, there is a broad range of approaches to interpreting and discussing Not I. As John Kundert-Gibbs asserts, “...there should never be...a consensus about work of this complexity and power." ${ }^{\prime 9}$ As this study will show, these three compositions illustrate this very claim as each composition amplifies particular components of Beckett's style.

Chapter 2 will address Paul Rhys's Not I for solo piano (1995), a work that removes the text of Beckett's Not I. This chapter will explore Rhys's own writings on his

\footnotetext{
${ }^{8}$ James Knowlson and John Pilling, Frescos of the Skull: The later prose and drama of Samuel Beckett (New York: Grove Press, 1980).

9 John Kundert-Gibbs, No-Thing is Left to Tell: Zen/Chaos Theory in the Dramatic Art of Samuel Beckett (Cranbury, NJ: Associated University Presses, 1999), 17.
} 
compositional method, and how Rhys incorporates Beckett's rhythmic style in his composition. The majority of literary criticism recognizes a structural role in Beckett's use of rhythm. For example, H. Porter Abbott writes lucidly about Beckett's rhythmic techniques, specifically describing the larger formal technique of "recurrence" that occurs over larger stretches of material in Beckett's work. ${ }^{10}$ However, Rhys's Not I goes beyond utilizing Beckett's rhythmicity as a mere structural feature. Instead, his composition reflects interesting parallels to Maria Ristani's research of rhythmic devices in Beckett that function beyond a structural role. Ristani's linguistic-based research describes Beckett's rhythm as "an alternative to conventional syntax." ${ }^{\text {"1 }}$ Ristani demonstrates how Beckett's style is rooted in "affect" as opposed to "emotion;" thus his style does not require a semantic understanding of the text to be fully appreciated, relying instead on "visceral intensity." 12 As my musical analysis will demonstrate, Rhys not only imitates the visceral intensity of Beckett's text; but his piano work removes the semantic noise of Beckett's text to bring his rhythmic style to the fore.

Chapter 3 will discuss Heinz Holliger's Not I für Sopran und Tonband (1978), a work that allows the listener to experience MOUTH from an entirely new perspective. This chapter will begin by discussing the soprano's vocal style and its relationship to the tape. Next, Eric Prieto's insightful study of internal and external voices in Beckett's late works will be described in detail. ${ }^{13}$ Prieto is particularly fascinated by Beckett's narrative voices in literary works; the narrators of Beckett's texts are tasked with describing all the

\footnotetext{
${ }^{10}$ H. Porter Abbott, "Samuel Beckett and the Arts of Time," in Samuel Beckett and the Arts: Music, Visual Arts, and Non-print Media, edited by Lois Oppenheim (New York: Garland Publishing Inc., 1999), 1820.

${ }^{11}$ Maria Ristani, “Articulated Arrhythmia: Samuel Beckett's Shorter Plays,” In Beckett and Musicality, ed. by Sara Jane Bailes and Nicholas Till (Dorchester, UK: Henry Ling Limited, 2014), 120.

${ }^{12}$ Ibid., 131.

${ }^{13}$ Eric Prieto, Listening In, 194.
} 
internal and external stimuli of Beckett's literary characters. ${ }^{14}$ However, the narrative voice is stuck between these two stimuli sources; Beckett's characters cannot manage to "say I" and locate their own "founding voice." ${ }^{.15}$ Holliger shifts the audience into this narrative voice in his composition. The listener hears the internal and external voices of MOUTH as she delivers her monologue.

Chapter 4 will discuss Agata Zubel's composition Not I for vocalist, small ensemble, and tape, a composition that does not follow the same compositional process throughout like the Rhys and Holliger. Instead, Zubel presents a variety of musical textures and contrasting sections. Utilizing a diverse, small instrumental ensemble with a solo female voice, Zubel was inspired by the "birth of sound, of the voice, [in] Beckett's [Not I]" and also subscribes to the narrative-based reading of the drama as depicting a woman who suddenly begins to speak at the age of seventy. ${ }^{16}$ Zubel's depiction of MOUTH's character is the most humanizing within the three compositions; Zubel's MOUTH exhibits an ebb and flow of emotions. Zubel's reading of MOUTH contrasts with literary criticism that often ignores MOUTH's experience. As Dina Sherzer states in her study of MOUTH's marginal status, “....it seems as if critics have shied away from the literal content of the play, from the actual experience of the woman called Mouth."17 Zubel builds musical tension and employs a variety of vocal styles to portray her human character MOUTH.

\footnotetext{
${ }^{14}$ Eric Prieto, Listening In, 194.

${ }^{15}$ Ibid., 195.

16 “Agata Zubel - GiNoNeWaMo," YouTube video, 19:00, a documentary produced by Marek Obszarny and Magda Pawlinow, posted by "MrModerna," April 21, 2015, https://www.youtube.com/watch?v=BXCB5xqI-ps.

${ }^{17}$ Dina Sherzer, "Portrait of a Woman: The Experience of Marginality in Not I," in Women in Beckett: Performance and Critical Perspectives, ed. Linda Ben-Zvi (Urbana, IL: University of Illinois Press, 1980), 201.
} 
Chapter 5 will return to one of Beckett's quotes from earlier in this chapter. One of Beckett's highest goals with language was "to bore one hole after another in [language], until what lurks behind it - be it something or nothing - begins to seep through." ${ }^{\prime 18}$ After the detailed analysis of each composition and the relevant features of Beckett's style, this chapter will conclude by discussing what things are "lurking behind" language. Each composition brings out one significant aspect of Beckett's use of language without relying strictly on semantic content. Chapter 5 will argue that these features are part of the things behind language that Beckett references.

${ }^{18}$ Beckett, Disjecta, 172. 


\section{CHAPTER 1}

\section{BECKET'S LATE DRAMATIC STYLE IN NOT I}

Samuel Beckett's Not I is representative of his late dramatic style. Before beginning the more nuanced discussion of Beckett's style in the following chapters, this chapter will introduce some basic aesthetic considerations of Beckett's Not I. When possible, the general consensus of literary criticism will be provided. Discussion of other features of Beckett's work, however, will have to be limited to showing some examples of the spectrum of scholarship on the matter. These discussions will focus on the aspects of Beckett's late dramatic style that are most pertinent to my analysis of the three compositions in this study. Very brief biographies for each composer are also included at the end of this chapter.

\section{Beckett's Monologue Not I: Deconstruction of Narrative and Character}

Beckett calls for extremely sparse resources in Not I. The female character MOUTH is situated on the darkened stage "about eight feet above stage level."19 Only the actress's mouth is to be lit. A non-speaking role is played by AUDITOR, a "tall standing figure, sex undeterminable, enveloped from head to foot in loose black djellaba,

\footnotetext{
${ }^{19}$ Samuel Beckett, Samuel Beckett: The Complete Dramatic Works (Boston, MA: Faber and Faber, 1986), 376.
} 
with hood. ${ }^{20}$ Beckett situates AUDITOR four feet above the stage and desires the character look towards MOUTH throughout the performance. AUDITOR's only action is four slight movements, a raising and lowering of the arms "in a gesture of helpless compassion" when notated in the text. MOUTH's task is much more demanding. ${ }^{21}$ MOUTH delivers a monologue with over 1500 words as fast as possible with only seven short pauses; performances only last between 10-15 minutes. ${ }^{22}$

For such an extended period of talking, MOUTH's monologue is surprisingly unhelpful in explaining to the audience what this drama is all about. Bernard Beckerman's flippant explanation of MOUTH's monologue is humorous yet appropriately imprecise:

It has something to do with an elderly woman of seventy who, orphaned from birth and isolated from human contact, has a strange seizure which turns her from an all but mute solitary into a compulsive babbler eager to tell, to tell something, though whether it is her story or some obscure mystery, we never learn. Throughout, Mouth insists on referring to the subject of the story, the elderly woman, as "she." Gradually, the reader perceives that "she" must be Mouth. ${ }^{23}$

Usually, it would be inappropriate for a literary critic to start the summary of a dramatic work with the vague phrase "it has something to do with." However, Beckett's Not I resists being molded into an intelligible narrative; for the monologue is composed of short textual fragments with little or no syntactical relationship to the words around them. Additionally, as might be concluded from the title of the work, MOUTH never uses a

\footnotetext{
${ }^{20}$ Beckett, Complete Dramatic Works, 375.

${ }^{21}$ Ibid.

${ }^{22}$ To clarify, the seven pauses consist of the five first-person denials and the two moments of "silence" after the screams in the second section.

${ }^{23}$ Bernard Beckerman, "Beckett and the Act of Listening," in Beckett at 80/Beckett in Context, ed. Enoch Brater (New York: Oxford University Press, 1986), 154.
} 
first-person pronoun; and there is no logical referent for the third-person pronouns she continues to repeat. The viewer must assume that MOUTH refers to herself. ${ }^{24}$

Most literary critics offer their opinions about the meaning of particular phrases of the work. Dramatically varying opinions are common. For example, both James Knowlson/John Pilling and Enoch Brater reference the fragment "face in the grass." Knowlson/Pilling describes this as a reference to MOUTH as an old woman mistakenly getting stuck in the dark out in a field and, presumably, falling into the grass. ${ }^{25}$ Brater makes a much darker suggestion that this might refer to the repressed memory of a rape. ${ }^{26}$ This one example of contrasting interpretations is representative of the wide spectrum of interpretations of MOUTH's narrative.

However, in my study of Not I, I have found little merit in arguing over the specifics of MOUTH's life story. Every aspect of Beckett's Not I purposely discourages the audience from comprehending the actress's monologue or safely assuming MOUTH is a human. Beckett desired that the words be performed much too fast to be understood, saying: "I'm not unduly concerned with intelligibility. I want the piece to work on the nerves of the audience. ${ }^{, 27}$ The written text is not even held sacred in the script; Beckett calls for at least ten seconds of ad-libbing by MOUTH before and after the scripted text of the monologue. ${ }^{28}$ As for MOUTH's humanity, she is only visible to the audience as a garish gesticulating mouth. Of course, depending on the venue and position of the viewer,

\footnotetext{
${ }^{24}$ For an interesting discussion of the appearance of first-person pronouns in some stages of Beckett's manuscripts for Not I, see S.E. Gontarski, The Intent of Undoing in Samuel Beckett's Dramatic Texts (Bloomington, IN: Indiana University Press, 1985), 147.

${ }^{25}$ James Knowlson and John Pilling, Frescoes of the Skull: The Later Prose and Drama of Samuel Beckett (New York: Grove Press, 1980), 202.

${ }^{26}$ Enoch Brater, "The 'I' in Beckett's Not I," Twentieth Century Literature 20, no. 2 (July 1974): 202.

${ }^{27}$ As quoted in Kyle Gillette, "Zen and the Art of Self-Negation," Comparative Drama 46, no. 3 (Fall 2012): 288.

${ }^{28}$ Beckett, Complete Dramatic Works, 376, 383.
} 
the appearance of the actress's mouth can vary widely. The mouth may be an indistinguishable spot of light or a more jarring spectacle. Whether or not the mouth represents the whole human behind it is up to interpretation. Since Beckett holds little regard for the semantic details of the text and does not humanize MOUTH's character, I do not consider the wide variety of narratives constructed for MOUTH in literary criticism to be significant or informative in this study. As Beckett would say, "If people want to have headaches among the overtones, let them. And provide their own aspirin."29 Therefore, Beckerman's description, with all its ambiguities, is sufficient for this study. Generally, audiences assume MOUTH is human, despite her ambiguous form; and her tale seems to refer to some of her own experiences. (Whether they are past or present experiences is much more complicated.) Her outpouring of words does not sound completely voluntary; this is not a positive experience for MOUTH. Also, these bouts of logorrhea seem to be a rare occurrence. These basic descriptors of MOUTH's narrative are sufficient to understand this study.

The characters and narrative of Not I serve as the most obvious examples of Beckett's deconstruction of dramatic elements. By “deconstruction,” I refer to Beckett's subversion of a dramatic element's function or reordering the hierarchy of dramatic features. In the case of character, Beckett's Not I foils the audience's expectation of a monologue. Although only one speaking character is presented, the drama describes little about her. She is the lone speaking character but receives no character development. Instead of using the opportunity to provide details about the actress, Beckett avoids clearly attributing any part of the text to MOUTH.

\footnotetext{
${ }^{29}$ Keir Elam,"Not I: Beckett's Mouth and the Ars(e) Rhetorica," in Beckett at 80/Beckett in Context, ed. Enoch Brater (New York: Oxford University Press, 1986), 124.
} 
The narrative is closely entwined with the subject of character in Not I. MOUTH does not clearly describe herself, nor does she clearly describe someone else's story. Her oration is not linear, either. As the comparison above of Knowlson and Brater's interpretations of the work shows, there is no evidence of what is distant past, recent past, or present event in MOUTH's monologue. In Not I, character and narrative are the most obvious victims of Beckett's deconstructive approach to drama. However, as these typically primary elements of drama are diminished, Beckett brings other aspects of the medium to the fore.

\section{The Sound of MOUTH's Monologue}

As my introduction to Not I has made clear, MOUTH is not a typical protagonist. She rejects the life story the audience presumes to be her own, so she lacks a clear backstory. She lacks the most basic of human characteristics, not even exhibiting a human form. Yet MOUTH is of paramount importance in the drama as the single source of sound in Not I. Her rapid delivery creates the physical immediacy that initially captures the viewer's attention. She shapes the underlying rhythmic structure of the text

for audience, sometimes even mimicking the character of the words themselves. MOUTH also describes the processes of her inner conscious, explaining sounds and sensations that are completely foreign to her narrative. These aspects of MOUTH's monologue are of utmost importance to this study, for the three compositions considered in this study primarily respond to how MOUTH's monologue sounds rather than what the words mean. 
The rapid delivery of the words is a key feature of Not I and, also, the most obvious aural feature of the work. Beckett's demands for a fast tempo in Not I is also unique to this drama within his oeuvre; none of his other dramas demand such a swift outpouring of words. Most importantly, the actress's athletic speech shifts the viewer's attention from interpreting the words of the monologue to simply hearing the raw sound of the monologue. The tempo in Not I represents Beckett's initial attack on the semantic meaning of words. Beckett wishes the words' sound to be valued above the words' meaning. As Maria Ristani states, “The moment we pause to 'appreciate' or make sense of what we hear, we are lost." ${ }^{, 30}$ Therefore, the viewer begins to appreciate sound over meaning. Beckett's Not I presents more than just a 12-minute barrage of meaningless words, however. The only thing that makes these words "meaningless" is their nonconformity to the norms of language. Without proper punctuation and syntax, these words do not communicate a clear story. However, Beckett's text has underlying smallscale and large-scale structures that morph the semantically meaningless words into aurally meaningful sounds.

\section{Large-Scale and Small-Scale Forms}

Literary criticism generally agrees that Not I has a textual fragment that serves as a refrain: “...what?..who?..no!..she!..." This text occurs five times in the monologue and is described in the script as MOUTH's "refusal to relinquish third-person." ${ }^{31}$ In addition to the exact repetitions, Beckett gives this fragment particular significance through AUDITOR's gestures and writing a pause after every occurrence of this phrase.

\footnotetext{
${ }^{30}$ Maria Ristani, “Articulated Arrhythmia: Samuel Beckett's Shorter Plays," in Beckett and Musicality, ed. Sara Jane Bailes and Nicholas Till (Dorchester, UK: Henry Ling Limited, 2014), 131.

${ }^{31}$ Beckett, Complete Dramatic Works, 375.
} 
AUDITOR's four motions occur after the first four appearances of this text. This textual refrain serves as a clear delineation of five larger sections of text. Section 1 ends with the appearance of the first textual refrain, Section 2 ends with the appearance of the second textual refrain, and so on. The last textual refrain is followed by a few textual fragments as the curtain begins to fall.

I do not find any particular significance to the ordering of the sections, especially not enough to force some comparison to musical forms, but a few brief notes are helpful. Sections 1,4 , and 5 are of similar length, being significantly shorter than the longer Section 2 and 3. Section 5 also features the most repeated material of the work. For this study, the textual refrain is important as a way to reference particular sections of the text. Also, as the following chapters will demonstrate, the three composers considered in this study give varying amounts of significance to this large-scale form in their musical settings.

Small-scale structures in Not I are much more significant than the large-scale form. The repetitions, variations, and permutations within the text give momentum and fluidity to the monologue. The opening text from the work will serve as source material for insightful commentary:

...out ... into this world...this world...tiny little thing...before its time...in a godfor-... what?..girl?..yes...tiny little girl...into this...out into this...before her time... godforsaken hole called... ${ }^{32}$

Like the issue of the textual refrain in Not I, some features of Beckett's text are generally agreed upon in literary criticism. For example, I have not seen any scholarly writing on Beckett that does not mention the aspect of repetition in some way. H. Porter Abbott's discussion of repetition is especially useful because he delineates between

\footnotetext{
${ }^{32}$ Beckett, Complete Dramatic Works, 376.
} 
"recurrence" and "reiteration. ${ }^{, 33}$ Recurrence refers to repeats that are separated by a long stretch of time or, in the case of a text, intervening material. Abbott would refer to the textual refrain in Not I as recurrence. Reiteration refers to repeats that occur close to one another. While recurrence highlights similarities, reiteration accentuates variations in the material. The opening text is full of reiteration. Consider the words "out into this." One of these three words appears in five of the fragments of the opening text. This produces five iterations that are rhythmically significant to the audience because they occur so close together.

Abbott also refers to an underlying structure of "internal echoes" that can be demonstrated in this excerpt. ${ }^{34}$ This is a more nuanced interpretation of the text that is not as widely accepted as the feature of repetition. Abbott draws attention to the repetition and variations of individual sounds and articulations within each word of Beckett's text. In this example, the hard consonant [t] is overtly present. Additionally, Beckett plays with many variations of this sound with [th] and [tz] articulations. Therefore, below the word patterning that is obvious at a surface level, the arrangements of these articulations operate as an additional underlying pattern.

Maria Ristani's research on Beckett's texts points out an additional feature of this excerpt. Ristani is especially sensitive to the contrast between interruptive and flowing aspects of Beckett's text. The words “...what?..girl?..yes" is an example of what Ristani would call "structure-producing interruption." ${ }^{, 35}$ This interruption to the flow of the text

\footnotetext{
${ }^{33}$ H. Porter Abbott, "Samuel Beckett and the Arts of Time: Painting, Music, Narrative," in Samuel Beckett and the Arts: Music, Visual Arts, and Non-print Media, ed. Lois Oppenheim (New York: Garland Publishing Inc., 1999), 20.

${ }^{34}$ Ibid., 18-19.

${ }^{35}$ Maria Ristani, “Articulated Arrhythmia," 120.
} 
creates delineates between two larger lines of text that are variations of one another, as shown below.

[A]: ...out ... into this world...this world...tiny little thing...before its time...in a godfor[Interruption]: ...what?..girl?..yes

[A']: ...tiny little girl...into this...out into this...before her time...godforsaken hole called...

Both lines of text start with permutations of a similar collection of words (i.e.-tiny little thing vs. tiny little girl). And both lines terminate after phrases with "before" and "godfor-." Ristani highlights the importance of the intersecting interruptions like this in underscoring small-scale forms.

These three features, repetitions, variations, and permutations, collectively create the essential elements of Beckett's rhythmicity. Beckett's rhythmic style is based largely in these small-scale patterning forms. Throughout this study, rhythm can easily become a misleading term if viewed through the paradigm of music. Rhythm in music also relies on patterning of larger rhythmic units, such as the repeat of an entire measure of rhythm. However, the musical element of rhythm often refers to a particular pattern of sounds, such as "eighth-quarter-eighth." Beckett's Not I is less concerned with the latter, for the work is constrained by the notation of the dramatic medium. For example, musical rhythm might concern how "into this" is performed. Should it be said "eighth-eighthquarter" or "eighth-quarter-eighth?" A musical score can designate the difference precisely. Beckett's rhythm is concerned with the immediate succession of "into this" by the variation "out into this." 


\section{MOUTH's Character: "Theatereality" and Voices}

While the sounds MOUTH makes are more important than the individual words she says, certain phrases in the work are so strange that the audience will certainly begin to wonder what exactly these words mean. For example, MOUTH talks about "buzzing" fifteen times in her monologue. This is not a buzzing of bees or machinery, but a buzzing whose source MOUTH struggles to identify. At first MOUTH states “...for she could still hear the buzzing...so-called...in the ears..." Later, however, she shifts the sound source to her skull saying -“....what?..the buzzing?..yes....all the time the buzzing...socalled...in the ears...though of course actually...not in the ears at all...in the skull...dull roar in the skull..."

MOUTH's situation is far from atypical for Beckett's characters in his late works. ${ }^{36}$ Eric Prieto would likely describe this as a symptom of MOUTH's "quest to say I. ${ }^{, 37}$ She cannot distinguish between the voice of her inner conscious and the sounds of the external world. MOUTH is similar to many of the Beckett's narrative voices in his prose. As the narrative voice for the audience of Not $I$, she is describing her present situation from in-between her two worlds of sensory perception: the external world and her inner conscious. ${ }^{38}$ Because of her present state, however, she is not always entirely accurate.

Some literary critics describe this situation in an entirely different manner. ${ }^{39}$ For example, Ruby Cohn defines this talk of buzzing as "theatereality." 40 Theatereality is a

\footnotetext{
${ }^{36}$ Eric Prieto, Listening In, (Lincoln, NE: University of Nebraska Press, 2002), 194.

${ }^{37}$ Ibid., 195.

${ }^{38}$ Ibid., 194.

${ }^{39}$ See both: Enoch Brater, "The 'I' in Not I," 198; Dina Sherzer, "Portrait of a Woman: The Experience of Marginality in Not I," in Women in Beckett, ed. Linda Ben-Zvi (Urbana, IL: University of Illinois Press, 1980), 205.

${ }^{40}$ Ruby Cohn, Just Play: Beckett's Theater (Princeton, NJ: Princeton University Press, 1980), 29.
} 
moment in the drama when a character is actually describing the audience's experience to them... as they are experiencing it. So in Not I, Cohn claims “...if our concentration flags in the theater, Mouth and her words become for us an actual buzz..." ${ }^{41}$ In other words, the "buzz" MOUTH is describing is not from her skull, but buzz of her words in the viewers' ears. Cohn's idea of theatereality certainly has merit since Beckett himself describes a similar feature in the works of one of his most beloved writers: James Joyce.

Beckett's often quoted writing about the author is worth citing at length:

Here form is content, content is form. You complain that this stuff is not written in English. It is not written at all. It is not to be read - or rather it is not only to be read. It is to be looked at and listened to. His writing is not about something; it is that something itself... When the sense is dancing, the words dance. ${ }^{42}$

Beckett describes the sound of the words dancing when the words describe dancing. Similarly, Cohn describes the viewer's ears buzzing when the words from the stage describe buzzing. In both cases, the words highlight the sound or action involved in the text or dramatic work instead of the semantic meaning of the text.

\section{"Fundamental Sounds"}

As this chapter has shown, the features of Beckett's late dramatic style emphasize the sound of words over the meaning of words. Beckett might summarize his late dramatic style thus: "My work is a matter of fundamental sounds (no joke intended) made as fully as possible..." ${ }^{43}$ The features described in this chapter all relate to sound. As will be discussed in the following chapters, all three compositions in this study reflect meaningfully on the sounds of Beckett's text. Some aspects of the compositions reflect

\footnotetext{
${ }^{41}$ My emphasis; Ruby Cohn, Just Play, 30.

${ }^{42}$ Emphasis in the original; Quoted in Daniel Albright, Beckett and Aesthetics (Cambridge: Cambridge University Press, 2003), 3.

${ }^{43}$ Keir Elam, “Ars(e) Rhetorica," 124.
} 
more nuanced readings of Beckett's late dramatic style that will be further explored in their respective chapter. Holliger and Zubel also comment significantly about MOUTH as a character. Regardless of what aspects of Beckett's style each composition emphasizes, each work gives the listener the opportunity to experience the sound of Beckett's late dramatic style in new and significant ways.

\section{Short Composer Biographies}

Paul Rhys, Heinz Holliger, and Agata Zubel are all contemporary composers. As the introduction of this thesis mentioned, most studies of Beckett and musical compositions have taken the approach of discussing a composer's Beckett-based works within that composer's style. I take a different approach in this study, attempting to highlight the unique qualities of each composition by contrasting them with the other two composers' works. This approach has allowed me focus on which aspects of Beckett's Not $I$ are truly represented in a significant manner in each composition. ${ }^{44}$

\section{Paul Rhys}

Paul Rhys is currently an active composer and lecturer at Anglia Ruskin University in England, having taught previously at Reading University and Clare College-Cambridge. Rhys's Not I for piano solo lasts about fifteen minutes (slightly longer than Billie Whitelaw's well-known BBC performance) and was written as a

\footnotetext{
${ }^{44}$ Chapter 3 will feature a discussion of how I notice finding different results from some scholars in my analysis because I do not analyze these works through the paradigm of each composer's particular style.
} 
"direct transcription" of Beckett's text. ${ }^{45}$ The piano work is extremely demanding; Rhys incorporates complex rhythms in the style of Brian Ferneyhough. ${ }^{46}$ The modernist piano virtuoso Ian Pace was enlisted to perform the premiere at Reading University. ${ }^{47}$ Rhys's Not $I$ is an anomaly in his oeuvre. As he describes in his article about his compositional experience with the work, this was a new style of music for him; and he has not recreated this aesthetic in later works. ${ }^{48}$

Concerning academic criticism, Rhys has written an article on his compositional process that appears in the collection of essays Beckett and Musicality cited in the bibliography. Additionally, Mary Bryden discusses Rhys's Not I and includes an interview with Rhys and Ian Pace about the work in Samuel Beckett and the Arts: Music Visual Arts, and Non-print Media.

\section{Heinz Holliger}

Heinz Holliger is widely recognized as a premier oboist, but his compositions have also received critical attention. Holliger's Not I fur Sopran und Tonband is one of three compositions Holliger based on Beckett's works. ${ }^{49}$ The work features a solo soprano that is accompanied by an electronic tape recording. The tape consists of recorded voices that progressively become more intrusive to the soloist's live voice. Holliger explores many electronic manipulations of the voices of the tape, creating an intriguing musical texture.

\footnotetext{
${ }^{45}$ Mary Bryden, "Reflections on Beckett and Music, with a Case Study: Paul Rhys's Not I," in Samuel Beckett and the Arts: Music, Visual Arts, and Non-print Media, ed. by Lois Oppenheim (New York: Garland Publishing Inc., 1999), 88.

${ }^{46}$ Paul Rhys, "Not I for Solo Piano: Beckett's Text as Music," in Beckett and Musicality, ed. by Sara Jane Bailes and Nicholas Till (Dorchester, UK: Henry Ling Limited, 2014), 159.

${ }^{47}$ Mary Bryden, "Reflections on Beckett and Music," 96.

${ }^{48}$ Paul Rhys, "Beckett's Text as Music," 167.

${ }^{49}$ Holliger also composed Come and Go (1977) and What Where (1988).
} 
Michael Kunkel presents a lengthy analysis of Holliger's musical settings of Beckett's works alongside the series of Beckett compositions by György Kurtàg in his book “...dire cela, sans savoir quoi...:” Samuel Beckett in der Musik von György Kurtág und Heinz Holliger, cited in the bibliography. Kristina Ericson's published dissertation on Heinz Holliger, Heinz Holliger-Spurensuche eines Grenzgängers, chooses to focus on Not I to represent Holliger's interest in Beckett's works. Both of these publications will be discussed in more detail in Chapter 3 .

\section{Agata Zubel}

Agata Zubel is an active composer and lecturer at the Academy of Music in Wrocław as well as an extremely talented vocalist. In fact, my first experience of Zubel's Not I was a live performance at the University of Louisville with Zubel as the vocal soloist. Zubel's Not I is written for a female vocalist, small instrumental ensemble, and tape. The work is similar to other compositions in her oeuvre as it explores the wide range of timbral possibilities in the voice.

Zubel, like Holliger, has composed multiple pieces based on Beckett's texts. Her work Cascando (2007) and What is the Word (2012) are also based on Beckett's works. In my opinion, Zubel is grossly underrepresented in the realm of music criticism. My research was only able to uncover liner notes, program notes, and a few documentaries with largely biographical information. 


\section{CHAPTER 2}

\section{"VISCERAL INTENSITY” IN RHYS'S NOT I FOR PIANO SOLO}

Paul Rhys's Not I for piano solo is a bold response to Beckett's monologue Not I, for Rhys removes the most elementary feature of Beckett's work: the voice. Yet Rhys's Not I is an excellent starting point for this study because his composition grants an opportunity to clear away the semantic noise of the text in Beckett's Not I. Without Beckett's text, the listener does not seek to decode MOUTH's monologue or analyze MOUTH's character. Instead, only the raw sound of Beckett's Not I remains. Within the sonic content of Beckett's work, Rhys still had to focus his efforts on which aspects of the monologue to portray. As this chapter will demonstrate, Rhys's Not I highlights the rhythmic style of Beckett's Not $I$.

\section{"Visceral Intensity"}

Rhys's compositional approach parallels many aspects of Maria Ristani's recent research into Beckett's late dramatic style. Ristani goes beyond claiming that rhythm functions solely as a structural feature in Beckett's late dramas, instead asserting that Beckett utilizes rhythm as "an alternative to conventional 
syntax. ${ }^{, 50}$ As the late dramatic style of Beckett begins to deconstruct narrative function by stripping the text of semantic meaning, rhythm takes on a more prominent role. Ristani describes this eloquently, writing that within Beckett's texts “...syntactic threads are clearly severed with elided phrases piling up...but acoustic kinship is established with particular phrasal segments steadily repeated through and across the broken syntax. ${ }^{.51}$ Ristani claims Beckett's approach results in artworks that rely on the "affect" of language, an aesthetic that does not require a semantic understanding of the words to be effective. ${ }^{52}$ Instead, Beckett's works function by creating "visceral intensity," resulting in a physical immediacy for the viewer. ${ }^{53}$

Rhys's Not I recreates this quality of visceral intensity that Ristani claims is so essential to Beckett's late dramatic style. Rhys removes the semantic aspects of Beckett's text by omitting the words, therefore only the affect of the text remains. Instead of relying on MOUTH's abstract narrative to create a comprehendible composition, Rhys creates musical fragments that are explicitly linked to Beckett's text. These musical fragments operate like the "textual fragments" Ristani describes in Beckett's work; an acoustic kinship is established as these musical statements recur in various patterns. In Rhys's Not I, the listener hears these musical fragments as they follow the repetitions, permutations, and variations of Beckett's text. The interaction of these fragments creates a coherent musical work driven by Beckett's rhythmic style.

\footnotetext{
${ }^{50}$ Maria Ristani, “Articulated Arrhythmia: Samuel Beckett's Shorter Plays,” In Beckett and Musicality, ed. by Sara Jane Bailes and Nicholas Till (Dorchester, UK: Henry Ling Limited, 2014),120.

${ }^{51}$ Ibid., 128.

${ }^{52}$ Maria Ristani, “Articulated Arrhythmia,” 131.

${ }^{53}$ Ibid.
} 


\section{Rhythm in a Textual Medium}

Before continuing this discussion, the term "rhythm" requires some additional clarification regarding its role within a textual medium (such as a dramatic work). Rhythm within a text is not limited to the pattern of sounds associated with the delivery of each individual word. The patterning of words by repetition, permutation, and variation also creates a rhythmic feature in the text. Additionally, the pronunciation of the words create accents to add more subtle variations in the rhythm. This short excerpt from Beckett's Not I demonstrates all of these features:

...out...into this world...this world...tiny little thing...before its time...in a godfor-...what?..girl?..yes...tiny little girl...into this...out into this...before her time...godforsaken hole called... ${ }^{54}$

Any of the multi-syllable words or textual phrases could be delivered with a wide variety of rhythmic patterns. However, the most important aspects of this excerpt involves the various styles of patterning. The aspect of repetition is fairly obvious, particularly phrases like "tiny little" that return multiple times. Variations are also noticeable as certain phrases return with small changes. For example, "before its time" becomes "before her time." Permutation occurs in this passage when the excerpt is considered on a larger scale. I rearrange the layout below to make this clear.

Original: (1) out (2) into this world (3) this world (4) tiny little thing Permutation: (1) tiny little girl (2) into this (3) out into this

\footnotetext{
${ }^{54}$ Samuel Beckett, Samuel Beckett: The Complete Dramatic Works (Boston, MA: Faber and Faber, 1986), 376.
} 
The fragments of the original are rearranged in the return in a permutation. The "tiny little" clause is moved from the last position to the first position. "Out" is moved from the first position of the original to the last position of the permutation. Beckett's rhythmic style is based in these types of patterning techniques. As my musical analysis will show, Rhys reflects these aspects of Beckett's rhythmic style.

\section{Rhys's Compositional Process}

Rhys's composition Not I for Piano Solo has arguably the most unique circumstances surrounding its creation among the three works involved in this study. This work was commissioned by the Annenberg/Beckett Fellowship established at Reading University. ${ }^{55}$ His proposal for the composition was short and precise. The work would be "a musical work for either solo piano or organ, of at least fifteen minutes, structured as a direct transcription of Beckett's Not I, each verbal fragment to be represented by its own musical idea, repeated or modified as the text demands. ${ }^{56}$ While writing a musical work on commission is not unusual, the requirement of the Annenberg/Beckett Fellowship for Rhys to keep a detailed account of his compositional procedures is rather odd. ${ }^{57}$ This particular criterion makes Not I for Piano Solo an excellent starting point for this discussion

\footnotetext{
${ }^{55}$ Mary Bryden, "Reflections on Beckett and Music, with a Case Study: Paul Rhys's Not I," in Samuel Beckett and the Arts: Music, Visual Arts, and Non-print Media, ed. by Lois Oppenheim (New York: Garland Publishing Inc., 1999), 88.

${ }^{56}$ Ibid., 89.

${ }^{57}$ Ibid.
} 
as the composer's own notes and his incredibly informative article regarding the experience of composing this work can inform the musical analysis. ${ }^{58}$

As evidenced by Rhys's proposal, the work uses specific musical ideas for each fragment of text from Samuel Beckett's drama Not I. Although the text is not present in the performance, the words are printed in the musical score below the corresponding musical fragment; and Rhys's composition was dependent on Beckett's text for many of his musical choices. Rhys followed a strict process in determining the duration of each musical fragment. Rhys states "I chose the expedient of counting syllables in each text fragment and allocating each syllable the musical duration of one demisemiquaver at a tempo of quaver=54." ${ }^{, 59} \mathrm{He}$ points out that this resulted in the work lasting slightly longer than Billie Whitelaw's 12-minute performance of the drama. ${ }^{60}$ To be clear, however, this did not restrict Rhys to writing one note per syllable. For example, the first textual fragment "out...into this world...this world..." has seven syllables while the corresponding musical fragment has twelve notes, as shown in Example 2.1.

Once the duration of time was established for each fragment, Rhys relied on either the "speech rhythm" of the Billie Whitelaw performance or "visual or sonic images" to compose each musical fragment. ${ }^{61}$ Rhys faced a compositional challenge in each of these sources of inspiration for his musical fragments. Regarding speech rhythms, Rhys had to find a rhythmic tool to express the "wealth of music...inside spoken language" that is so elaborately explored within

\footnotetext{
${ }^{58}$ Paul Rhys, "Not I for Solo Piano: Beckett's Text as Music," in Beckett and Musicality, ed. by Sara Jane Bailes and Nicholas Till (Dorchester, UK: Henry Ling Limited, 2014), 155-169.

${ }^{59}$ A demisemiquaver is a sixteenth note. Paul Rhys, "Beckett's Text as Music," 159.

${ }^{60}$ Ibid.

${ }^{61}$ Ibid., 161.
} 
the Beckett drama. ${ }^{62}$ The rhythmic style utilized by Brian Ferneyhough provided the model for rhythms with the diversity, subtlety, and precision Rhys required to mimic Beckett's speech rhythms. ${ }^{63}$ (Fortunately, the challenge of finding a performer to execute these rhythms successfully was answered in his attendance of pianist Ian Pace's recital that included Ferneyhough's Lemma-Icon-Epigram. $)^{64}$ Representing the "visual or sonic images" of Beckett's text presented a compositional issue for Rhys. One of his journal entries during composition reads "If, in composition, I attempt too close a representation of each text fragment, then the result is very unsatisfactory....and makes me think of cartoon filmmusic..." ${ }^{65}$ Examples of both types of musical fragments will be found later in this chapter.

Rhys's process of choosing a harmonic progression for chains of musical fragments was more complex and requires an understanding of how Rhys interpreted the original text. Rhys copied down the text as part of his working notes before he began to compose. Instead of copying the text verbatim, however, he demarcated the primary "trains of thought" from the multiple interruptions and interjections by using indentations. ${ }^{66}$ In Rhys's analysis, the text that he perceived as part of the narrative of Mouth's monologue is aligned just to the left of the page. Interruptions and more abstract fragments of text are indented further and further to the right of the page.

\footnotetext{
${ }^{62}$ Mary Bryden, "Reflections on Beckett and Music," 96.

${ }^{63}$ Paul Rhys, "Beckett's Text as Music," 159.

${ }^{64}$ Ibid., 156.

${ }^{65}$ Mary Bryden, "Reflections on Beckett and Music," 91.

${ }^{66}$ Paul Rhys, "Beckett's Text as Music," 158.
} 
Within his textual analysis, Rhys also determines which sections of the text refer to Mouth's present situation and which are flashbacks. He sets these two different functions of the narrative with opposing harmonic motions. The text that refers to Mouth's present moment is treated with various progressions of twelvenote chords constructed from a group of twelve trichords. ${ }^{67}$ Rhys intends for these progressions of twelve-note chords to create a "referential tonality" that the listener begins to follow within the work. ${ }^{68}$ In sharp contrast, fragments of the text that Rhys determined to be a part of a flashback are set to harmonic progressions based on relatively consonant six-note chords. Rhys describes the development of these harmonic progressions in much finer detail in his aforementioned article "Not I for Solo Piano: Beckett’s Text as Music."

Rhys focused much of his compositional energy into interpreting Beckett's text as either an instance of MOUTH's present state or a flashback since it determined his choice of pitches, as described above. He describes the purpose of this semantic interpretation in his article about his composition:

The narrative continuity that lies hidden within the text of Beckett's Not I is understood, I suggest, on a subconscious level when we witness a performance of [Beckett's] work. My semantic analysis...aimed to bring these continuities to the fore, sometimes uniting fragments of text separated by large intervening spans of time. It was through the use of harmony and voice-leading that I was able to express these continuities and interruptions in the musical version of Not I. ${ }^{69}$

This is an instance where I have to disagree with the composer on his own work.

Rhys claims Beckett's Not I has a narrative that "lies hidden within the text," but his piano work "bring[s] these continuities to the fore." However, through my

\footnotetext{
${ }^{67}$ Paul Rhys, "Beckett's Text as Music,” 162.

${ }^{68}$ Ibid., 163.

${ }^{69}$ Ibid., 162.
} 
own effort to hear and analyze the underlying harmonic progression, I have found that the rhythmic style of Beckett is brought to the fore, not the narrative continuity. In fact, my impression of Beckett's Not I is a complete reversal of Rhys's statement. The narrative of Beckett's work is not hidden in the performance by disconnected fragments. Instead, the semantic noise of Beckett's words, which the audience tries to piece into a narrative, hides the sonic content of the words. As my analysis will show, Rhys certainly brings this sonic content to the fore by relying on Beckett's rhythmic style.

\section{Sounding like Beckett}

Out of the three Not I compositions in this study, it can easily be argued that Rhys's piano solo has the most similar sound to the original drama. This might seem surprising since Rhys's Not I does not use a vocalist, and the piano makes no attempt to match the timbre of a human voice. Additionally, since Rhys omits the words of the monologue, MOUTH's narrative is not present. However, these two artworks sound similar because of the unrelenting tempo and, to return to Ristani's term, the visceral intensity of both works. ${ }^{70}$

Ristani uses the phrase while describing the difference between "emotion" and "affect." Ristani states "If emotion is understood as qualified intensity framed into socio-linguistic function and meaning... affect, on the other hand, is visceral intensity, volatile, infectious and emergent."71 (The string of descriptors "volatile, infectious and emergent" are just as useful in describing both Beckett's drama and

\footnotetext{
${ }^{70}$ Maria Ristani, “Articulated Arrhythmia: Samuel Beckett's Shorter Plays,” In Beckett and Musicality, ed. by Sara Jane Bailes and Nicholas Till (Dorchester, UK: Henry Ling Limited, 2014),131.

${ }^{71}$ Maria Ristani, "Articulated Arrhythmia," 131.
} 
Rhys's composition. However, "visceral intensity" is more practical and precise.)

This excerpt from Ristani's discussion concerning "emotion vs. affect" is significant in the matter of the similarity in sound between Rhys's composition and Beckett's drama. If a listener of both works connects strongly to the emotion of Beckett's drama, they will likely not find many similarities between the two works. The emotion of the work is rooted in the "function and meaning" of the words. Rhys removes the words. This omission of the text does not remove Beckett's artistic fingerprints from the work, however. As Ristani argues, Beckett's late dramas are much more concerned with "affect" than "emotion" and create a "pre-, extra- or para-linguistic tension." ${ }^{.72}$ Without the presence of the text of Beckett's drama in Rhys's Not I for Solo Piano, a critical component of Beckett's late style remains in the visceral intensity of affect.

It seems likely that Beckett would strongly agree with Ristani's proposed hierarchy of affect above emotion in Beckett's work. In a conversation with an actress preparing to perform Not I, Beckett wrote "I'm not unduly concerned with intelligibility. I want the piece to work on the nerves of the audience. ${ }^{, 73} \mathrm{His}$ reference to "intelligibility" would be part of the emotional component of Ristani's argument. By contrast, "working on the nerves of the audience" is part of the affect of a viscerally intense performance.

Rhys's initial experience of Beckett's drama seemed to focus on affect over emotion, as well. He describes happening upon a television broadcast of Billie Whitelaw's performance of Not I late at night without prior knowledge of

\footnotetext{
${ }^{72}$ Ibid.

${ }^{73}$ As quoted in Kyle Gillette, "Zen and the Art of Self-Negation," Comparative Drama 46, no. 3 (Fall 2012): 288 .
} 
the work or its narrative. ${ }^{74} \mathrm{He}$ found the words "too fast to understand" and noted the "urgent intensity of communication.",75 Whitelaw's performance had "worked on his nerves," to use Beckett's phrase; and this initial experience of the work was surely a response to the physicality of the actress's performance. The actress strained to deliver the text fast enough. The spotlight was unbearably focused on her mouth. Rhys's mind struggled but failed to "correctly" comprehend the stream of text. Rhys claims that he only "properly understood the play" after having the opportunity to read the text years later. ${ }^{76}$ While reading the text of Not I is meaningful and insightful for enjoying the work, I would argue that Rhys's initial experience of Not I was far more significant than his recognition of the narrative within the text. And although his compositional process for the piano solo was rooted in the text, the visceral intensity of his first encounter with the drama comes to the fore in his finished composition.

\section{Visceral Intensity and Rhythm}

The physicality and rhythmicity of Beckett's drama is recreated in Rhys's piano solo in multiple ways. Several are quite obvious upon first listening. Both works present an onslaught of sounds to the listener. The actress of the drama delivers the text rapidly while the pianist plays exceptionally quick rhythms. These outpourings of sound continue with hardly any breaks or slowing in tempo. In both works, this creates an uneasy tension in the audience member due to the sheer physicality of the work. The arresting nature of Mouth's monologue is

\footnotetext{
${ }^{74}$ Paul Rhys, "Beckett's Text as Music,” 155.

${ }^{75}$ Ibid.

${ }^{76}$ Ibid.
} 
effectively maintained in Rhys's composition. However, as Ristani claims, the visceral intensity of the drama Not I is created by more than just the easily identifiable characteristics of the production. While the physical demands and unrelenting tempo contribute to the work's sound, Ristani asserts that the underlying rhythmic structure of Beckett's text is significant in highlighting affect over emotion. In the following musical examples, I will analyze excerpts that show how Rhys's Not I highlights the repetitions, variations, and permutations within Beckett's text.

Rhys's composition parallels many of Ristani's claims in significant ways. As detailed earlier in this chapter, Rhys was inspired during the compositional process to recreate many of Beckett's speech rhythms. However, Rhys did not seek to simply dictate every speech rhythm into his composition. If Rhys often utilized rhythms that were not direct transcriptions of Beckett's speech rhythms, does his composition reflect meaningfully on Beckett's rhythmic style?

Considering Ristani's research, the answer is yes; for Beckett's rhythmic style is not rooted in specific patterns being stubbornly applied to each speech rhythm. Instead, the shift of the audience member from understanding the semantic meaning of the text in Beckett's drama to listening to the sonic quality of the text is the salient feature of the work most strongly portrayed in Rhys's composition. Listening to the sonic qualities of the text brings the "acoustic kinship" to the fore and diminishes the semantic meaning that is subverted in Beckett's text by the broken syntax. Rhys's use of rhythm and patterning serves as the primary element of this acoustic kinship. 


\section{Recreating Speech Rhythms}

Many of Rhys's rhythmic choices in Not I are clearly inspired by the speech rhythms within the text, specifically Billie Whitelaw's performance. Example 2.1 highlights many instances of this mimicry. The text and its corresponding rhythm are marked in the example. Notice that all but one of these textual fragments share a similarity in rhythmic pattern: a longer value follows three equally short values. The influence of Billie Whitelaw's performance for Rhys's rhythmic choices in this section is hardly disguised. While many composers may have naturally set some phrases like "into this world" and "forsaken hole" to these rhythms, the unusual setting of "similarly" is particularly striking as a reflection of Whitelaw's rhythmic delivery of that line. Since the accent of "similarly" falls on the first syllable, one would expect the composer to elongate the stressed syllable. Instead, the last syllable "-ly" receives the longer duration, seemingly to reflect Whitelaw's performance.

However, Rhys does not restrain himself to precisely transcribing Whitelaw's rhythms. In measure 7, for example, the fragment “...into this...out into this..." is set to a different rhythm than Whitelaw's speech rhythm. While the sixteenth note triplet of the right hand piano part aligns with the three syllables of “into this," this even rhythm does not match Whitelaw's performance. (Whitelaw performs "into" with two shorter notes than "this" instead of saying each syllable evenly.)

A quick comparison of many of the unmarked words and rhythms of Example 2.1 will reveal a quite obvious feature that continues throughout much of 
the work. The rhythms are often clearly not rooted in a speech rhythm. This does not mean that the rhythmic style of Beckett's original drama is lost, however. In fact, Rhys brilliantly chose to keep the most significant speech rhythm (the one marked in Example 2.1) of this section in tact. ${ }^{77}$ This particular rhythm is what creates the "acoustic kinship" across this section both musically and within the musical drama. Additionally, Rhys communicates Beckett's broken syntax by setting the textual interruptions differently than the surrounding fragment. The small interruption to MOUTH's primary train of thought receives a very different treatment in rhythm and pitch than the textual fragments surrounding it. Specifically, the left hand of the piano plays the first chords of the work and uses a roll to draw more attention to the new sound. This is an example of the broken syntax of Beckett's original text functioning within Rhys's composition.

\section{Visual and Sonic Images}

Another source of inspiration for Rhys's setting of each textual fragment was the sonic or visual image associated with the words. As quoted earlier in the work, Rhys was careful in making these compositional choices to not employ musical clichés when musically setting the semantic meaning of the text. Example 2.2 shows one such situation. In the drama, MOUTH says "scream" and "scream again," both followed by the actress actually screaming. In this case, however, the piercing sound of a screaming voice is insinuated by marcato attacks in the

\footnotetext{
${ }^{77}$ I have no evidence regarding Rhys's awareness of the significance of this rhythm. However, listening to the Whitelaw performance and Rhys's piano solo is quite illuminating of this feature.
} 
extreme uppers of the piano register. This setting is anything but banal yet does resemble the arrestingly strident timbre of a scream.

This is also one example of Rhys adding rhythmic interest to a textual phrase that would not be rhythmically interesting as a speech rhythm (since "scream" is a one syllable word). Instead of resorting to a loud, cacophonous strike of a chord to reflect the sound of a "scream," Rhys resorts to a more rhythmically interesting option. In looking at Example 2.2, the left hand rhythm of the piano features a slight variation. This change in rhythm parallels the slight variation in the text while not reflecting the words as a speech rhythm. Musical choices like this are examples of Rhys highlighting the rhythm within Beckett's textual patterning in ways that align with Beckett's late dramatic style.

\section{Binding Beckett's Broken Syntax}

Example 2.1 and 2.2 are both brief examples that show Rhys's predilection for using rhythmic means to create acoustic kinship in his composition, whether by using speech rhythms or visual and sonic images. However, I find that the most effective moments in the music do not rely on an analysis of Whitelaw's performance or an understanding of the semantic meaning

of the textual fragments. Instead, Rhys's music follows the rhythmic flow created by the repetitions, variations, and interruptions in the text. One particular moment in Rhys's piano solo is particularly striking as it parallels Ristani's analysis of the same text in an uncannily similar fashion (see Example 2.3).

First, it is necessary to quote the original text of Beckett's drama at length: 
..whether standing...or sitting...but the brain-...what?..kneeling?..yes... whether standing... or sitting... or kneeling... but the brain-

...what?..lying?..yes...

whether standing...or sitting... or kneeling... or lying...but the brain still... ${ }^{78}$

Ristani analyzes this section as a clear example of "rhythmic constraint" as the verbs (standing, sitting, kneeling, and lying) create a "rushing stream" that is controlled by repetition and "halting blocks" with the interjections of 'what?,' 'but the brain-,' and 'yes.' 79 The back and forth of this flowing rhythm and constraining of the resulting momentum is finally ended by the word "still" that leads to a new group of textual fragments. ${ }^{80}$

As the annotated score in Example 2.3 shows, Rhys practically mirrors Ristani's analysis of this section. The strings of verbs occur three times, each one a little longer in duration than the last. Rhys chooses a jarring staccatissimo secco articulation that starkly contrasts with the "halting blocks." Another interesting part of Rhys's interpretation of this text is the elaboration of each appearance of 'but the brain.' As if each iteration of this phrase needs to grow to stop the momentum of the ever-lengthening chain of verbs, Rhys adds more and more grace notes to the start of the music fragment associated with 'but the brain.' To make it clear that the word 'still' designates the end of this textual cycle, Rhys writes a rolled chord before moving on to the next section of text.

\footnotetext{
${ }^{78}$ Samuel Beckett, Samuel Beckett: The Complete Dramatic Works (Boston, MA: Faber and Faber), 377.

${ }^{79}$ Maria Ristani, "Articulated Arrhythmia," 134.

${ }^{80}$ This particular section of Not $I$ is treated in a particularly interesting manner in all three compositions in this study. The affinity every composer seemed to have for this particular section is a testament to Beckett's rhythmic style. Although this portion of text is practically devoid of meaningful semantic or narrative content, the rhythmic material did not go unnoticed among any of the three composers.
} 
A particularly striking feature of these measures is that while neither speech rhythms nor sonic or visual images seem to play a role as inspiration for Rhys's rhythmic choice and pitch selection, the relationship between the chains of verbs as a "rushing stream" and the various interjections as "halting blocks" is quite clear. In other words, Beckett's rhythmic style is reflected in this musical composition without a concerted effort by the composer to painstakingly transcribe the speech rhythms. Fortunately, Rhys's understanding of Beckett's rhythmic style led to these artistically sound choices. One could imagine how the contrast between the flow and constraint within this fragment would be ruined by an approach that attempts to project the semantic meaning of each word!

The artistically inappropriate nature of such a hypothetical composition is indicative of the issue of syntax within Beckett's text. Although the full text around this fragment is not provided, reading the entire drama reveals that this section certainly represents a diversion from MOUTH's main train of thought. In terms of syntax, we find a chain of words ("whether standing or sitting or kneeling or lying') being consistently interrupted by inquisitive interjections ('what?..kneeling?') and unfitting acclamations ('yes'). Obviously, traditional syntax is not applicable. This is a perfect example of the rhythm becoming the "alternative to traditional syntax," creating a meaningful experience based not in semantics (emotion) but in rhythm (affect). Therefore, Rhys's composition is able to mimic this important aspect of Beckett's late dramatic style without the texts' sonic presence. 


\section{Rhys's Unique Application of Rhythms}

While the similarity between academic interpretations of Beckett's use of rhythm (like Ristani) and Rhys's composition are enlightening and intriguing, Not I for Piano Solo has some interesting musical moments that result from Rhys's multiple approaches. I will offer one example here that is shown in Example 2.4. Again, the full text of this section of the drama will be given:

“... a few steps then stop...stare into space...then on...a few more...stop and stare again...so on..."81

This excerpt is another typical example of Beckett's texts from his late dramas. Though the fragment does not advance the narrative, the acoustic kinship is quite prevalent. Every word within this fragment except 'and' and 'so' occur more than once, each time in a different context. Within those repeats, the distinctive "st" sound appears in front of four of nineteen of the words, creating a sonic similarity. The terse two syllable fragments 'then on' and 'so on' aid as structural features of the text. The fragments leading up to 'then on' become shorter in syllabic length (5 and 4 syllables, respectively) while the fragments leading up to 'so on' increase in syllabic length ( 3 and 5 syllables, respectively). It is this kind of detailed arrangement that strongly contributes to Beckett's unique textual rhythms.

In Rhys's musical setting of these fragments, we see some of these patterns reflected. The most obvious is the syllabic arrangement, since, as described earlier, Rhys's compositional process based the duration of each musical fragment strictly on the number of syllables in the text. He takes this a step further, however, by using very similar rhythms to set the text fragments in

\footnotetext{
${ }^{81}$ Beckett, Complete Dramatic Works, 376.
} 
corresponding roles. The longer textual fragments 'a few steps then stop' and 'stop and stare again' receive a quintuplet division of a sixteenth note for half of their measures. The shorter textual fragments 'stare into space' and 'a few more' both receive the same rhythmic treatment with a slight variation in the left hand for 'stare into space.' Notice that this treatment of the text preserves the general form of the phrase without preserving the speech rhythm. Yet it effectively maintains Beckett's rhythmic idiom. Another example is seen in the rhythm for 'then on' and 'so on.' These rhythms are strikingly similar but offer a slight variation in the left hand for 'so on.' This mimics the slight variation in the text (much like the example of 'scream' and 'scream again' in Example 2.2).

This example also shows, however, that Rhys adds some musical choices that are completely different from the Whitelaw performance. For example, the first instance of 'stop' is set in a descriptive manner as a rest follows it to insinuate stopping. The next occurrence of stop is more representative of the rhythmic flow of the text. The trill in the left hand during 'stare into space' is also descriptive, representing the image of the text.

The significance of this analysis of Beckett's text and Rhys's subsequent musical setting is based in a consideration of a larger question regarding Beckett's style and its applicability to a musical composition. It serves as evidence that due to Rhys's artistically refined approach to Beckett's text, the rhythmic idiosyncrasies of the text become apparent in the piano solo without requiring Rhys to adapt a compositional process that strictly determines his musical choices. 
The culminating effect of Rhys's compositional process occurs in the section he refers to as the "recapitulation." ${ }^{82}$ Rhys refers to this as a recapitulation since the opening text of the drama return here. Example 2.5 shows my annotation of Beckett's text that is set musically by Rhys in this section. The underlined words represent text that is being repeated in this section after appearing in other lines of the drama. The italicized words represent text that is repeated within this section. As is made clear in Example 2.6, very little of this material is brand new. Therefore, this section is remarkably intelligible. Yet its intelligibility is not based in a harmonic progression, but in the identifiable rhythmic figures whose sound have become very recognizable by this point in the work. As a parallel to Beckett's drama, this section in the work represents a moment when, hopefully, the audience member has stopped trying to understand the words and finally begins to listen to the words' sounds.

\section{Removing Semantic Noise}

In conclusion, Rhys's Not I is rooted in the rhythmic quality of Beckett's text. Ristani identified the rhythm of Beckett's text as a functional substitute for conventional syntax, creating texts that become meaningful because of the acoustic kinship shared between the various textual fragments. As a replacement to a musical syntax based on identifiable harmonic progressions, the disjunct musical fragments in Rhys's Not I become intelligible through its basis in Beckett's text. In this manner, Rhys mimics the visceral intensity of Beckett's drama, emphasizing the affect of Not I's rhythmic text.

\footnotetext{
${ }^{82}$ Paul Rhys, "Beckett's Text as Music," 164.
} 
Rhys's Not I is capable of highlighting an aspect of Beckett's work that can often go unappreciated in the medium of theater. Since Rhys virtually removes the semantic aspect of Beckett's monodrama, the composer is given the opportunity to emphasize other characteristics of the text, specifically its rhythmic qualities. Yet Rhys's composition still functions as an autonomous work of art separate from Beckett's drama. Although both works employ a similar rhythmic style and delivery, the viewer of Beckett's Not I is faced with a different challenge than the viewer of Rhys's Not I. Beckett's drama requires the listener to hear past the semantic features of the text to consider the sonic content. As I described earlier in this chapter, Beckett favored the sound of the words more than their "intelligibility." Through the medium of music, Rhys clears away this semantic noise. Rhys highlights the aural content of the text exclusively, creating an opportunity for the listener to focus solely on the unique rhythmic qualities within Beckett's original text. 


\section{CHAPTER 3}

\section{REINTRODUCING THE INTERMEDIARY VOICE:}

\section{AUDIENCE AS TYMPANUM IN HOLLIGER'S NOT I}

Heinz Holliger's Not I is composed for solo soprano and electronic-tape and is designated as a monodrama by the composer. Simply the addition of a vocalist in Holliger's Not I presents a wide array of different issues in analyzing the music that were not applicable to the study of Rhys's Not I. While Rhys's composition emulated the physicality of the original drama through complex rhythms and a quick tempo, Holliger's composition surprisingly makes few attempts to replicate the vocal style of the actress of Beckett's drama. The soprano delivers the text much more slowly than in Beckett's drama (the work is more than twice as long as the original drama, lasting 30 minutes), and the tape consists mostly of recorded voices that are replayed with a variety of electronic manipulations. ${ }^{83}$ This establishes a musical dichotomy between live voice and electronic voice(s). ${ }^{84}$ Because of this dual nature of the musical setting, the sound source of each word in Holliger's composition is more important than the ordering or patterning of each word; for the tape introduces a complexity of recorded and manipulated voices that often threatens to overshadow the live voice's role. This chapter will focus on how

\footnotetext{
${ }^{83}$ The only non-vocal sound on the tape is the sound of a heartbeat.

${ }^{84}$ Kristina Ericson discusses how the conflict between the tape-overlay (Tonbandüberlagerungen) and the live voice supports a reading of MOUTH as a dichotomous character. See Kristina Ericson, Heinz Holliger: Spurensuche eines Grenzgängers (Bern, DE: Peter Lang AG, 2004), 423.
} 
this multitude of voices reflects significantly on a key theme of Beckett's late dramatic works: internal and external voices.

Before discussing the specifics of Holliger's compositional process, the significance of voices in Beckett should be explored further. Beckett's late dramatic and literary works both emphasize the internal and external voices of his characters. ${ }^{85}$ Eric Prieto's study of voices in Beckett is particularly enlightening and relevant to this study even though he primarily focuses on Beckett's literary texts. Prieto claims that characters from Beckett's late works are obsessed solely with voices and images, yet these characters often seem confused about the source/location of these voices and images. ${ }^{86}$ Prieto argues articulately that the narrator has a crucial role within Beckett's literary texts in conveying a character's confused state, and his words are worth quoting at length:

The narrative voice - the voice that we the audience have access to in Beckett's texts - can only be understood as an intermediate voice, equally estranged from the founding voice of the ego and from the outside world of social relationships and interpersonal communication. The voice that speaks (or writes) in the Beckettian text is nothing but an intermediary between an inside/ego that (we suppose) must exist (but that the narrative voice cannot locate) and an outside/world that remains equally inaccessible to knowledge. The narrative voice is in between: his inside is still the I's outside. ${ }^{87}$

Prieto draws the analogy that the narrative voice of Beckett's text operates as "tympanum," operating in between the conscious ego within the character and the physical world outside the self, but belonging explicitly to neither dimension. ${ }^{88}$

In Beckett's original drama Not I, Prieto's description breaks down to some

degree since the dramatic medium is different than the literary media. The only narrative

\footnotetext{
${ }^{85}$ Specifically, Eric Prieto points to Beckett's novel Watt as a turning point for this fascination with voices. See Eric Prieto, Listening In, 193.

${ }^{86}$ Eric Prieto, Listening In (Lincoln, NE: University of Nebraska Press, 2002), 193-194.

${ }^{87}$ My emphasis, Ibid., 194.

${ }^{88}$ Ibid, 195.
} 
voice available to the audience member is the disembodied voice of MOUTH, and the audience can only access the textual content of the drama through her rapid delivery. Therefore, MOUTH becomes the narrative voice, the sole source of revelation to the audience member regarding the voices ("what?..the buzzing?..yes... all the time the buzzing...”) and the images (“... and a ray of light came and went...came and went...such as the moon might cast...") that her character experiences.

Holliger's composition does not imitate the single-sound-source model of the original drama. Instead, as this chapter will demonstrate, Holliger's introduction of the tape to the musical texture creates a dichotomy of sound sources, each with a distinct role: MOUTH's internalized conscious ego (represented by the tape) and MOUTH's externalized monologue (represented by the live soprano). ${ }^{89}$ Thereby, Holliger reintroduces the intermediary voice of Beckett's literary texts to the dramatic work Not I. The audience members witness the external voice and internal voice(s) of the character MOUTH occurring simultaneously. The audience becomes, to borrow Prieto's words, the tympanum, residing between the internal voices and external voice of MOUTH, but belonging to neither.

\section{Holliger's Compositional Process}

Before exploring the dichotomy between the electronic voices and the live voice in Holliger's Not I, it is necessary to elaborate on the notation of the musical work itself. Holliger's composition poses some significant challenges to academic study. First, the

${ }^{89}$ This focus on the conscious ego as opposed to the unconscious alter ego is in itself a significant statement. MOUTH is framed by some scholars as a character that seeks to escape the shame and guilt associated with the alter ego, attempting to force this identity onto a third-person. For an example, refer to the cited article in the Bibliography by Enoch Brater titled "The 'I' in Beckett's Not I." 
tape is not fully realized in musical notation, yet its role is paramount to understanding the work. ${ }^{90}$ Second, the manuscript of the work is the only form of the score readily available for academic study, and there are no bar lines to divide up the work into measures. ${ }^{91}$ Third, a recording of the work is not available for public purchase. ${ }^{92}$ Due to these limitations, some musical considerations of the work in this study will have to go without the visual aid of musical notation.

Holliger's Not I reflects important structural features of Beckett's original text, even though this is not the most significant feature of the composition. Holliger admired Beckett's text as an artistic object by nature of its construction, saying "Beckett's splendid text does not itself require my music. Its entire structure - with pre-planning, imitation, ritornellos, permutations - is already eminently musical." ${ }^{, 93}$ Example 3.1 exemplifies the typical vocal style for the soprano soloist. While the score occasionally calls for a few extended techniques like speaking, sprechgesang, and laughing, the entire text is delivered by the live voice in a manner similar to this short excerpt. Evidence of the structural features that Holliger mentioned in the previous quote are shown in Example 3.1. Here, the phrase "a few days" and "a few more" are slight textual variations in the original text. In Holliger's setting, they receive an almost identical rhythmic setting but a distinct change in pitch content. Examining the phrases "stare into space" and "stop

\footnotetext{
${ }^{90}$ Publications by both Kristina Ericson and Michael Kunkel (cited in the bibliography) tackle some of these theoretical challenges, and their theoretical work will be drawn on occasionally throughout this study.

${ }^{91}$ Due to this logistical issue, references to the manuscript score will be given with a page and system number that relates to the provisional edition made available by Schott Music International. Both Ericson and Kunkel refer to this same manuscript in this manner, and I was always able to locate the proper excerpt of the score easily with this notation.

${ }^{92}$ Fortunately, Schott Music was kind enough to lend me the recording that accompanies the perusal materials of the work.

${ }^{93}$ My translation; as quoted in Kristina Ericson, Holliger, 421. "Der grossartige Text Becketts hat sicher meine Musik nicht nötig. Seine ganze Struktur - mit Engführungen, Imitationen, Ritornellen, Permutationen - ist schon eine eminent musikalische."
} 
and stare again" reveals two phrases related more by semantic content than raw textual content. Yet Holliger creates a pitch relationship by applying the interval sequence $<-1$, $+2>$ to both fragments. Holliger also illustrates the semantic content of the words with the music on occasion. For example, the word "stop" is followed by a rest with a fermata.

In consideration of the previous chapter, many of these musical features may seem like a rehash of the compositional process used in Rhys's composition. However, there are several significant differences between Holliger and Rhys's compositional approaches to Beckett's text that create completely different musical results. Although Holliger gives the structure of Beckett's text its due attention, he does not strictly set each line of text with the same music every time it returns. For example, Kristina Ericson's study of the composition extensively details the changing pitch patterns and rhythms that Holliger applies to certain words as they recur in the work. ${ }^{94}$ Therefore, the live voice in Holliger's work does not accrue a number of musical motifs that occur in varying patterns based on the original text as was the case in Rhys's composition. In fact, while Rhys often chose distinct musical fragments that resulted in clear aural delineations between the various textual fragments, Michael Kunkel's analysis of Holliger's Not I reveals that the composer relied on slight variations within a limited means of musical material. $^{95}$

Holliger's treatment of the tempo is even more important than his choices of pitch patterns and rhythms, however. As Example 3.1 shows, Holliger demands that the soloist change tempo sometimes as often as every new textual fragment. Comparing the Rhys

\footnotetext{
${ }^{94}$ For an example that does not require any knowledge of the German language, see Kristina Ericson, Holliger, 471.

${ }^{95}$ For an example that does not require any knowledge of the German language, see Michael Kunkel, “...dire cela, sans savoir quoi...." Samuel Beckett in der Musik von György Kurtág und Heinz Holliger (Saarbrücken, DE: PFAU-Verlag, 2008). 256.
} 
and Holliger, the musical scores can be misleading in this respect since the changes in tempo may be overlooked. Because of the ever-shifting tempo, a rhythmic flow never establishes itself in Holliger's Not I and the physicality of the actress's monologue in the original drama is not conveyed in the live soprano part. Unlike the original monologue, the words are not delivered with a desperate intensity and breaks in the sound do not provide a strongly desired respite from the outpouring of words. Instead, the soprano's delivery rejects rhythmic qualities and imitates instead a dysfunctional automaton. The shifting tempos subvert the listener's ability to anticipate the next entrance or feel satisfied in appreciating the rhythmic precision of the performer. Every word, while often following the natural declamation of the language within its own tempo, becomes rhythmically stilted in the context of the phrases around it.

Holliger's refusal to create a flowing rhythmic line in the soprano voice is demonstrated in Example 3.2. Despite this phrase being limited to one tempo, Holliger foils the listener's expectation for words with similar syntactical function, pronunciation, and pitch content to share rhythmic similarities. Consider the words "sitting," "kneeling," "standing," and "sitting." All these words function as infinitives, end in the same sound (ing), and ascend with ic1 motion. ${ }^{96}$ The listener perceives these three similarities but is denied a rhythmic relationship. Instead, Holliger creates an awkward rhythmic relationship by writing rhythms for these words that differ by a small fragment of time. For example, the first iteration of "sitting" has two articulated attacks separated by $1 / 2$ of a beat while the next iteration of "sitting" has two articulated attacks separated by $2 / 5$ of a beat. Other examples of this type are prevalent throughout the work. The soprano's

\footnotetext{
${ }^{96}$ The term "ic1" refers to all intervals made up of pitch classes that are separated by a semitone in pitch class space. In other words, a minor second, major seventh, and augmented octave are all ic1 intervals. The list could continue with the addition of compound intervals greater than an augmented octave.
} 
disjunct rhythmic style is essential to this argument for two reasons. First, this claim differs strongly from other academic studies of Holliger's Not I, particularly Ericson's published dissertation on Holliger. Second, the soprano in Holliger's composition effectively removes one of the key characteristics of the original drama: the unrelenting outpouring of words.

\section{Removing the Wortschwalls}

As mentioned above, Ericson's study of Holliger reaches a different conclusion regarding the slower tempo of the composition. Ericson addresses the issue of tempo in Holliger's Not I directly, reiterating that the Wortschwalls (literally, "word-torrent") is a crucial element of Beckett's original drama. ${ }^{97}$ Yet Ericson asserts that Holliger brings out this significant feature not by the live voice, but by the use of the tape that becomes a choir of self-reflective voices ("ein Chor selbstreflektierender Stimmen"). ${ }^{98}$ These electronic voices, therefore, provide a parallel to the Wortscwhalls of the original dramatic work.

However, these particular claims by Ericson mistakenly equate torrents of words (Wortschwalls) with a torrent of sounds (perhaps a Klangschwall). As the work progresses, the voices of the tape indeed become more active; but these voices gradually lose their human characteristics. ${ }^{99}$ Voices are distorted to sound at unnatural octaves for a female voice or tiny intervals are performed in rapid succession in a physically impossible feat. As Holliger describes it, "One hears [in the tape] that something is not

\footnotetext{
${ }^{97}$ Kristina Ericson, Holliger, 422.

98 Ibid.

${ }^{99}$ There is one exception to this in the work when, suddenly, the tape stops playing, leaving the live voice to sing alone for a short time. Both Kunkel and Ericson point out this moment in their respective studies, but it is a moment that is quite obvious upon even the first listening to the work.
} 
entirely natural, but does not know exactly what occurred. Then with each following layer come greater distortions..." ${ }^{100}$ Holliger mutates words into sound material to be used in the tape. The audience member is confronted with sounds without a clear source. This is a different situation than for the audience of the Beckett drama, who would be confronted with a string of words (that they suppose should create some kind of narrative) with an identifiable human source. I would agree with Ericson that a torrent of sounds certainly do develop over the course of the work. However, the torrent of words found in Beckett's original drama does not have a musical corollary within Holliger's Not $I$.

To be clear, Ericson's argument is still significant and insightful despite her interest in preserving the Wortschwalls element of the original drama in Holliger's Not I since this is not a substantial underpinning of the rest of her argument. In fact, perhaps if I approached this composition with the same paradigm as her study (an exploration of the wide range of compositional styles in Holliger's oeuvre), I might have reached a similar conclusion, finding that this composition sounds like a torrent of words in the context of Holliger's works. In the present study, however, I could not produce any musical evidence to support that Holliger recreates the outpouring of words that occurs in Beckett's drama more convincingly than either Rhys or Zubel.

\section{Whose Voices?}

One of Ericson's statements with which I completely agree is the significance of the Wortschwalls element in the context of the original drama. Since Holliger effectively

\footnotetext{
${ }^{100}$ My translation; as quoted in Kristina Ericson, Holliger, 488. "Man hört, dass irgend etwas nicht ganz natürlich ist, aber man Weiss noch nicht genau, was passiert. Dann kommen bei jeder folgenden Schicht grössere Verzerrungen dazu..."
} 
removes this paramount feature of the drama, another aspect of the work is brought to the fore. Here, I return to the issue of internal and external voices in Beckett's works. Holliger forces the audience to reconcile a conflict between the live voice and taped voice(s) within his composition, encouraging them to consider challenging questions about the work; and these questions all involve voices: Who is speaking? Who can hear these voices? How are they related? Perhaps unsurprisingly, Holliger's audience is confronted with similar questions as Beckett's reading audience of his late novels.

Prieto's aforementioned study provides an excellent example of Beckett's reading audience sorting through the voices referenced in one of Beckett's late novels, Watt. ${ }^{101}$ Beckett forces the listener to begin considering the source of internal and external voices as early as the first chapter of this novel; the main character Watt has decided to rest in a ditch and begins to hear an unusual four-part threne performed by a choir. (Beckett even provides musical notation for this humorous vocal piece.) However, these voices do not have a clear source, as the novel's narrator struggles to describe their location as "from afar, from without, yes, really from without."102 Prieto feels this description should raise some questions from the reader:

Should the threne really be understood as an overheard concert on a country road? Could it be an auditory hallucination? Or are we meant to suppose the presence of voices of an entirely different order?... What, then, it might be asked, happens to our interpretation of this piece if we think of it in terms of imagined voices? ${ }^{103}$

Prieto argues extensively that "Watt... has lost that fully internalized voice of consciousness... and [begins] to hear a multiplicity of voices." ${ }^{104}$ Prieto's discussion of Watt seemingly presents multiple parallels to Holliger's Not I. The audience member

\footnotetext{
${ }^{101}$ Eric Prieto, Listening In, 155.

${ }^{102}$ As quoted in Eric Prieto, Listening In, 162.

${ }^{103}$ Ibid.

${ }^{104}$ Ibid.
} 
hears a "multiplicity of voices" and, since the composition's designation as monodrama frames the soprano as a character, the listener searches for the relationship between these disembodied voices and the singer on stage. However, the differences between the medium of music and the medium of the novel need to be considered before declaring these two artworks analogous. Specifically, the listener/reader within these two mediums accesses the network of voices by different sources.

\section{Narrative Voice as Tympanum}

Prieto argues that the narrative voice grants access to Beckett's characters within his novels. ${ }^{105}$ While understanding literary characters through a narrative voice is typical for a novel, Beckett's narrators are challenged with the impossible task of encoding the sensory perceptions of characters that, like Watt, have lost the ability to accurately distinguish between internal and external voices. The reader is forced to make assumptions (or maybe encouraged to give up making assumptions) regarding the source of the sounds described in Beckett's novels. The narrative voice is not capable of accurately portraying this information, for, as Prieto explains, the narrator does not truly reside within the conscious ego of Beckett's character nor does it have access to the external world: "The voice that speaks (or writes) in the Beckettian text is nothing but an intermediary between an inside/ego that (we suppose) must exist (but that the narrative voice cannot locate) and an outside/world that remains equally inaccessible to knowledge."106

\footnotetext{
${ }^{105}$ Eric Priet, Listening In, 194.

${ }^{106}$ Ibid.
} 
The narrative voice that Prieto describes applies aptly to the role of MOUTH's monologue in Beckett's original drama. The actress's monologue divulges an incoherent narrative filled with allusions to internal and external voices (if the listener is able to decode her outpouring quickly enough). In reference to internal voices, she cites "buzzing" frequently throughout the monologue, and, similar to the narrator of Watt, has trouble pinpointing the source of sound. Initially, the buzzing is "in the ears;" but later, MOUTH claims it "though of course actually...not in the ears at all...in the skull...dull roar in the skull..." and never brings to question that the buzzing is in her ears throughout the rest of the monologue. Her relationship to sounds in the physical world is confounding, as well. Consider MOUTH's relationship to her own sound production in this excerpt:

...couldn't make the sound...not any sound...no sound of any kind...no screaming for help for example...should she feel so inclined...scream...[Screams.]... then listen ...[Silence.]...scream again...[Screams again.]...then listen again...[Silence]...no...spared that...all silent as the grave... ${ }^{107}$

MOUTH purportedly cannot hear her own scream. She screams twice and listens for signs of her own voice in the external world, but reports all is "silent as the grave."

MOUTH's relationship to internal and external voices is part of what makes her a fascinating character in Beckett's original drama. She is stuck in the space between the external world and her internal thought process. As demonstrated above, she describes her internal thoughts with words (like "buzzing") that are more apt for describing external phenomena, yet she does not seem to recognize distinct sounds (like her own screams) that occur outside of her inner conscious. MOUTH is suffering from what Prieto

${ }^{107}$ Samuel Beckett, Samuel Beckett: The Complete Dramatic Works (Boston, MA: Faber and Faber, 1986), 378. 
diagnoses as a common symptom of Beckett's characters. "The primary symptom of this lost [faith in the identity between consciousness and self] is that...the voice of consciousness gest lost or becomes confused with an other's voice or even with a plurality of other voices." ${ }^{108}$ But unlike characters within Beckett's novels that do not have a physical presence, since they are interpreted through the decoding of language on a page, MOUTH's narration of her sensory perceptions is immediate and visceral, being delivered from the dramatic stage. This is why academics like Ericson claim the torrent of words is such an important element of Beckett's drama Not I.

Holliger's MOUTH character is embodied by the soprano, but her singing style does not replicate the physicality and rhythmic flow of the original drama. This is not a lapse in Holliger's understanding of Beckett's work. Instead, as the rest of this chapter will demonstrate, Holliger's reinterpretation of MOUTH's style of delivery also shifts her role from that of narrative voice to the role of external voice. The live voice simply represents the event of MOUTH's logorrhea; the soprano is the clear source of sound of this outpouring of words. Yet, there is another complex of voices in the composition. The sounds of the tape, clearly inhuman and unnatural, operate as the disorganized internal voice(s) of MOUTH. The listener experiences the sounds of both the external and internal voices, but often without a clear sense of the source of sound. Therefore, the listener experiences Holliger's composition in the same space as the narrator of Beckett's novels, positioned between the internal voice(s) and external voice of the character MOUTH. And just as the narrator of Beckett's novel does not always clearly delineate the source of every sound in the novel, Holliger forces an ambiguous blend of internal and external voices on the listener. The audience functions as tympanum.

${ }^{108}$ Eric Prieto, Listening In, 195. 


\section{Holliger's Interpretation of MOUTH}

Holliger presents MOUTH as a human character. This is a significant fact that must be supported to make the interpretation of audience as tympanum a viable argument. MOUTH's humanity in Beckett's play is not as clear since she exhibits inhuman characteristics. Beckett constructs a garish synecdoche for a human in MOUTH by compressing her entire being into an articulating mouth. In a live production, Beckett's stage directions call for the actress to be elevated about eight feet above the stage and suggests that the source of her elevation should not be visible. ${ }^{109}$ Oddly enough, the hooded figure AUDITOR is much more human in appearance than MOUTH. Although robed and essentially formless, he/she at least stands like a human. As Enoch Brater points out in his study of the drama, AUDITOR's few movements within the play are intended to draw the attention of the audience away from MOUTH. ${ }^{110}$ Hopefully, this prevents the viewer from slowly uncovering the human figure behind the illuminated mouth of the actress as their eyes adjust to the darkness of the stage. These are just a few ways that Beckett denies the viewer of the drama the security of safely assuming MOUTH represents a human.

Holliger's Not I, however, features a soprano as MOUTH singing. Her singing alone does not suggest anything unearthly like the staging of Beckett's MOUTH. As was discussed earlier in this chapter, the soprano sings with disjunct, stilted rhythms and the pitch content creates some difficult intervallic passages. However, the soprano's singing

\footnotetext{
${ }^{109}$ Beckett, Complete Dramatic Works, 376.

${ }^{110}$ Enoch Brater, "The 'I' in Beckett's Not I," Twentieth Century Literature 20, no. 2 (July 1974): 195.
} 
style does not replicate the physicality of MOUTH's monologue in the original drama. ${ }^{111}$ The stuttering rhythms do, however, suggest that the soprano is recreating an involuntary bout of logorrhea. More words continue to be spoken (for more than thirty minutes) even though they lack any rhythmic momentum within Holliger's work. Therefore, the soprano certainly creates an element of tension in the work by virtue of the music's lengthy duration.

Interestingly, Holliger does not highlight MOUTH's external expression of emotion. The soprano does not react to fragments of the text that semantically lend themselves to an emotional response. In this manner, Holliger's MOUTH parallels Beckett's MOUTH. Since Beckett's MOUTH delivers the monologue at a dazzling speed, the actress can hardly be expected to emote a reflection of the words' meaning. In the context of the works considered in this study, a listener might be tempted to label Holliger's MOUTH as cold and inhuman, simply an automaton. ${ }^{112}$ However, the negative emotions detailed in the semantic content of MOUTH's monologue only represent a fraction of MOUTH's tragic state. Instead of musically representing the ebb and flow of MOUTH's recollection of her past, Holliger focuses his composition instead on MOUTH's internal struggle with the multiple voices of her inner consciousness.

Holliger recreates the chaotic structure of MOUTH's inner mental processes with the electronically manipulated voices of the tape. However, Holliger introduces the tape in a manner that does not immediately correlate to the soprano's inner consciousness. Upon the initial entrance of the tape, the listener likely recognizes that a two-part canon

\footnotetext{
${ }^{111}$ I was surprised to find that both Ericson and Kunkel's studies of the work mention the physicality of the soprano's singing style. Although the rhythms are stilted and unnatural, the physicality does not nearly approach the feat of Beckett's actress in Not $I$.

112 This is most likely when Holliger's Not I is compared to the dynamic vocal part in Zubel's Not I.
} 
has begun. As Example 3.3 shows, the tape consists of a single voice that repeats the opening music of the live voice. ${ }^{113}$ (This is one of the few occasions that the manuscript score shows the entirety of the tape realized in music notation.) However, as the composition continues, it is clear that Holliger is not simply creating a canon that will continue to compound musical material over the course of the work. The voices of the tape quickly become much less human-like with further manipulations. Holliger describes the tape manipulation process succinctly:

From [the first voice of the tape], that in itself contains a fugato, I have made a 16-voice fugue. Everything that this voice sings becomes absorbed, played again later, and, furthermore, becomes absorbed in dialogue with its own past tense (Vergangenheit), subsequently playing again in a third layer, until it is part of sixteen layers. ${ }^{114}$

Although a canonic structure underlies the tape's construction, the aural result is not a neatly organized progression of related music. Instead, the tape adds seemingly unrelated interjections of sound to the live voice. Although the live voice continues singing in the same musical style throughout the work, the tape morphs into voices that become evermore distorted. Despite the tape's disjunct relationship to the live voice, Holliger characterizes these sounds from two sources as forming "one unity." united by their mutual origin from MOUTH's inner conscious and spoken monologue.

Holliger shifts the listener's focus from the semantic content of MOUTH's monologue to MOUTH's internal experience of speaking her monologue by incorporating the tape into his composition. To clarify, while Beckett's MOUTH can only

\footnotetext{
113 See Holliger's own quote in Kristina Ericson, Holliger, 488.

${ }^{114}$ My translation, as quoted in Kristina Ericson, Holliger, 486. "Ich habe aus dieser einen Stimme, die in sich ein Fugato einthält, eine 16-stimmige Fuge gemacht. Alles, was die Stimme singt, wird aufgenommen, später wieder eingespielt, und dazu wird die Stimme weiter im Dialog mit ihrer eigenen Vergangheit aufgenommen, später wieder eingespielt zu einer dritten Schicht, bis es zum Teil 16 solcher Schichten sind."

${ }^{115}$ Quoted in Philippe Albèra, "Beckett and Holliger," trans. Mary Bryden, in Samuel Beckett and Music, ed. Mary Bryden (Oxford: Clarendon Press, 1998), 94.
} 
deliver a monologue with words that occasionally allude to her own experience, Holliger's composition can replicate the sounds of MOUTH's inner processes while she is compulsively continuing her outpouring of words. Multiple voices can obviously occur simultaneously within the medium of music in a manner that is impossible to replicate with one single character in a dramatic work. The listener therefore hears the conflict between the inner and outer voices of the character MOUTH instead of simply reading a description of these multiple voices.

\section{Inability to Say "I"}

MOUTH is never able to claim the first-person "I" within her monologue, always forcing her words onto an unknown third-person "she" in the textual refrain of the original drama. This denial of the first-person is an aspect of Not I that has been comprehensively explored by literary critics. ${ }^{116}$ Holliger's Not I proposes a nuanced interpretation of MOUTH's denial-of-I. As discussed earlier, the soprano does not musically emote the semantic content of the text in Holliger's Not I. This is particularly significant since many studies of Beckett's Not I stress that MOUTH's denial-of-I is largely a denial of her tragic life-story. A prime example is the early (and still frequently cited) study by Enoch Brater. Brater argues that MOUTH's denial-of-I is a coping mechanism to avoid a confrontation with her inner unconscious self, her alter ego. ${ }^{117}$ Brater's argument is not faulty and is based on the MOUTH of Beckett's drama, not Holliger's composition. As this chapter has already demonstrated, Holliger's MOUTH is different; and the implication of her denial-of-I is not an exception.

\footnotetext{
${ }^{116}$ See Chapter 1 for a review of some of the common arguments.

${ }^{117}$ Enoch Brater, "The 'I' in Beckett's Not I," 193, 195-196.
} 
Holliger's MOUTH struggles with the declaration of the first person "I" because she hears so many voices, she cannot locate what Prieto terms the "founding voice.",118 This inability to find a founding voice is another feature Prieto ascribes to Beckett's late characters: "The quest to say I...is the search for a founding voice...This is why related questions of provenance (where do the voices come from?) and ownership (are they mine?) have such importance in Beckett's work." ${ }^{119}$ In Holliger's composition, MOUTH cannot escape the ever-growing multitude of voices and never answers the "questions of provenance and ownership" Prieto mentions. She cannot locate the "I," the ego that is the source of both her physical production of sound and the voice(s) of her inner conscious.

Example 3.4 shows the excerpts in Holliger's work that support this interpretation. This example isolates the five moments of denial-of-I in the composition. Significantly, the live voice reaches higher in pitch with every repeat of this figure. Additionally, the voices of the tape become more active with every denial-of-I. (Unfortunately, what is not shown in the manuscript is the full realization of the tape. I have given a short description of the tape in Example 3.4.) Holliger composes musical climaxes at these textual refrains; thereby, Holliger designates MOUTH's denials-of-I as the most important events in the work.

Obviously, the listener should consider what is so important about these moments in the music. Structurally speaking, in Beckett's original text, the textual refrains are clear demarcations of five sections of text. However, Holliger does not reiterate this function as clearly since the music is different every time this returns. He focuses instead on MOUTH's struggle in saying "I." At these moments when MOUTH asserts her use of the

\footnotetext{
${ }^{118}$ Eric Prieto, Listening In, 195.

${ }^{119}$ Ibid.
} 
word "she," Holliger musically highlights the source of MOUTH's struggle: internal voices. The active role of the tape at these points in the music pinpoint why MOUTH cannot say "I." It is not an avoidance of confronting her life-story, as Brater suggests. Instead, MOUTH cannot locate the "I" within this multiplicity of voices. Holliger's MOUTH lacks a locus of identity, a symptom all too common among Beckett's late characters.

\section{Conclusion}

Holliger's Not I creates an entirely different experience of the character of MOUTH than the original drama. Beckett's MOUTH can only describe the internal voices and external voices she experiences in a linear fashion. She becomes the narrative voice, the tympanum between the external world and internal consciousness. By contrast, Holliger's MOUTH projects sounds that mimic her own perception of her internal voices and external monologue in real-time. The listener resides in the space usually reserved for the narrator of Beckett's late works. The listener is the tympanum that is privy to the sounds of MOUTH's external world and internal consciousness.

Prieto's study of voices in Beckett has been cited frequently in this chapter. While the idea of internal and external voices can seem complicated, Prieto is not interested in overcomplicating Beckett. His analysis of Watt and the threne is soon followed by Prieto reminding his readers that “...Beckett's works all participate in an attempt to represent as accurately as possible areas of subjective experience that have been particularly resistant to more established modes of interpretation." ${ }^{120}$ Beckett's MOUTH experiences an oral outpouring that certainly resists "established modes of interpretation." However, Holliger

${ }^{120}$ Eric Prieto, Listening In, 163. 
is able to recreate an experience of MOUTH's internal and external voices that is not possible in the literary medium. Holliger's Not I is certainly a step closer to an accurate representation of MOUTH's subjective experience. 


\section{CHAPTER 4}

\section{REINSTATING MOUTH AS HUMAN IN ZUBEL'S NOT I}

Agata Zubel's Not I contrasts sharply with the other compositions of this study in one especially significant way: her composition features contrasting sections of music. As the previous chapters have demonstrated, Rhys and Holliger both apply homogenous processes within their works. The entirety of Rhys's piano work employs complex rhythms and dissonant harmonies. Holliger's soprano sings a steady tempo as the canonic layers of the tape grow in intensity. To be clear, Rhys and Holliger do not present static works; instead, their compositions entertain the same compositional process throughout. Both composers' settings parallel Beckett's original monologue in this manner since the actress continues to pour forth her speech with a similar delivery style. Zubel's composition, however, presents a vocalist who changes tempo, timbre, style, and is accompanied with a variety of orchestrations. Zubel's clear departure from Beckett's precedent deserves attention, and the feature of contrasting sections is the most distinguishing aspect of Zubel's Not I from the other two compositions. As this chapter will demonstrate, Zubel supplies an answer to an important question still argued in literary criticism today: Who or what is Beckett's character MOUTH?

As discussed in the overview of literary criticism on Beckett's Not I in Chapter 1, the identity of MOUTH has been described in many ways. One extreme identifies MOUTH as a woman who is indeed retelling details of her life in a phantasmagoric 
fashion. The other extreme rejects that MOUTH is a human individual and explains her monologue through linguistic theories, feminist theories, or other approaches. As would be expected, most academics argue for a nuanced version in between the extremes. Zubel's Not I, however, reinstates MOUTH as human.

The term "reinstate" carries enough semantic weight to be explained further in this argument since it is integral to the significance of Zubel's composition. How has MOUTH's human quality been stripped from her that it must be reinstated? First, the previous compositions discussed in this study have not given the human experience of MOUTH significant musical representation. Second, Zubel's original source, Beckett's drama, attempts to remove identifiable human characteristics from MOUTH by the staging. According to the staging directions, MOUTH is to be eight feet above the stage level without any lighting of the apparatus suspending her, portraying a physical impossibility for a human. ${ }^{121}$ The other obvious dehumanizing feature is the invisibility of MOUTH's figure to the audience save her mouth. The drama immediately presents the audience with the task of deciding what kind of creature is being represented on-stage delivering the text. Does this mouth on stage function as a synecdoche for the entire human or is this a being of another world? ${ }^{122}$

As this study has already made clear up to this point, there is valuable insight in approaching MOUTH's character in a variety of ways. However, Zubel's portrayal of MOUTH as a human that is experiencing the text in real-time is a unique approach, not just from the previous compositions of this study, but in literary criticism in general. As

${ }^{121}$ Samuel Beckett, Samuel Beckett: The Complete Dramatic Works, (Boston, MA: Faber and Faber, 1986), 376.

${ }^{122}$ For a discussion arguing the importance of synecdoche and litotes in Beckett's oeuvre, see Keir Elam, "Not I: Beckett's Mouth and the Ars(e) Rhetorica," in Beckett at 80/Beckett in Context, ed. Enoch Brater, 124-148, (New York: Oxford University Press, 1986). 
Dina Sherzer states in her discussion of MOUTH's marginal status, “.... it seems as if critics have shied away from the literal content of the play, from the actual experience of the woman called Mouth." ${ }^{123}$ Although this statement is from the mid-80s, it is still applicable at the time of this current study. However, it is important to clarify Sherzer's statement. She does not seem to refer to a simple lack of interest in the semantic meaning or literal interpretations of the text in literary criticism. For example, as early as 1974 , Enoch Brater writes about the "face in the grass" line of the drama possibly referring to MOUTH's memories of a rape. ${ }^{124}$ But while Brater hypothesizes what kind of experience this literal interpretation of the text refers to, his argument about the work is focused on an academic discussion of MOUTH's conscious and unconscious self, as discussed in Chapter 3. Sherzer is not referring to a simple recognition that MOUTH speaks about human experiences. Instead, Sherzer seems to question why MOUTH's character is not discussed in regards to a human currently reliving and reacting to these various (and mostly negative) experiences.

Zubel's composition presents the character MOUTH as a human figure emotionally engaged in the subject matter of her dialogue. As my musical analysis will show, two features of the composition create this re-humanizing of MOUTH. First, Zubel accentuates the drama of MOUTH's experience, primarily through orchestration and creating climactic tension. Second, Zubel emphasizes the most physical, mundane human-quality of MOUTH's monologue: speech-production. Both of these techniques

\footnotetext{
${ }^{123}$ Dina Sherzer, "Portrait of a Woman: The Experience of Marginality in Not I," in Women in Beckett: Performance and Critical Perspectives, ed. Linda Ben-Zvi (Urbana, IL: University of Illinois Press, 1980), 201.

${ }^{124}$ Enoch Brater, “The 'I' in Beckett's Not I,” Twentieth Century Literature 20, no. 2 (July 1974): 190.
} 
result in what Ruby Cohn terms "theatereality" (to be described in detail later). ${ }^{125}$ By highlighting MOUTH's humanity, Zubel's music dramatizes MOUTH's experience of her own outburst of logorrhea.

\section{Beckett's Rhythmicity}

While MOUTH's humanity is the main focus of this chapter, Zubel's treatment of Beckett's rhythmicity in Not I deserves attention, especially because it contrasts with Rhys's composition. This section of the chapter will demonstrate how Zubel highlights the slight variations within Beckett's text in a more pronounced manner than both Rhys's piano work and Beckett's original drama. Through use of a compositional process applied strictly to individual words (as opposed to textual fragments, as in the case of Rhys), Zubel's Not I clearly emphasizes the subtle permutations and variations within Beckett's text. These textual features become more perceptible in Zubel's Not I than Beckett's Not I through the use of pitch. For the purpose of clarity in this comparison, this portion of analysis will focus primarily on mm 89-260 in Zubel's Not I. This section will be referred to as the "rhythmic pitched" section, for it is the longest stretch of pitched notation with precise rhythms for the vocalist in the work. ${ }^{126}$

In Chapter 2, Rhys's compositional process was described in detail. Using Beckett's text as a strict template, Rhys created complex musical fragments for each textual fragment. Rhys highlights the patterning of the words in Beckett's drama and the rhythmic quality of the text. Because of the structure of Beckett's text, the seemingly

\footnotetext{
${ }^{125}$ Ruby Cohn, Just Play: Beckett's Theater (Princeton, NJ: Princeton University Press, 1980), 29-30.

${ }^{126}$ Giving the sections of Zubel's composition a descriptive name is more useful than a formal name (i.e.Section A, Section B') because the sections are not significantly relatable by these traditional labels. Also, to clarify, there are a few important exceptions of unpitched and sprechgesang techniques in this rhythmic pitched section. However, the pitched notation is most prominent over other vocal techniques.
} 
disjunct musical fragments of Rhys's piano work become coherent. Zubel employs a similar compositional process in some sections of Not I, such as the rhythmic pitched section. However, Zubel differs from Rhys in one crucial aspect. Rhys divided the text into various sized fragments whereas Zubel uniquely sets each individual word. Additionally, Zubel employs relatively simple musical figures for each word as opposed to Rhys's intentional complexity. These variations in approach create aural effects that highlight Beckett's dramatic style in significantly different ways.

This comparison of Zubel and Beckett is informed by the insights provided by $\mathrm{H}$. Porter Abbott's application of musicologist Leonard Meyer's "law of return" to Beckett's texts. ${ }^{127}$ Abbott gives a simple explanation of Meyer's use of the terms "recurrence" and "reiteration" in reference to the law of return: "Where [reiteration] is ever present and therefore requires constant variation to avoid the effect of 'saturation,' recurrence happens over larger intervals and requires intervening development, without which no real 'return' can be said to have happened." ${ }^{128}$ Abbott also points out "Meyer argues that, in [reiteration], successive comparison brings out differences, while in [recurrence] similarities override differences." ${ }^{129}$ The text of Not I is rife with examples of reiteration (.... a few steps then stop...stare into space...then on... a few more...stop and stare again...so on...) and recurrence (five iterations of “...what?..who?..no!...She!..”). Since both Rhys and Zubel (in the rhythmic pitched section) follow a compositional process that is linked to the text, reiteration and recurrence become stylistic features of both composers' works.

\footnotetext{
${ }^{127}$ H. Porter Abbott, "Samuel Beckett and the Arts of Time: Painting, Music, Narrative," in Samuel Beckett and the Arts: Music, Visual Arts, and Non-print Media, ed. Lois Oppenheim (New York: Garland Publishing Inc., 1999), 20.

128 Abbott, "Beckett and the Arts of Time," 20.

${ }^{129}$ Ibid.
} 
However, not all instances of reiteration and recurrence are equally perceptible. Beckett deliberately focused on repetition and variation written in his dramas, and often movements (like the motions of AUDITOR described in Chapter 1) and other elements of the drama aside from the text were part of these formal constructions. He complained that these repetitions, although explicitly in the script, could go unnoticed by the audience if the directors of his works were not insistent on making them perceptible.

Producers don't seem to have any sense of form in movement. The kind of form on finds in music, for instance, where themes keep recurring. When, in a text, actions are repeated, they ought to be unusual the first time, so that when they happen again - in exactly the same way - an audience will recognize them from before. ${ }^{130}$

In this statement, Beckett expresses his conviction that repetition is not always noticeable by an audience unless highlighted by the actor. In the Rhys and Zubel compositions, the musical choices of the composers are responsible for highlighting instances of reiteration and recurrence. As my analysis will demonstrate, the rhythmic pitched section of Zubel's Not I brings attention to instances of reiteration as opposed to Rhys's piano solo that highlighted recurrence.

\section{Rhythmic Pitched Section: Compositional Process}

The rhythmic pitched section of Zubel's Not I follows a process of repetition based on the individual words of the original dramatic text. Zubel gives each word a pitch and simple rhythmic duration that is performed by the vocalist and piano in unison every

\footnotetext{
${ }^{130}$ My emphasis; Quoted in Eric Prieto, Listening In, 165.
} 
time the word is repeated. ${ }^{131}$ The simplicity of the vocal/piano rhythms is demonstrable by the fact that all the patterns of this section are derived using only five different durations. ${ }^{132}$ Additionally, Zubel limits the notes of the vocalist to the number of syllables in the corresponding text. Therefore, each word has a small number of rhythmic options dependent, of course, on how many syllables each word contains.

Zubel is not a composer who shies away from rhythmic complexity, so it is logical to attribute the simplicity of this pitched outpouring section to an intentional reduction of options by the composer. Since Zubel restricts her rhythmic vocabulary in this section, each word does not receive a unique rhythm. Therefore, her choices of pitch and text delivery become key factors in emphasizing the structure of Beckett's text. ${ }^{133}$ Instruments other than the piano and vocalist are treated more freely in this section. Sometimes, certain words or phrases always trigger the same sounds in the instruments. For example, the word "buzzing" is always accompanied by a trill figure in the winds and strings. At other times, new orchestrations accompanying repeats in the text suggest Zubel is presenting the same words with a different musical emphasis. (This will be discussed further in the upcoming discussion of dramatic build in the work.)

${ }^{131}$ A few words that are fairly common in the text, like "she," are treated a little more freely and have different pitches and rhythms based on their context. Also, the piano occasionally plays a collection of pitches or slightly different rhythms than the voice. These small deviations are not significant within this study, however.

${ }^{132}$ This figure increases to eight if you count the rhythm assigned to "screaming" at the end of the section. However, this provides an opportunity to sustain and represent the physical act of "screaming" instead of actually creating more rhythmic complexity.

${ }^{133}$ These musical choices will become significant pieces of evidence for analyzing her interpretation of the narrative and her focus on timbre in the later sections of this chapter. 


\section{Rhythmic Pitched Section: Analysis}

A short excerpt (Example 4.1) of the vocalist's music from the rhythmic pitched section is sufficient to demonstrate how Zubel's setting of Beckett's text emphasizes reiteration. The short phrase of most interest here is "not suffering." In these few measures, the word "not" occurs three times, each repetition being in a different arrangement of words. However, the word "not" is highlighted in Zubel's setting because it is sounded at the relatively high pitch E5 and sustained longer than the other text. In fact, the dotted-eighth duration of "not" is one of the longest durations applied to any word in this section, especially given the relative semantic insignificance of the term. ${ }^{134}$ The word "suffering" is also given a distinct musical gesture. The rapid, monotone delivery of this word in the low register is further accented by the reinforcement of its precise articulation in the winds and strings.

Her musical setting highlights the reiteration within Beckett's text; the original is reprinted here: “...she was not suffering...imagine!..not suffering!..indeed could not remember...off-hand...when she had suffered less..."135 The bold words in this excerpt highlight the relationship between the patterning in the text. In the original text, the initial phrase "she was not suffering" is reiterated as a fragment "not suffering." Then, this textual motif of "not suffering" is divided up, creating a variation of the text. The fragment "indeed could not remember" is followed by "when she had suffered less." In Zubel's composition, the listener can easily identify these textual reiterations of "not" and

\footnotetext{
${ }^{134}$ The "semantic insignificance" I refer to here is based in the word's function as constructing a clearer narrative. Many literary critics find the word "not" significant in the dramatic text due to its relationship to Beckett's negation techniques and, of course, its presence in the title of the work. For one particularly focused example, see Keir Elam “Not I: Beckett's Mouth an dthe Ars(e) Rhetorica." The literary use of litotes and synecdoches are argued to be the most important parts of Beckett's late dramatic style.

${ }^{135}$ Bold print added by the author for clarification; Beckett, Complete Dramatic Works, 377.
} 
"suffering" since they marked by distinct aural sounds. "Not" is a relatively high pitch sustained longer than most other words. "Suffered" and "suffering" are rapid monotone declamations on C4s. To steal from Beckett's statement, these words sound "unusual the first time so that when they happen again...the audience will recognize them from before."

Beckett's text provided Zubel with plenty of opportunities to emphasize the variations within Beckett's text. However, Zubel actually rearranges or adds to Beckett's text to further accentuate features of Beckett's rhythmicity. An extended sample of music from the rhythmic pitched section serves as an example (Example 4.2). (Additionally, this section can be meaningfully contrasted with the analysis of Rhys's setting of the same text (Example 2.3).)

The text of Zubel's vocalist is provided here. Italicized words represent phrases that Zubel has added to the original text:

what position she was in...what position she was in...imagine!... what position she was in...imagine!...imagine!... what position she was in... whether standing....or sitting...but the brain...what?..kneeling?..yes...whether standing...or sitting...or kneeling...but the brain...what?.lying?..yes...whether standing...or sitting...or kneeling... or lying...but the brain still...

The repetitions within the text that Zubel added herself offer insights into her compositional choices, especially since she edits the text of the drama on very few occasions in this work. Zubel opts for a moment of textual stagnation with the alternation of two lines in mm 105-111. The word "imagine!" becomes a barricade for the energetic phrase "what position she was in." The angular pitch content of the phrase "what position she was in," composed of two ascending figures, is neutralized by the three-note musical figure in "imagine" that, essentially, closes in on itself. Maria Ristani would likely label 
this technique a "break and repeat."136 "Imagine" interjects itself into the flow of words, but the text continues to be repeated as before despite the interruption. The winds and strings of the ensemble are in no hurry to progress past this textual impasse either. The strings are performing extended, multi-measure glissandi while the winds slowly descend down a microtonally inflected chromatic scale with misaligned rhythms.

The portions of the text beginning with "whether standing" are reproduced exactly as in the original drama in Zubel's composition. As previously discussed in Chapter 2, the accumulating chain of verbs in this text grows larger after every interruption by the phrase "but the brain...what?" Zubel draws the listener's attention to this moment by utilizing extended rests in the voice for the first time in this section. Each verb is set with a wide interval, and the chain of verbs gains momentum as the intervals become more extreme. The silences of the voice are filled with a flurry of microtonal runs in the winds and strings. However, the progress of these verb chains is broken by the interjections of "what." The notation of Zubel's score requires the vocalist to speak this word while taking in a breath, and the entire ensemble rests every time "what" appears. In effect, Zubel highlights the interjections of Beckett's text by allowing these words to instantly derail the rhythmic momentum she has created.

\section{Summarizing Zubel's Rhythmicity}

The comparison of Rhys's piano solo to the rhythmic pitched section of Zubel's Not I is effective because both works rely on Beckett's text in a similar way. However, the differences between the two composers' compositional processes create significantly

\footnotetext{
${ }^{136}$ See Chapter 2 for a detailed discussion of Ristani's studies of Beckett; Ristani, “Articulated ArrhythmiaL Samuel Beckett's Shorter Plays," in Beckett and Musicality, ed. Sara Jane Bailes and Nicholas Till, 119-135 (Dorchester, UK: Henry Ling Limited, 2014).
} 
different results. In Rhys's work, Beckett's rhythmicity is perceptible despite complex rhythms and abstract pitch patterns. The listener relies on the patterning of Beckett's text to comprehend Rhys's Not I. By contrast, Zubel uses of relatively simple rhythms and carefully chooses pitches that accentuate small variations in Beckett's text. Because of the addition of precise rhythms and specific pitches with each word, Beckett's rhythmicity is easier to recognize in Zubel's Not I than in a performance of Beckett's Not I. Zubel gives each word the additional aural markers of pitch and rhythm to individual words in addition to pronunciation; the audience member of Beckett's Not I relies mostly on pronunciation to recognize the variations in the text.

\section{Humanizing MOUTH}

As stated at the beginning of this chapter, Zubel presents the character MOUTH uniquely as a human character. This contrasts clearly with both Rhys and Holliger's portrayal of MOUTH. The general musical characteristics of both compositions remain essentially the same throughout their works. Rhys's MOUTH (the piano) delivers a torrent of words that ends as abruptly as it begins. Holliger's MOUTH does experience some change as the work progresses since her inner voice(s) (i.e.-the sound's of the tape) continue to multiply and become more active as the music progresses. Yet a gradual build in agitation that stretches over thirty minutes is not a realistic portrayal of a human's experience. Additionally, Holliger's MOUTH cannot be appreciated as a human character by the audience because, as Chapter 3 discussed in detail, the audience is positioned between MOUTH's inner voice and the external world. Zubel's MOUTH, however, is a dynamic, human character. MOUTH's emotional response to the text results in 
contrasting sections of music as well as crescendos and decrescendos in emotional tension. Zubel portrays MOUTH to the listener as a human reacting to her present situation. Additionally, Zubel focuses the listener's attention on the physicality of speech production in her composition. This not only highlights MOUTH's humanity for the audience, but it also highlights aspects of Beckett's late dramatic style that are not as aptly explored in the other compositions of this study. Finally, Zubel's MOUTH enacts what Ruby Cohn designates "theatereality." ${ }^{, 137}$ As will be described in more detail in my analysis, Zubel's MOUTH employs musical gestures that match the semantic content of the text. The remainder of this chapter will how Zubel uses these three techniques to humanize MOUTH.

\section{Dramatizing MOUTH}

Unlike Rhys and Holliger, Zubel's MOUTH exhibits an emotional ebb-and-flow. Zubel's music reacts sympathetically to the situation of MOUTH's logorrhea. When MOUTH recalls painful memories or realizes she is unable to stop her bout of logorrhea, the orchestration often follows with growing intensity. Zubel largely relies on two compositional techniques to represent a build in emotional angst. One technique involves simply increasing rhythmic activity, especially in the instrumental lines. The second technique involves aligning the rhythms of all parts. This becomes particularly effective when the words of the vocalists are accentuated by attacks from every other member of the ensemble. In contrast to building tension, Zubel also finds several ways to abruptly dispel the emotional stress of the music. Both of these aspects of the music present MOUTH as a dynamic human character.

${ }^{137}$ Ruby Cohn, Just Play, 29-30. 
Zubel writes two dramatic rises in tension quite early in the work, soon after the first entrance of the winds and strings. The first of these instances occurs in measure 61 with the text "...what?..seventy?..good God!.." and is shown in Example 4.3. Up to this moment, the strings and winds have been playing sustained notes. Suddenly, the soprano begins to rapidly deliver every line. Fittingly, the instruments interject with pointed articulations that begin to occur more frequently as the tension builds. Beckett's text provides an option for relief from this dramatic build-up, however, with a repetitious text begins. In measure 68 , Zubel dispels the rising tension by drastically changing the texture. Each member of the ensemble begins to repeat static musical figures. This reprieve from the dramatic build-up ends in measure 75 , as the rising tension from earlier returns with a similar texture and active rhythmic figures. MOUTH utterance of the textual refrain “...what?..who?..no!..she..” finally halts the growing intensity.

The rhythmic pitched section features an example of Zubel creating emotional intensity in the composition by gradually aligning the instruments' rhythms with the vocalist's text delivery. As discussed previously in this chapter, the vocalist and piano both have identical rhythms throughout this section. The winds and strings, however, play dissimilar musical figures from the vocalist/piano at the beginning of this section. As the music progresses, the text begins to be further accentuated and dramatized as the winds and strings occasionally match the rhythm of the voice. By measures 209-260, this texture becomes virtually homorhythmic, with almost every articulation of text being matched in the winds and strings. Sometimes the rhythms are identical; sometimes the instruments further subdivide the vocal part (e.g.-two eighth notes against four sixteenth notes). The text becomes a seemingly unstoppable rhythmic force strengthened by the 
rhythmically interlocked instruments until the dramatic climax of the section on the word "scream." Zubel builds tension throughout the entire section by gradually approaching this homorhythmic texture. The written-in "screams" of Beckett's monologue is a fitting target for the dramatic setting.

The climax of the work in measures $469-493$ features a similar emotional trajectory, as unison rhythms mark the apex of tension. As shown in Example 4.4, the soprano's rhythm is accentuated by the other members of the ensemble. The vocalist's textual delivery becomes melded with the strident sounds of the entire ensemble. To avoid monotony, Zubel adds slight variations to the ensemble's timbre by writing in occasional rests for the winds and strings. The semantic implications of the text was surely the reason Zubel chose this moment as the dramatic climax of the work:

not that?..nothing to do with that?..nothing she could tell?...all right...nothing she could tell...try something else...think of something else...oh long after...sudden flash...not that either...all right...something else again...so on...hit on it in the end...think everything keep on long enough...then forgiven...back in the...what?..not that either?..nothing to do with that either?.. nothing she could think?..all right...nothing she could tell...nothings she could think...nothing she...what?..who?..no!..she!..[Pause and movement 4] ${ }^{138}$

After more than eighteen minutes of making sounds, MOUTH seems to be overburdened by the insignificance to her outpouring. She frantically searches for the correct phrase to remedy this, repeating numerous phrases from earlier in the monologue, but she never finds the right words. After the soprano repeats the textual refrain one last time, her voice gradually disintegrates into silence in the last section.

${ }^{138}$ Beckett, Complete Dramatic Works, 382. 


\section{Speech Production and Beckett's "Fundamental Sounds"}

Zubel's soprano executes a wide range of vocal acrobats in Not I, focusing the listener's attention on speech production and, thereby, MOUTH's humanity. Additionally, Zubel's vocalist presents an opportunity to discuss an aspect of Beckett's late dramatic style that is not significantly emphasized in the Rhys or Holliger compositions. Beckett's own praise for the writings of Joyce addresses this stylistic feature succinctly: "[Joyce's work] is not to be read - or rather it is not only to be read. It is to be looked at and listened to." ${ }^{, 139}$ While this study has frequently addressed the structure of Beckett's text (e.g.-patterning, repetition, interruptions, etc.), there is a wide range of sonic material within these words that has not yet been fully discussed. In fact, Beckett describes his own work as "a matter of fundamental sounds (no joke intended) made as fully as possible."140

The significance Beckett gives to these "fundamental sounds" merits a discussion of how these sounds within the dramatic medium relate to the broader range of sounds within the medium of music. First, the term "fundamental sounds" needs to be defined. The context of the quote suggests that Beckett is referring to the sonic content of the words in his drama as opposed to the semantic content of the words. To the reader familiar with music academia, the concept of "sonic content" may seem strange since it lacks enough specificity to be useful when discussing music. However, literary academia pertaining to Beckett often refers to the sonic content of Beckett's work to address the raw sounds of the words. The sonic content of the words includes features such as articulation, inflection, vocal timbre, rhythm, and any other audible feature that is not

\footnotetext{
${ }^{139}$ Quoted in Daniel Albright, Surrealism and Beckett (Cambridge: Cambridge University Press, 2003), 3.

${ }^{140}$ Quoted in Keir Elam, “Not I: Beckett's Mouth and the Ars(e) Rhetorica," 124.
} 
dependent on semantic meaning to be perceived. ${ }^{141}$ As this section will demonstrate, Beckett's Not I text serves as an example that he was just as cognizant of the sonic elements of the words as their semantic content.

Zubel's Not $I$ is especially sensitive to highlighting the raw sounds within Beckett's text. Her recognition of these elements of the text is not surprising considering her fascination with timbral exploration in her compositions. To be clear, I am not proposing that the musical element of timbre and the sonic content of words are equivalent. Instead, both qualities require a listener to hear beyond the surface features of their respective mediums. The audience member at a drama is likely to focus on the semantic content of the dialogue and the actors' gestures and expressions. The sonic content of the words is subservient to this goal of understanding the story or moral of the play. In a similar manner, the typical musical concertgoer recognizes variations in musical elements like pitch and rhythm much more easily than subtle shadings of timbre. Because of the conditioning of audience members of both artistic mediums, any artists (such as Beckett or Zubel) that desire to highlight characteristics of their works that are not part of these immediately perceptible surface qualities often find ways to refocus the audience's attention to these lesser explored elements. In Beckett's drama Not I, he minimizes the role of narrative, character, and movement on the stage. This encourages a shift of the audience members' attention to the sonic content of the words.

Conveying this aspect of Beckett's late dramatic style in a significant manner within a musical work with a vocalist requires ingenuity. The introduction of a vocalist does not guarantee the listener will be more appreciative of the sonic content of the

\footnotetext{
${ }^{141}$ In Chapter 2, I discuss how Rhys's piano solo portrays the rhythmic aspect of the words in his mimicking of Whitelaw's rhythms in his composition. This would be the only example up to this point of the sonic content of the text being highlighted in the work.
} 
original text. In fact, it is just as likely the listener will be distracted by the new musical "sonic content" that has been added to the text (especially pitch and rhythm) and may not even decode the words within the new context. As this analysis will show, however, Zubel's composition focuses the listener's attention on the sonic content of the original text, primarily by emphasizing individual articulations and exploring a wide range of vocal effects to underscore these characteristics of the original text.

\section{Fragmenting the Text}

Zubel's vocalist begins the work by exploring Beckett's "fundamental sounds" by fragmenting every word into individual articulations. Zubel's approach highlights what H. Porter Abbot terms the "internal echoes" within Beckett's text. ${ }^{142}$ Writing out his own textual analysis, Abbott draws multiple lines connecting similar sounds that occur within an excerpt of Beckett's text from For the End Yet Again. For example, in Abbott's analysis of the textual fragment "grey cloudless sky glutted," the [gl] of "glutted" is annotated to show it is an amalgamation of the $[\mathrm{g}]$ in "grey" and the $[\mathrm{kl}]$ in "clouded."

However, Abbott describes this feature of "internal echoes" as an outgrowth of "music's repetitive and recursive character." ${ }^{143}$ This statement seems to place this feature of Beckett's texts in the same category as the patterning and repetition of entire words. The distinction is not as important within Abbott's discussion because he assumes the medium of spoken (or, internally audiated, in the case of reading) word. In this current study, the distinction is of paramount importance because of the text being represented in a musical work. These two characteristics, patterning of entire words and patterning of

\footnotetext{
${ }^{142}$ H. Porter Abbott, "Samuel Beckett and the Arts of Time," 18-19.

${ }^{143}$ Ibid., 18.
} 
individual sounds, do not necessarily survive the translation into music depending on the composer's choices. As the earlier section on Zubel's treatment of Beckett's rhythmicity, I demonstrated how Zubel's strict treatment of individual words highlighted Beckett's text differently than Rhys's strict treatment of textual phrases. Now, I will show how Zubel focuses the listener's attention on individual sounds and articulations within the words.

Example 4.5 shows the first thirty-two measures of the Zubel's Not I. A comparison of Beckett's original text and the soprano's text is insightful. Beckett's original reads as follows:

....out...into this world...this world...tiny little thing...before its time...in a godfor-...what?..girl?..yes...tiny little girl...into this...out into this...before her time... godforsaken hole called... ${ }^{144}$

Abbott's analysis of the text would likely draw special attention to the "godfor-." This word combines the underlined sounds shown above. The $[\mathrm{d}]$ in "world," [ə] of "world" and "before," and [g] of "thing" are all present within "godfor-" with a new sound that has yet to appear, [a].

Contrast Beckett's text with the soprano's text (the repetitions of consonants have been omitted here unless they constitute an entire measure. A backslash denotes a bar line.)

[o] / out / [o] / out / [o] / [o] / out / out / out / out / into this world / [d] / this world/ [d] / this world / [d] / tiny little thing / [g] / before its / time in a godfor- / what? / girl? / yes / $[\mathrm{t}]$ / [t] / tiny little / girl? / into this / out / into this / before her time / godforsaken hole /

\footnotetext{
${ }^{144}$ Underscore marks have been added to make the textual analysis more clear. Beckett, Complete Dramatic Works, 376.
} 
Dramatically speaking, the opening of the work reflects Zubel's understanding of the character of MOUTH. In a documentary about the composer, Zubel says Beckett's Not I "tells the story of an old woman who was mute all her life and then, aged seventy, she suddenly starts to speak." ${ }^{\prime 145}$ The opening certainly simulates the human character MOUTH struggling to speak after seventy years of silence. Zubel also focuses the listener's attention on the sounds within each word. The dry consonants $[\mathrm{t}]$, $[\mathrm{d}]$, and $[\mathrm{g}]$ receive special attention. These consonants are significant features of the internal echoes of the original text. [T] makes numerous appearances in the original text, and the roles of [d] and $[\mathrm{g}]$ trace the development of sounds leading to "godfor-". Zubel's fragmentation of the original words into individual phonetic articulations draws attention to these internal echoes and variations within the original text.

However, Zubel also brings the listener's attention to sounds that the original text does not. For example, the pronunciation of the word "out" is essentially reconstructed in Zubel's setting, becoming a two-syllable word ([au]-[t]) that elaborates the diphthong and dry consonant. Additionally, Zubel forces the listener to begin differentiating between two exceptionally similar sounds, the dry consonants $[\mathrm{t}]$ and $[\mathrm{d}] .{ }^{146}$ Even within these specific articulations, Zubel adds more timbral variety. For example, the [t] sound is notated with five different rhythms. (See measures $2,11,17,20$, and 21 for an example of each.) Because of the precision provided to Zubel within the medium of music and her

\footnotetext{
145 “Agata Zubel - GiNoNeWaMo,” YouTube video, 19:00, a documentary produced by Marek Obszarny and Magda Pawlinow, posted by "MrModerna," April 21, 2015, https://www.youtube.com/watch?v=BXCB5xqI-ps.

${ }^{146}$ It is interesting to consider the physical maneuvers of the mouth during this section. The progression from $[\mathrm{t}]$ to $[\mathrm{d}]$ to $[\mathrm{g}]$ is a progression from articulations of the tongue in the front of the mouth to the back of the mouth. In the last measures of the vocalist's part in Zubel's composition, this progression is given the extra step of $[\mathrm{k}]$. The "theatereality" discussion will reopen this discussion later in this chapter.
} 
own notation system, she is able to explore a broader range of sounds in the text that are not possible within the dramatic medium.

Zubel's exploration of these various articulations at the beginning of the work serves a larger structural purpose, as well. In considering the form of the work as a whole, the composition begins and ends with an exploration of articulations.

Approximately the last ninety seconds of the work is composed for tape and percussion only. ${ }^{147}$ The multiple voices of the tape are hardly intelligible at this point. Despite this, the listener is able to distinguish between different loops of sound because of the number of repetitions. The final thirty seconds of the work are particularly striking because of Zubel's focus on vocal articulations within the tape. ${ }^{148}$ A one-second loop of sound on the tape begins to repeat several times. A clear pattern of articulations among the voices becomes discernable. Gradually, the loop is divided in half, becoming a shorter segment of time. As this halving process continues, the only remaining sound in the tape is the percussive attacks of the voices articulating the beginning of various words. Therefore, Zubel starts the work with dry, percussive articulations of a live voice and ends the work with an impossibly fast collection of articulations of pre-recorded voices.

\section{Speech Production}

Zubel's exploration of articulations reveals more than the "internal echoes" of Beckett's text; Zubel's vocalist is obsessed with speech production. Zubel's MOUTH parallels Keir Elam's analysis of Beckett's Not I. Elam finds the drama shows “.... an increasing attention...to the sheer physical process of speech production" and MOUTH

\footnotetext{
${ }^{147}$ The score does not provide a realization of the tape, therefore I have not provided a copy of this section in the score.

${ }^{148}$ The timestamp for this moment on the cited recording with Zubel and the Klangforum Wien is [23:23].
} 
"remains acutely aware of oral sensation and of phonetic mechanics."149 Elam refers here to excerpts of MOUTH's monologue like the one in Example 4.6:

...her lips moving...imagine!..her lips moving!..as of course till then she had not...and not alone the lips...the cheeks...the jaws...the whole face...all those...what?..the tongue?..yes...the tongue in the mouth...all those contortions without which...no speech possible... ${ }^{150}$

Elam draws her conclusion from the semantic content of Beckett's text and the striking physicality of MOUTH's delivery. MOUTH speaks about the anatomical members of her face that enable her to speak (e.g.-cheeks, jaws, tongue, etc.) and is engaged in a painful outpouring of words. As Chapter 2 mentioned, Rhys parallels the raw physicality of MOUTH's monologue with a complex, unrelenting piano texture. Zubel's Not I also imitates this intense delivery style in certain sections, such as the rhythmic pitched section. However, Zubel is able to highlight the "physical process of speech production" that Elam mentions in a unique way from Rhys and Holliger.

The most obvious evidence of Zubel's focus on speech production is the wide variety of vocal styles she writes for MOUTH, as shown in Example 4.7. Initially, the vocalist stutters over consonants with a seemingly unsuited rhythmic precision while managing to gasp out a few audible phrases. Intelligibility increases as the vocalist begins to speak rhythmically or sing in Sprechstimme style. During the "Pause and Movement I" text of the drama, Zubel writes a textless, sustained line for the vocalist that contrasts sharply with the vocal techniques of the rest of the work. ${ }^{151}$ The rhythmic pitched section previously discussed occurs next, featuring an unrelenting stream of pitched text at a quick tempo. After another short section depicting AUDITOR, Zubel presents an

\footnotetext{
${ }^{149}$ Keir Elam, "Ars(e) Rhetorica," 141.

${ }^{150}$ Beckett, Complete Dramatic Works, 379.

${ }^{151}$ Interestingly enough, Zubel gives the only musical representation of the character of AUDITOR of any of the three compositions in this study.
} 
extended section of "half-whisper" singing. After this section, the vocalist explores a range of combinations of the previous vocal techniques. Zubel's musical setting of the original drama enables her composition to reflect on two aspects of Beckett's drama in significant ways.

Zubel's emphasis on speech production goes beyond various vocal styles, however. The most intriguing example of this occurs in measures 334-380; Example 4.6 shows a small excerpt from this section that shows the essential musical characteristics Zubel employs. At this point in the work, a long, pulseless section that demands a "halfwhisper" from the soprano has ended. Gradually, the vocalist sings more active lines. The vocalist draws out seemingly random sounds from individual words, in this case an [i], [a], and [n], then delivers rhythmic speech patterns with some timbral variations. By sustaining meaningless sounds, Zubel's vocalist highlights physical processes by singing sustained lines in this section with a multitude of oral shapes. Vowels are sustained, bringing the listener's attention to the formation of the mouth. The tongue's position is underscored as the [n] sounds are elongated, bringing the tongue to the top of the vocalist's palate. The listener has time to actually consider the sensation of the vocalist's pronunciation in this section. Therefore, speech production becomes an equally strong factor in Zubel's Not I as in Beckett's Not I.

\section{"Theatereality"}

Zubel's Not I encourages the audience to listen closely to MOUTH's words by creating an interesting array of sound, many of which have been referenced in my analysis. For the listener that begins to comprehend the words of Zubel's MOUTH, 
another feature of Beckett's Not I is revealed. This feature is termed "theatereality" by Ruby Cohn. ${ }^{152}$ In theatereality, the actors on stage describe the experience of the audience members in their dialogue. Cohn considers Not I to be "Beckett's most radical concentration of theater to the immediate perceptions of an audience." ${ }^{, 153}$ Some of Cohn's examples of theatereality from Beckett's Not I include the phrases about "buzzing" and the "ray of light." 154 According to Cohn, as MOUTH describes a "ray of light" in her fragmented monologue, audience members realize they themselves are assaulted by the spotlight garishly illuminating MOUTH's face. In a similar way, MOUTH's words become just a "buzz" of sound for the audience. Several instances of theatereality are highlighted by Zubel's composition, but not simply because the text is reproduced by the vocalist. As this discussion will show, the exploration of multiple vocal timbres and the articulation features described previously emulates the theatereality features.

The section just discussed, shown in Example 4.6, is one example of Zubel utilizing theatereality. The text in this excerpt reads “...[e]...the cheeks...the jaws...the whole face...all those-... what?..the tongue?..yes...the tongue in the mouth...all those contortions without which...no speech possible." The quality of theatereality is powerfully conveyed in this section as the semantic meaning of the words serves as a description of what Zubel's audience is witnessing on stage. Zubel's vocalist has been especially focused on contorting her face to sustain a variety of strange sounds throughout this section. If the listener has not yet noticed the anatomical workings of this feat, the soprano begins to describe them for the audience in these lines. And what occurs when these physical contortions stop? Speech is not possible, of course! Instead, the

\footnotetext{
${ }^{152}$ Ruby Cohn, Just Play, 30.

${ }^{153}$ Ibid., 29.

${ }^{154}$ Ibid., 29-30.
} 
vocalist elongates odd vowels and consonants instead of delivering words whenever her face becomes less motile.

Another moment of theatereality is underscored by Zubel with the text "not catching the half...not the quarter...no idea what she's saying." In addition to the vocalist delivering the text in an unclear manner at this moment, the orchestration of the rest of Zubel's forces contribute to making the soprano less intelligible. The tape's recorded voices continue to grow louder and increase in textural density. The winds and strings interject with seemingly aleatoric glissando figures. While the live vocalist is still distinguishable within the sound of the ensemble, her text is not nearly as intelligible as in other sections of the work.

The last instance of theatereality presented in this analysis also contains an example of what Daniel Albright refers to as Beckett's ability to "incarnate [his] subject stereomorphically" with the text. ${ }^{155}$ This brings us back to Beckett's quote earlier about Joyce's writings. "[Joyce's writings are] to be looked at and listened to. His writing is not about something; it is that something itself...When the sense is dancing, the words dance." ${ }^{156}$ Albright argues that Beckett's praise of Joyce becomes a characteristic within his own writing. Interestingly enough, when the written word of Beckett's dramatic text is spoken by a voice, the words not only act in the same manner as their semantic meaning (i.e.-when they describe dancing, they should dance), but the situation they describe is exactly what the audience is witnessing on stage (theatereality).

This is precisely the situation that occurs at the end of one of Zubel's climactic builds, as shown in Example 4.8. The vocalist's text reads “...like maddened... and can't

\footnotetext{
${ }^{155}$ Albright, Beckett and Aesthetics, 3.

${ }^{156}$ Quoted in Albright, Beckett and Aesthetics, 3.
} 
stop...no stopping it... and can’t stop...no stopping it...not stopping it... and can’t stop...no stopping it...something she...something she had...something she had to...what?..who?..no!...she!..." In this instance, Zubel adds to Beckett's original text by adding several more repetitions to “... and can't stop...no stopping it" and one variation between "... something she... something she had to..." In considering a performance of the original drama, this functions as a moment of theatereality as the audience is confronted by an actress whose monologue seems to never stop. Consider that this text occurs at the end of the longest stretch of text without a pause (about 800 words). ${ }^{157}$

Within the context of the original drama, however, this is not a particularly convincing example of what Albright termed "stereomorphic writing." In Beckett's original, these words are delivered in a similar manner as the rest of the monologue. By contrast, Zubel's translation of the drama into music does indeed present a musical texture that refuses to stop. First, the vocalist begins to deliver the text in a different style from the rest of this section. The soprano is no longer held back by sustaining various consonants and vowel sounds and performs the text with a precise rhythmic drive. But even when the vocalist stops in measure 381 , the music continues. The cascading figures are repeated for twenty-six measures and the tape continues to sound without signs of diminuendo. In this way, Zubel's music resembles the stereomorphic quality often found in Beckett's text. Just as the text speaks of an unstoppable wave of words, Zubel's presents a musical texture that becomes a seemingly unstoppable loop of sound. ${ }^{157}$ The previous second longest section of the work precedes this one, containing approximately 500 words.
At least the audience experiences a few pauses for MOUTH to scream in that section! 


\section{Shouldn't Beckett Be Confusing?}

Sherzer's recognition of the apprehension among literary scholars to address the dramatic content within a modernist work like Beckett's Not I parallels a general trend to analyze modernist musical compositions in a similar way. The previous analysis of Zubel's composition makes clear that she intended to highlight the drama of MOUTH's human experience, and I fear that my claim may be misread as a negative critique of the Zubel's Not I. One might ask what is significant about an artwork that presents a complicated character like Beckett's MOUTH as simply a human. Can Beckett's MOUTH be reduced to a human? Would Beckett not reject such a simplistic interpretation, wishing instead to remain confusing?

Instead of overcomplicating Beckett's drama, many academic critics would welcome Zubel's interpretation of MOUTH. Scherzer has already been mentioned, but another Beckett critic that writes about this issue is Eric Prieto. He writes “...I would like to insist that Beckett's overarching goal is not limited, as some have supposed, to outsmarting or mystifying his audience or, as other have suggested, to translating into narrative terms the classic problems of metaphysics and epistemology." ${ }^{, 158}$ To be clear, Prieto does not discount any of the intriguing readings of Beckett's works that have drawn on advanced academic theories. Instead, he does not want to continue to see Beckett's works limited to these complex readings. I wholeheartedly agree with both Sherzer and Prieto, and I would feel confident that other academics have read enough obfuscations of Beckett's work. When Zubel re-humanizes MOUTH, she creates a musical work that is emotionally effective without necessitating an academic understanding of Beckett's work.

\footnotetext{
${ }^{158}$ Eric Prieto, Listening In, 163.
} 
While the studies of several Beckett scholars have been discussed in this chapter, I find Zubel's efforts to dramatize MOUTH's character parallel actress Billie Whitelaw's initial reception of Beckett's text. Whitelaw clearly identified with the human side of MOUTH upon her first reading of the work. "Not I came through the letter-box. I opened it, read it and burst into tears, floods of tears. It had a tremendous emotional impact upon me. I knew then that it had to go at great speed. It was incredibly moving." ${ }^{159}$ Whitelaw's reaction was not because she had acquired a taste for Beckett's style. Not I moved her even though she did "not understand one word of it...intellectually," but she recognized "the inner scream; I recognized a wound that's in there somewhere." ${ }^{160}$ Her response is intrinsically reliant on her recognition of MOUTH as a human character. Zubel's dramatic setting of the work supports that she had a similar recognition of MOUTH's human condition as Whitelaw. The actress's emotional response to the text seems fitting for Zubel's musical setting, as well; for although Zubel's MOUTH is given the opportunity to vocalize a wide range of sounds, the sources of her "wound" do not seem resolved by the end of the work.

Zubel does not neglect the more cerebral aspects of Beckett's Not I for the sake of humanizing MOUTH, however. Zubel still gave the sonic content of Beckett's text prominence in her composition. In fact, these aural features of Beckett's text were perfectly suited to Zubel's penchant for timbral exploration. Zubel's fragmentation of words into individual articulations highlighted the internal echoes of Beckett's text, and her wide variety of vocal techniques underscores MOUTH's preoccupation with the physicality of speech production. Because of these features, Zubel's composition

\footnotetext{
${ }^{159}$ As quoted in Ruby Cohn, Just Play, 199.

${ }^{160}$ As quoted in Linda Ben-Zvi, Women in Beckett: Performance and Critical Perspectives, ed. Linda BenZvi (Urbana and Chicago: University of Illinois Press, 1992), 4.
} 
represents a harmonious union of both the semantic and the cerebral aspects of Beckett's work. The listener is presented with an artistic work that both details the plight of MOUTH as a protagonist while also highlighting the sonic content of Beckett's text. 


\section{CHAPTER 5}

\section{THE “THINGS” BEHIND LANGUAGE}

\section{Music's Contribution to Beckett}

Phillip Glass, György Kurtág, Morton Feldman, and Earl Kim have not only created fascinating musical analogues to Beckett's compositional strategies, but have, I believe, made possible certain understandings of Beckett's aesthetic that would never have come to pass without their sonorous realizations. ${ }^{161}$

In this one statement, Albright summarizes both my initial aspirations for this study and the potential pitfall of this endeavor. After considering Chapters 2-4 of this paper, it is obvious that the three compositions of this study hold "fascinating musical analogues to Beckett's compositional strategies.” All three works mimic key features of Beckett's drama Not I. However, whether or not these works create a unique understanding of "Beckett's aesthetic" is a much more difficult feat to prove. The potential pitfall mentioned earlier is related to these two features. While each composition of this study may highlight specific aspects of Beckett's Not I, that does not guarantee they lead to a better understanding of Beckett's style. However, as this chapter will demonstrate, each composition does indeed give the listener a better understanding of Beckett's late dramatic style and, as Albright suggests, the medium of music enables these revelations.

First, I want to modify Albright's statement slightly. I do not think anyone can prove what "understandings of Beckett's aesthetic" could potentially come to pass

${ }^{161}$ Daniel Albright, Beckett and Aesthetics (Cambridge: Cambridge University Press, 2003), 27. 
without "sonorous realizations." Literary critics have discussed aspects of Beckett's Not I without the aid of insightful musical realizations. I do not think Albright is guilty of hyperbole in this statement, but simply that this is not a statement he intends to support with irrefutable proof. This chapter will demonstrate how these three compositions are able to readily bring the listener's attention to features of Beckett's late dramatic style that might go unnoticed in the original drama. Whether or not another medium of art could possibly accomplish a similar feat is beside the question.

The most significant features of each composition seem to answer one of Beckett's self-proclaimed end goals in his deconstruction of language. Although this example is often quoted in literary criticism in various fragments, I find it worthwhile to quote Beckett at length:

It is indeed becoming more and more difficult, even senseless, for me to write an [sic] official English. And more and more my own language appears to me like a veil that must be torn apart in order to get at the things (or the Nothingness) behind it...As we cannot eliminate language all at once, we should at least leave nothing undone that might contribute to its falling into disrepute. To bore one hole after another in it, until what lurks behind it - be it something or nothing - begins to seep through; I cannot imagine a higher goal for a writer today. ${ }^{162}$

What are these "things behind" language? Is this simply an example of Beckett speaking like a cryptic intellectual simply as a right of being a celebrity of modern art? It would be unwise to seek too literal an interpretation of this quote since it was written by a man who specialized in avoiding literal writing. However, Beckett's statement is not completely indecipherable. This statement asserts that the surface meaning of language in Beckett's words does not accurately represent the goals of his art. By causing language to fail ("bore one hole after another in it"), other features of language "begin to seep through." The three compositions in this study capitalize on such features. Where Beckett's tool of

${ }^{162}$ Samuel Beckett, Disjecta, ed. Ruby Cohn (New York: Grove Press, 1984), 171-172. 
language begins to fail, the medium of music is able to thrive. This is how, as Albright suggested, music is able to give the listener a fuller understanding of Beckett's style.

\section{Removing Words to Expose Rhythmic Patterning}

Rhys's Not I translates the unique rhythmic qualities of Beckett's text into a musical work for piano solo. As discussed in Chapter 2, Beckett's rhythmic style goes beyond the precise rhythm given to each word. For example, translating Beckett's rhythm to music has nothing to do with ensuring a three-syllable word is performed as "eightheighth-quarter" rather than "quarter-eighth-eighth." Instead, Beckett's Not I has rhythmic characteristics appropriate to the dramatic medium since precise rhythms cannot be notated in the text. As long as the actress of Not I performs the work with an appropriate tempo, the rhythmic quality of the monologue is preserved regardless of the specific rhythms the actress uses for each individual word.

Beckett's Not I exhibits a type of rhythmicity that initially seems foreign to the medium of music. When describing most musical works, rhythm often refers to specifics such as a short rhythmic motif or its diminutions and augmentations. Yet Rhys tasked himself with reproducing Beckett's rhythmic style that is based in textual patterns (repetitions, permutations, and variations) without a vocalist to perform the words. Therefore, the individual rhythms Rhys chose became less important than how and when those rhythms returned. As Chapter 2 described in detail, Rhys was inspired to imitate some of the precise rhythms of Billie Whitelaw's performance of the monologue. However, while these choices result in a composition that imitates the idiosyncrasies of Whitelaw's performance, following Whitelaw's speech rhythms is not the most 
significant aspect of Rhys' composition. The patterning of the larger rhythmic fragments is the essential feature of the work. Due to these patterns, even without the text's presence, the rhythmic structure of Beckett's Not I is artistically mimicked in Rhys's Not $I$.

Rhys's composition is able to give the listener a better understanding of Beckett's rhythmicity even though it is strictly tied to the original work's form. If Rhys followed Beckett's form so closely, how can it help the listener understand the work better than the original drama itself? The answer lies in Rhys's removal of the words. As has been reiterated throughout this study, Beckett's Not I presents words that are utilized in a manner that subverts their semantic meaning. Although these words are not operating in a semantically logical manner, the audience member of Beckett's drama is still likely to try and interpret their meaning. Few audience members can easily forget their traditional approach to drama and forego trying to understand the words and phrases coming from MOUTH. In his study of Samuel Beckett and Morton Feldman, Guy Debrock describes the situation in this way:

We demand that words, or a painting, or a piece of music mean something first, and that this meaning is then conveyed to us, who are then regarded as the recipients of that meaning. A work of art, the meaning of which cannot immediately be read, is then regarded as meaningless, or - worse - something to be interpreted. ${ }^{163}$

The majority of the audience likely misses the rhythmic patterning of sounds, a key feature of Beckett's Not I, because they are too focused on decoding the words' meanings.

\footnotetext{
${ }^{163}$ Guy Debrock, "The Word Man and the Note Man," in Samuel Beckett and the Arts: Music, Visual Arts, and Non-print Media, ed. Lois Oppenheim (New York: Garland Publishing Inc., 1999), 74-75.
} 
Beckett is stuck with using words in the dramatic medium. Surely he could have removed the semantic interference for the audience by presenting nonsense syllables or transcribing MOUTH's monologue in a foreign language, but this would change the work's aesthetic entirely. The semantic noise of words obfuscates the underlying rhythmic structure in Beckett's Not I, so removing decodable language drastically transforms the work. Rhys, however, is able to present an autonomous musical work that changes the original drama. Rhys's wordless setting clears away the semantic noise for the audience; the rhythmic structure of Beckett's work is no longer hidden behind the potential meaning of individual words and phrases. Rhys's Not I focuses the listener's attention on the rhythmic patterning of Beckett's text by removing the words from his composition. Instead, a complexity of sound becomes intelligible through the underlying structure of Beckett's text.

Rhys using the medium of music certainly does not ensure his listeners will not try extrapolate meaning from the artwork. As Debrock alludes to above, generally speaking, few listeners are willing to appreciate a piece of music simply as a sound object without an underlying meaning. Because of this fact, Rhys's utilization of complicated rhythms is a significant feature of his composition. The complex rhythms encourage the listener to focus on the features of Beckett's rhythmicity without being distracted by Rhys's rhythms. Rhys's individual rhythms are difficult for the audience to comprehend in isolation; however, when these rhythmic fragments are contrasted with one another, the listener can appreciate the underlying structure of Beckett's rhythmicity. This highlights Beckett's rhythmic style instead of following a musically logical rhythmic flow. Comparing Zubel's composition to Rhys's composition clarifies the difference. 
Zubel's Not I also uses rhythmic repetition in a manner that replicated the structure of Beckett's text, however it does not create a listening experience that highlights Beckett's rhythmic style in the same way as Rhys's composition. This is because Zubel follows a musically logical rhythmic design as opposed to Rhys's composition that strictly follows Beckett's rhythmic logic. Several sections of Zubel's Not I are rhythmically intelligible with or without the reliance on the textual structure of Beckett's work. Rhys's composition, on the other hand, feature musical fragments that become comprehensible through their explicit reliance on Beckett's text. To summarize, Zubel's rhythmic language is too similar to other musical rhythms to give the audience a deeper understanding of Beckett's rhythmicity. Rhys, on the other hand, creates a work that relates unmusical rhythms by following Beckett's textual patterning.

Literary criticism on Beckett frequently demands that audiences and readers of his works should stop focusing on the semantic meaning of Beckett's words. This study has presented many of these examples. As valuable as academic writing can be for highlighting the aesthetics of a particular artist, these responses are limited to words and the reader's interpretation. Rhys goes beyond the limits of prose in Not I by creating a sound experience that mimics Beckett's rhythmic style. By demonstrating in sound Beckett's rhythmicity, Rhys's Not I gives the listener a better understanding of Beckett's Not I.

\section{An Audible Inner Voice}

Holliger's Not I removes many of the surface elements of Beckett's drama. As detailed in Chapter 3, Holliger does not preserve the fast tempo of MOUTH's 
monologue. Additionally, Holliger presents more than one voice, causing the listener to initially wonder if this work should be interpreted as a monologue. Of the three compositions considered in this study, Holliger's work differs the most from Beckett's original because of these two features.

In Chapter 3, I argued for a specific interpretation of the multiplicity of voices presented in Holliger's Not I. As my earlier discussion of Eric Prieto's study discussed, Beckett's texts (especially his prose) often position the narrative voice between the inner conscious and external world of the character. ${ }^{164}$ In Beckett's Not I, MOUTH is this narrative voice, describing her inner mental processes and delivering her outpouring at the same time. Holliger presents the audience with a different experience of MOUTH's monologue, however. In Holliger's Not I, all the voices belong to MOUTH, but not all the voices are products of her physical means of speech production. The voices of the tape belong to the inner conscious of MOUTH while the live soprano voice exists outside of MOUTH, representing the sounds of MOUTH's monologue. The audience is situated between MOUTH's internal and external voice(s), experiencing both in real-time.

By changing fundamental features (i.e.-tempo, monologue, and narrative voice) of Beckett's original drama, Holliger's Not I enables the listener to experience MOUTH's inner process, as discussed in Chapter 3. However, Holliger's composition extends beyond simply presenting a new experience of MOUTH. The electronic voices are also an exaggeration of a viewer's experience of Beckett's Not I. Holliger's Not I reflects how Beckett's drama demands active engagement in the inner conscious. In this way, Holliger demonstrates that the viewer's inner conscious is a key element in making Beckett's Not I an artistically viable work.

\footnotetext{
${ }^{164}$ Eric Prieto, Listening In (Lincoln, NE: University of Nebraska Press, 2002), 194.
} 
As has been made clear in this study, Beckett's Not I presents a plethora of sensory information. Despite the work being a monologue, the audience member has much to process. There is the raw act of decoding MOUTH's sounds into words. As described by Debrock in the previous section, most listeners will then attempt to extrapolate a meaning for both the words and the entire monologue, in general. The visceral physicality of the monologue is a factor, as well. As Chapter 2 detailed, Beckett "works on the nerves" of the audience with an onslaught of text. ${ }^{165}$ These aspects of the work do not even take into account the visual stimuli of the staging.

Holliger's Not I mirrors the viewer's inner processing of this spectrum of sensory information via the tape. For example, the entrance of the tape aligns with the first slight pause in Beckett's original monologue; and the voice of the tape almost strictly repeats what the soprano has performed so far. This seems analogous to the listener who identifies this slight pause as a chance to contemplate what they have heard. Finally, a break in the sound! Holliger conveys a listener that begins to retrace the words they have heard.

To be clear, interpreting specific moments in Holliger's composition as flawless replications of the viewer's mental process is not the foundation of this argument. Instead, I propose that Holliger's aural representation of inner voices emphasizes the important role the inner voice serves in appreciating Beckett's Not I. By giving an audible voice to MOUTH's many inner voices, Holliger makes the listener aware of their inner voice and its role as they experience Beckett's artwork. Sometimes, like Holliger's tape, the inner voice attempts to replay moments of MOUTH's monologue moments after

\footnotetext{
${ }^{165}$ Quoted in Kyle Gillette, “Zen and the Art of Self-Negation in Samuel Beckett's 'Not I', ' Comparative Drama 46, no. 3 (Fall 2012): 288.
} 
they occur, seeking to understand each short fragment. Other times, the inner voice blocks out new information from the monologue because it is fascinated with more extreme moments in the work, like MOUTH's scream. Holliger reiterates this scream in the tape frequently throughout the work, even though the original scream occurs only twice (in immediate succession) relatively early in the monologue. Regardless of how precisely Holliger's tape parallels the listener's inner voice, the significant fact is Holliger recognized the active role of the listener's inner voice for appreciating Beckett's Not I. Holliger finds the inner voice so significant, he gave it an audible voice in his composition.

\section{Fragmenting Words with Articulation}

Zubel's Not I presents the most dynamic approach to Beckett's drama in this study. As detailed in Chapter 4, Zubel's composition progresses through contrasting sections that highlight different characteristics of Beckett's work. Although many features of Beckett's drama are explored in Zubel's Not I, she makes a concerted effort to emphasize the physical process of speech production, specifically articulation. The vocalist explores a wide range of possible articulations, from emphatically short consonants to elongated open vowels. By fragmenting Beckett's text, Zubel gleans a wealth of timbral variety from ordinary words.

Similar to Rhys's contribution to understanding Beckett's Not I, Zubel presents a composition that encourages the audience to listen to the raw sounds of Beckett's text instead of the semantic meaning. Although both composers focus on highlighting the sonic content of Beckett's text, their strategies in bringing out these raw sounds are 
virtually antithetical. While Rhys focuses on patterning larger sound fragments, Zubel dissects the words into individual sounds and articulations. Rhys emphasizes the largescale relationships between the text fragments while Zubel explores the micro-scale relationships within the words.

Zubel does not completely forsake the large-scale relationships as was demonstrated in Chapter 4. However, her rhythmic language, pitch selection, and vocal resourcefulness focus the listener's attention on the individual articulations of each word. In the rhythmic pitched section, the syllables of each word return consistently with the same pitch and rhythm. Unlike Rhys's composition, Zubel's rhythms create momentum and an underlying rhythmic flow, relying on small variations of simple rhythmic durations. Additionally, pitch patterns are repeated strictly based on the text. Since Zubel's rhythmic language and pitch patterns are easily comprehendible in this section, the articulation of each word is highlighted. In the rhythmic pitched section, familiarity with rhythm and pitch elements in Zubel's music creates the opportunity to appreciate the subtle details like articulation.

Zubel also frames the entire work within the paradigm of focused attention on articulation. As discussed in Chapter 4, the composition begins with the solo vocalist exploring a wide variety of vocal techniques, many of which involve fragmenting the words into individual articulations. For example, repeating the hard consonant [t] multiple times in the first word "out." Starting the composition with this type of hyperfocus on sound production primes the listener to appreciate the wealth of sounds within individual words. These sounds are intrinsic to each word before pitch or even rhythm is applied, as proven by the opening of Zubel's Not I. 
Although I have purposely tried to analyze the compositions of this study in isolation from the composers' larger oeuvres, Zubel's penchant for timbral exploration in her works is particularly significant to this discussion. Zubel consistently creates new and intriguing sounds in compositions by drawing from often unusual sources. For example, in her composition Shades of Ice (2011), Zubel incorporates an electronic part comprised of her own field recordings of glaciers. Zubel's obvious obsession for creating new sounds in her music is significant when analyzing her work Not I. Within a common part of the human experience (language), Zubel finds a suitable source for timbral exploration.

Zubel's Not I certainly creates a deeper understanding of Beckett's Not I. After experiencing her composition, the listener is drawn to the wealth of sounds inherent within the individual words of Beckett's text. Hierarchically speaking, the complexity of articulations operates below the patterning of words within Beckett's text. This fact gives particular significance to Zubel's composition since she brings this secondary feature of the text to the forefront of her work. After listening to Zubel's Not I, greater appreciation is given to MOUTH's intricate articulations in Beckett's Not I.

\section{The "Things" Behind Language}

In response to Albright's hypothesis, this thesis demonstrates how the three compositions in this study enable a better understanding of Beckett's Not I. Rhys strips away Beckett's words to reveal the rhythmic structure of the text. Holliger creates audible inner voices, emphasizing the essential role of the listener's inner voice in appreciating Beckett's works. Zubel fragments Beckett's words into their individual articulations, exploring a wealth of sound in these fundamental features of language. This summary 
undoubtedly proves each work is a "fascinating musical analogue," but what significance do these works have beyond highlighting features of Beckett's Not I? Their significance lies in what Beckett describes as the "things behind" language.

As described above, Beckett's statements can seem incredibly cryptic (like those of many modernist artists). However, I contend that Beckett's earlier quote about finding what is behind language is not intended as a riddle without an answer. I also do not think it requires a doctorate in linguistics to discuss meaningfully. Instead, Beckett seems to simply refer to the fundamentals of language. This "higher goal" he sets for modern writers is to uncover all the potential in these language fundamentals. Beckett recognizes that many authors have developed narratives, character development, and poetic devices while other essential elements of language have yet to be comprehensively explored. These essential elements are surely the things behind language. Each composition in this study highlights these elements behind language. Rhys highlights the essential element of rhythm by removing the semantic noise of Beckett's text. Holliger highlights the essential element of inner mental processes by giving a voice to MOUTH's internal voices. Zubel highlights the essential element of articulation as a fundamental sound within individual words.

Each composition discussed in this study presents an essential element of language that is crucial to Beckett's art. While academics can describe these features in prose, these musical works give the listener a unique opportunity to experience each feature in sound. Each composition constitutes a unique, autonomous artwork, defendable on its own merits. However, the clearer understanding of Beckett's Not I provided by each composition should not be undervalued. The more cerebral, evasive elements of 
Beckett's use of language are presented clearly in each composition. After experiencing these musical works, viewers of Beckett's Not I will hopefully appreciate the elements behind the language of MOUTH's monologue. They can enjoy listening to Beckett's Not $I$ instead of understanding it.

\section{Areas of Further Research}

An academic study of this length would be a failure if it did not produce a host of meaningful questions for further research. Although these significant questions were not answered by this study, they should still be discussed. Several claims within this study serve as valuable evidence in the search for answers to some of these larger questions. Before addressing these concerns, I would like to encourage future academic studies of Beckett and music to search for opportunities to compare multiple musical settings of the same Beckett work as was done in this study. I believe this approach encouraged a more objective interpretation of the musical works in a few ways.

First, I studied the works through the paradigm of the original drama's salient features instead of through the lens of each composer's compositional style. By developing a strong knowledge of the original drama, the truly significant features of each musical work became fairly obvious. For example, Rhys's composition immediately struck me as a replication of the physicality and immediacy of MOUTH's breathless delivery of her monologue. Zubel's comprehensive exploration of vocal techniques in her composition reminded me of the dexterous articulation required of MOUTH in the drama. Instead of feeling required to draw out as much scholastic "mileage" out of each composition as possible, I was able to elaborate instead on the particularly exceptional 
similarities between the compositions and Beckett's drama. Additionally, I did not feel the need to defend each composer's interpretation of Not I. As this study has shown, all three composers reflected meaningfully on Beckett's Not I in different ways because they are themselves insightful and intuitive artists.

Second, analyzing multiple musical responses to Not I magnified the essential elements of the original drama. For example, the fact that all three composers reflect the repetitions and variations of Beckett's text in some manner is significant. Specifically, this stands as strong evidence that this textual feature is indeed a musical aspect of Beckett's work. ${ }^{166}$ There is no sign that Beckett's works will not continue to be set to music, and additional studies replicating this study method will surely reveal more essential elements of Beckett's work.

\section{Beckett's Influence on Music}

As made clear by this study, there is no shortage of musical compositions that exhibit significant parallels to Beckett's style; and literary critics and musicologists have started the process of studying the most intriguing and significant examples. While there are multiple examples of composers setting Beckett's works, I have not found a comprehensive discussion of Beckett's overarching influence on modern music (aside from his works serving as the template for a composition). Although it is fairly simple to find individual compositions that were explicitly influenced by Beckett, defining the relationship between Beckett's works and general currents in modern music is a much more difficult task.

\footnotetext{
${ }^{166}$ One reason that I find this to be a significant assertion is Eric Prieto's assertion that repetition is not necessarily a musical feature of Beckett's work. See Eric Prieto, Listening In, 164.
} 
Perhaps the absence of this kind of study is due to a lack of interest by scholars in the subject. Or another explanation might be that some scholars are satisfied with musical responses to Beckett's work as the limit of demonstrable influence. In other words, the fact that a relatively high number of compositions have been based on Beckett's works is enough case for considering him an influence on modern music.

My research on these three compositions exemplifies the difficulty of unraveling the degree and nature of influence between Beckett and composers. Another study of these three compositions could explore each work from an entirely different angle. Instead of analyzing which aspect of Beckett's style is highlighted in each composition, a study could examine the significance within the composer's larger oeuvre. Did the composers in this study change their compositional style to suit Beckett's text or, instead, do the features of Beckett's text align with the composer's typical compositional style? This study already provided some preliminary information for answering these kinds of questions. In the three compositions of this study, Rhys's musical setting of Samuel Beckett's Not I was the only composition that showed a marked change in the composer's musical style. ${ }^{167}$ However, there is no evidence to suggest that Rhys began to write compositions differently after his contact with Beckett's work. The influence of Beckett's Not I led to Rhys utilizing a style he had not explored up to that point, but did not lead to a long-term change in his compositional style.

Holliger and Zubel's compositional styles, however, already aligned with the stylistic features of Beckett's Not I. In Kristina Ericson's analysis of Holliger's Not I, she cites numerous stylistic features of Holliger's works that clearly correspond with

\footnotetext{
${ }^{167}$ Paul Rhys, "Not I for Solo Piano: Beckett's Text as Music," in Beckett and Musicality, ed. by Sara Jane Bailes and Nicholas Till (Dorchester, UK: Henry Ling Limited, 2014), 167.
} 
Beckett's Not I. ${ }^{168}$ In a similar way, many of Zubel's compositions before Not I focus on exploring subtle variations of timbre, specifically with the voice. In considering these compositions, it seems that Beckett certainly did not drastically change Holliger or Zubel's approach to music. Instead, Beckett's approach to the dramatic text of Not I was similar to both composers' approaches to sound. Still, further research may reveal a subtler shift in these composers' works after their close work with Beckett texts that has not been explored by the academic community yet. ${ }^{169}$

Regardless of whether or not Beckett's works changed a particular composer's musical style, many of Beckett's goals with language appear similar to many modern composers' goals with sound. This study did not survey a large enough sample of musical works to reach a definitive conclusion on this issue, but it certainly provided some evidence supporting parallels between the dramatic artist Beckett and some composers' compositional goals. One area of Beckett's intersection with music that should be explored further relates to the subject of creating intelligibility in a modern artwork. Beckett's late works clearly aim to avoid relying on the semantic meaning of the text to give each work meaning. However, Beckett does not produce unintelligible nonsense, only semantic nonsense. As the example of Not I demonstrated in this study, Beckett creates coherence in the work with multiple techniques that do not rely on narrative, character, or other elements that depend on the semantic meaning of words. Beckett's late

${ }^{168}$ Kristina Ericson, Heinz Holliger: Spurensuche eines Grenzgängers (Bern, DE: Peter Lang AG, 2004), 398.

${ }^{169}$ While Rhys has not composed multiple works based on Beckett's texts, both Holliger and Zubel have. Holliger's multiple Beckett works have been analyzed in the Kunkel work cited in the bibliography. Zubel has released three compositions based on Beckett works: Cascando (2007), Not I, and What is the Word (2012). These works have not received academic attention to this date, as far as I am aware, beyond liner/program notes. 
dramatic style requires the audience to listen past the semantic meaning of the text to truly appreciate his artwork.

Many modern musical works (such as the three compositions in this study) face a similar challenge in reception. If the audience seeks to understand the work through the musical elements that typically convey "meaning" (e.g.-harmonic progressions, melodic/motivic development, predictable underlying forms, etc.), then many modern compositions will be mislabeled as "nonsense." There is obviously no significance that both modern music and Beckett's modern dramas share the struggle of audience appreciation and comprehension. However, I suggest that further research may find that Beckett's demands on his audience parallel some compositions' demands on their listener.

Early evidence of this kind of relationship between Beckett and music is found in Rhys's Not I. In this particular study, I find that Rhys's Not I is the most challenging work in regard to comprehensibility. I initially struggled to identify the underlying structure of the various musical fragments in Rhys's Not I that creates the work's intelligibility. Without numerous attentive hearings, a listener could easily misidentify the work as belonging to the New Complexity compositional style or, possibly, a concerted effort by a composer to create a work without related material. As Chapter 2 described in detail, the musical fragments are definitely structured in a manner that highlights the more obvious repetitions and juxtapositions within the original text while also conveying the subtle variations and permutations of Beckett's Not I.

The difficult listening experience created in Rhys's Not I is significant because this work had the most explicit reliance on Beckett's text out of all three compositions in 
this study. As detailed in Chapter 2, the listener must recognize the return of complicated (and often stunningly fast) rhythmic patterns with some additional aid from pitch patterns. Rhys's Not I is a novel listening experience, even within the context of modern music. If the influence of a Beckett drama can result in a composition with unique features as late as the 1990s, Beckett's influence still holds significance to modern music. This leads to a larger question: What makes the intelligibility of Rhys's Not I unique from many other modern musical works? I would hypothesize that the novelty lies in the reliance on Beckett's style, but a satisfactory conclusion cannot be supported without a broader survey of musical compositions that are similar to Rhys's Not I. This type of survey should lead to broader questions about Beckett and music. Do some modern composers create comprehensibility in their works in a way that imitates the intelligibility of Beckett's works? Specifically, is there a musical corollary to Beckett's emancipation of words from semantic-meaning and syntactical structures?

As described in Chapter 1, most musicological discussions of Beckett still rely on studies of a single composition based on a work by Beckett. Broader studies that consider multiple works by one composer based on Beckett are also beginning to appear. I am not aware of any academic studies, other than my own, that compare multiple compositions by different composers based on the same Beckett text. While these three types of studies can all lead to significant conclusions, I hope that future studies of Beckett and music can become larger in breadth. Can Beckett's influence be found in modern compositions that are not specifically based on his texts? Are there convincing parallels between the aesthetics of some composers' works and Beckett's own stylistic features? This study presents more evidence to facilitate the answering of these questions. 


\section{REFERENCES}

Abbott, H. Porter. "Samuel Beckett and the Arts of Time: Painting, Music, Narrative." In Samuel Beckett and the Arts: Music, Visual Arts, and Non-print Media, edited by Lois Oppenheim, 7-24. New York: Garland Publishing Inc., 1999.

Albèra, Philippe. "Beckett and Holliger." Translated by Mary Bryden. In Samuel Beckett and Music, edited by Mary Bryden, 87-97. Oxford: Clarendon Press, 1998.

Albright, Daniel. Beckett and Aesthetics. Cambridge: Cambridge University Press, 2003.

Bailes, Sara Jane and Nicholas Till. Beckett and Musicality. Burlington, VT: Ashgate, 2014.

Beckerman, Bernard. "Beckett and the Act of Listening." In Beckett at 80/Beckett in Context, edited by Enoch Brater, 149-167. New York: Oxford University Press, 1986.

Beckett, Samuel. Disjecta. Edited by Ruby Cohn. New York: Grove Press, 1984.

Beckett, Samuel. Samuel Beckett: The Complete Dramatic Works. Boston, MA: Faber and Faber, 1986.

Brater, Enoch. "The 'I' in Beckett's Not I." Twentieth Century Literature Vol. 20, No. 2 (July 1974): 189-200.

Bryden, Mary. "Reflections on Beckett and Music, with a Case Study: Paul Rhys's Not I." In Samuel Beckett and the Arts: Music, Visual Arts, and Non-print Media, edited by Lois Oppenheim, 83-101. New York: Garland Publishing Inc., 1999.

Catanzaro, Mary. "Recontextualizing the Self: The Voice as Subject in Beckett's 'Not I'.” South Central Review Vol. 7, No. 1 (Spring 1990): 36-49. doi:10.2307/3189212.

Cohn, Ruby. Just Play: Beckett's Theater. Princeton, NJ: Princeton University Press, 1980.

Elam, Keir. "Not I: Beckett's Mouth and the Ars(e) Rhetorica." In Beckett at 80/Beckett in Context, edited by Enoch Brater, 124-148. New York: Oxford University Press, 1986.

Ericson, Kristina. Heinz Holliger-Spurensuche eines Grenzgängers. Bern, DE: Peter Lang AG, 2004. 
Holliger, Heinz. Not I. Manuscript score. Provisional edition. Schott Music International.

Gillette, Kyle. "Zen and the Art of Self-Negation in Samuel Beckett's 'Not I'." Comparative Drama Vol. 46, No. 3 (Fall 2012): 283-302.

Gontarski, S.E. The Intent of Undoing in Samuel Beckett's Dramatic Texts. Bloomington, IN: Indiana University Press, 1985.

Kennedy, Andrew. "Mutations of the Soliloquy: Not I to Rockaby. In 'Make Sense who May:' Essays on Samuel Beckett's Later Works, edited by Robin Davis and Lance St. J. Butler, 30-35. Irish Literary Studies 30. Gerrards Cross: Colin Smythe, 1988.

Knowlson, James, and John Pilling. Frescoes of the Skull: The Later Prose and Drama of Samuel Beckett. New York: Grove Press, 1980.

Kundert-Gibbs, John. No-thing is Left to Tell: Zen/Chaos Theory in the Dramatic Art of Samuel Beckett. Cranbury, NJ: Associated University Presses, 1999.

Kunkel, Michael. “...dire cela, sans savoir quoi...:” Samuel Beckett in der Musik von György Kurtág und Heinz Holliger. Saarbrücken, DE: PFAU-Verlag, 2008.

Laughlin, Karen. "Seeing is Perceiving: Beckett's Later Plays and the Theory of Audience Repsonse." In 'Make Sense who May:' Essays on Samuel Beckett's Later Works, edited by Robin Davis and Lance St. J. Butler, 20-29. Irish Literary Studies 30. Gerrards Cross: Colin Smythe, 1988.

Obszarny, Marek, and Magda Pawlinow. "Agata Zubel - GiNoNeWaMo." YouTube video. 24:56. Documentary posted by "MrModerna" on April 21, 2015. https://www.youtube.com/watch?v=BXCB5xqI-ps.

Oppenheim, Lois. "Anonymity and Individuation: The Interrelation of Two Linguistic Functions in Not I and Rockaby." In 'Make Sense who May:' Essays on Samuel Beckett's Later Works, edited by Robin Davis and Lance St. J. Butler, 36-45. Irish Literary Studies 30. Gerrards Cross: Colin Smythe, 1988.

Pountney, Rosemary. Theatre of Shadows: Samuel Beckett's Drama 1956-1976. Buckinghamshire: Colin Smythe, 1988.

Prieto, Eric. Listening In. Lincoln, NE: University of Nebraska Press, 2002.

Rhys, Paul. “Not I for Solo Piano: Beckett's Text as Music." In Beckett and Musicality, edited by Sara Jane Bailes and Nicholas Till, 155-169. Dorchester, UK: Henry Ling Limited, 2014.

. Not I for Piano Solo (unpublished score, September 16, 2016), PDF file. 
Ristani, Maria. “Articulated Arrhythmia: Samuel Beckett's Shorter Plays.” In Beckett and Musicality, edited by Sara Jane Bailes and Nicholas Till, 119-135. Dorchester, UK:

Henry Ling Limited, 2014.

Sherzer, Dina. "Portrait of a Woman: The Experience of Marginality in Not I." In Women in Beckett: Performance and Critical Perspectives, edited by Linda Ben-Zvi, 201-207. Urbana, IL: University of Illinois Press, 1980.

Simone, R. Thomas. "Beckett's Other Trilogy: Not I, Footfalls, and Rockaby." In 'Make Sense who May:' Essays on Samuel Beckett's Later Works, edited by Robin Davis and Lance St. J. Butler, 56-65. Irish Literary Studies 30. Gerrards Cross: Colin Smythe, 1988.

Stewart, Paul. Sex and Aesthetics in Samuel Beckett's Work. New York: Palgrave Macmillan, 2011.

Worth, Katharine. Smauel Beckett's Theatre: Life Journeys. Oxford: Clarendon Press, 1999.

Zubel, Agata. Not I. Kraków: Polskie Widawnictwo Muzyczne, 2012.

. "Not I.” On Not I. Kairos 0013362KAI, 2014. CD. 
Example 2.1

Paul Rhys, Not I, p. 1 with annotations

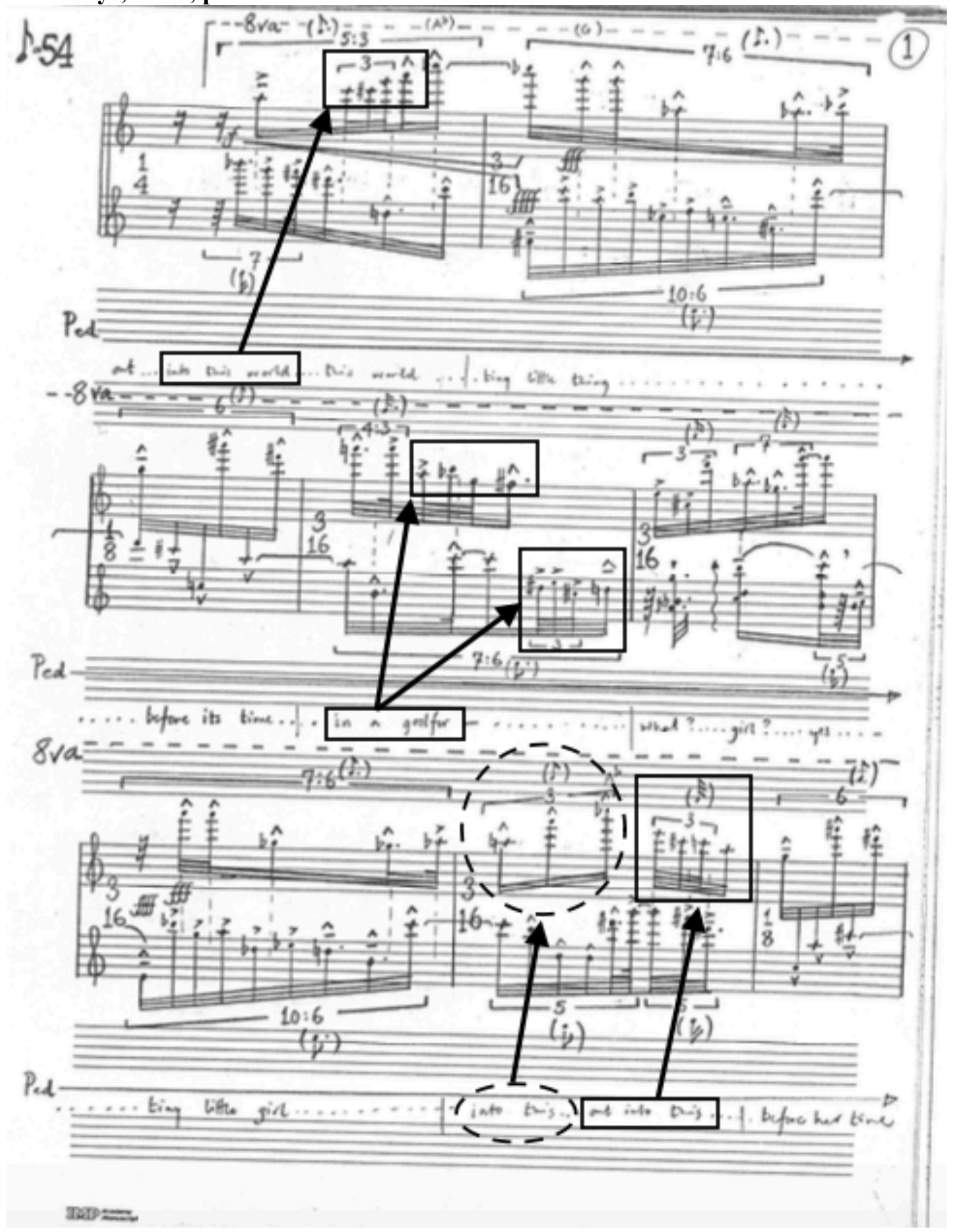

Example 2.1 (cont.) 
Paul Rhys, Not I, p. 2 with annotations

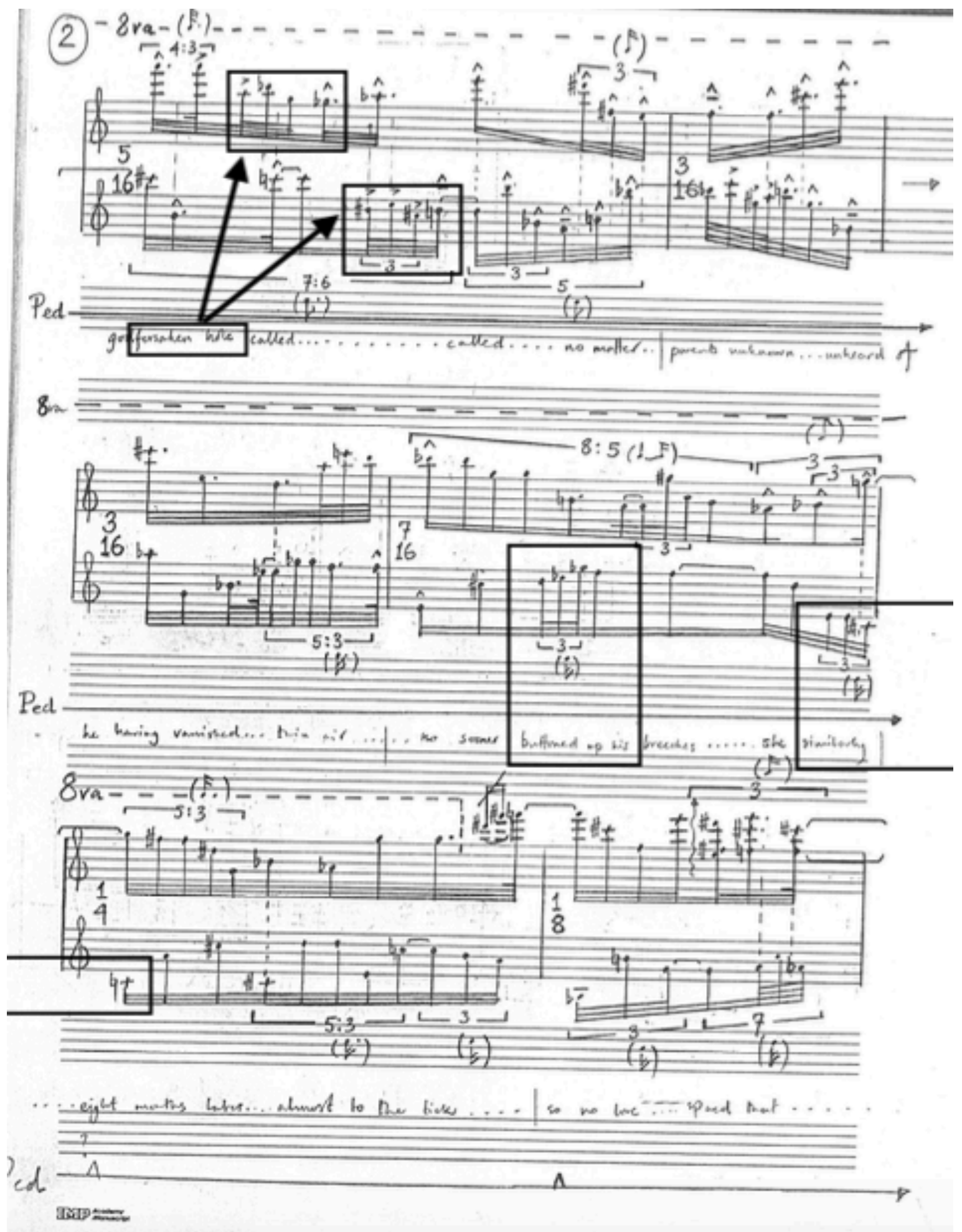


Example 2.2

Paul Rhys, Not I, p. 22
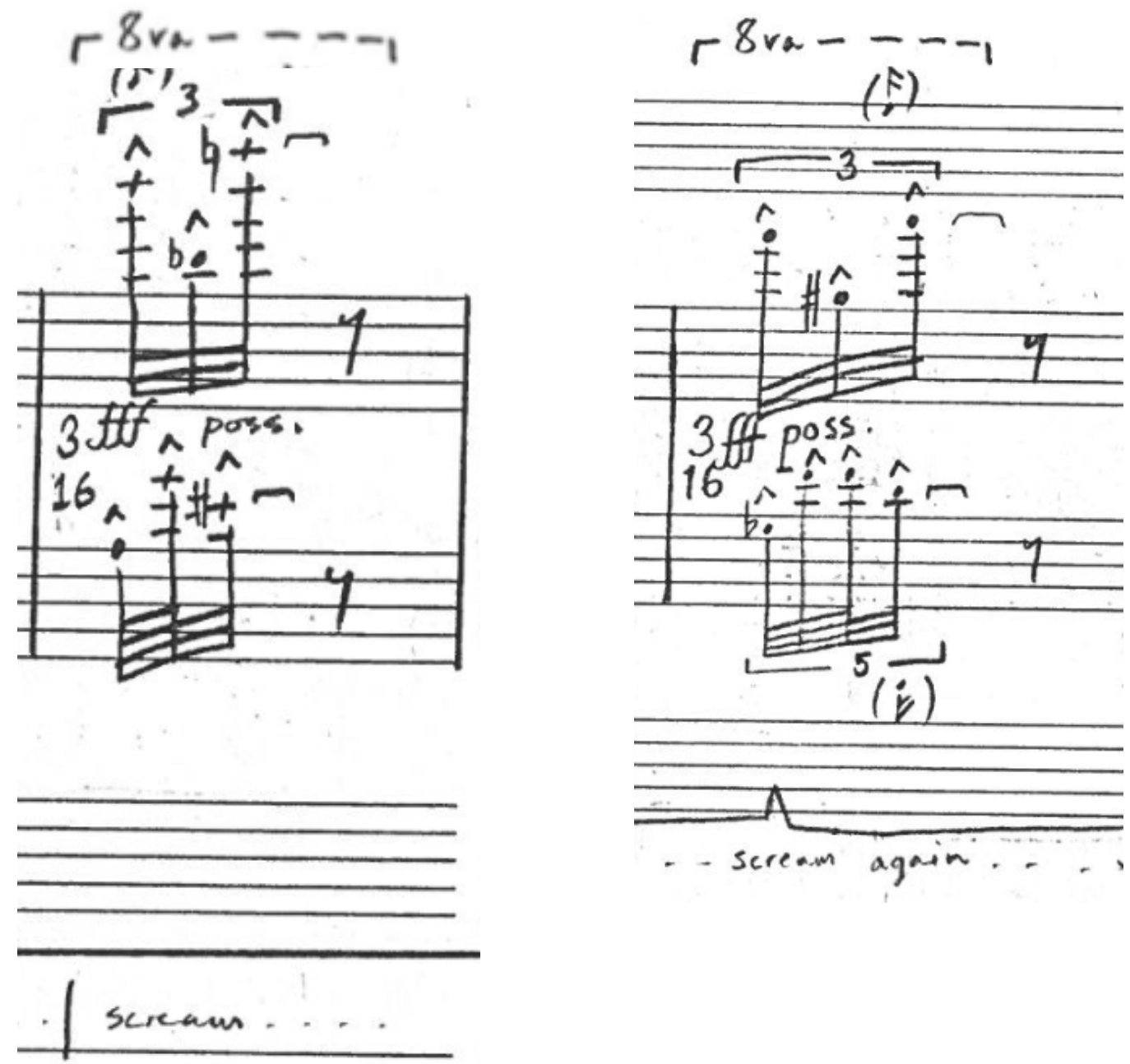

Example 2.3 
Paul Rhys, Not I, p. 8

(8)
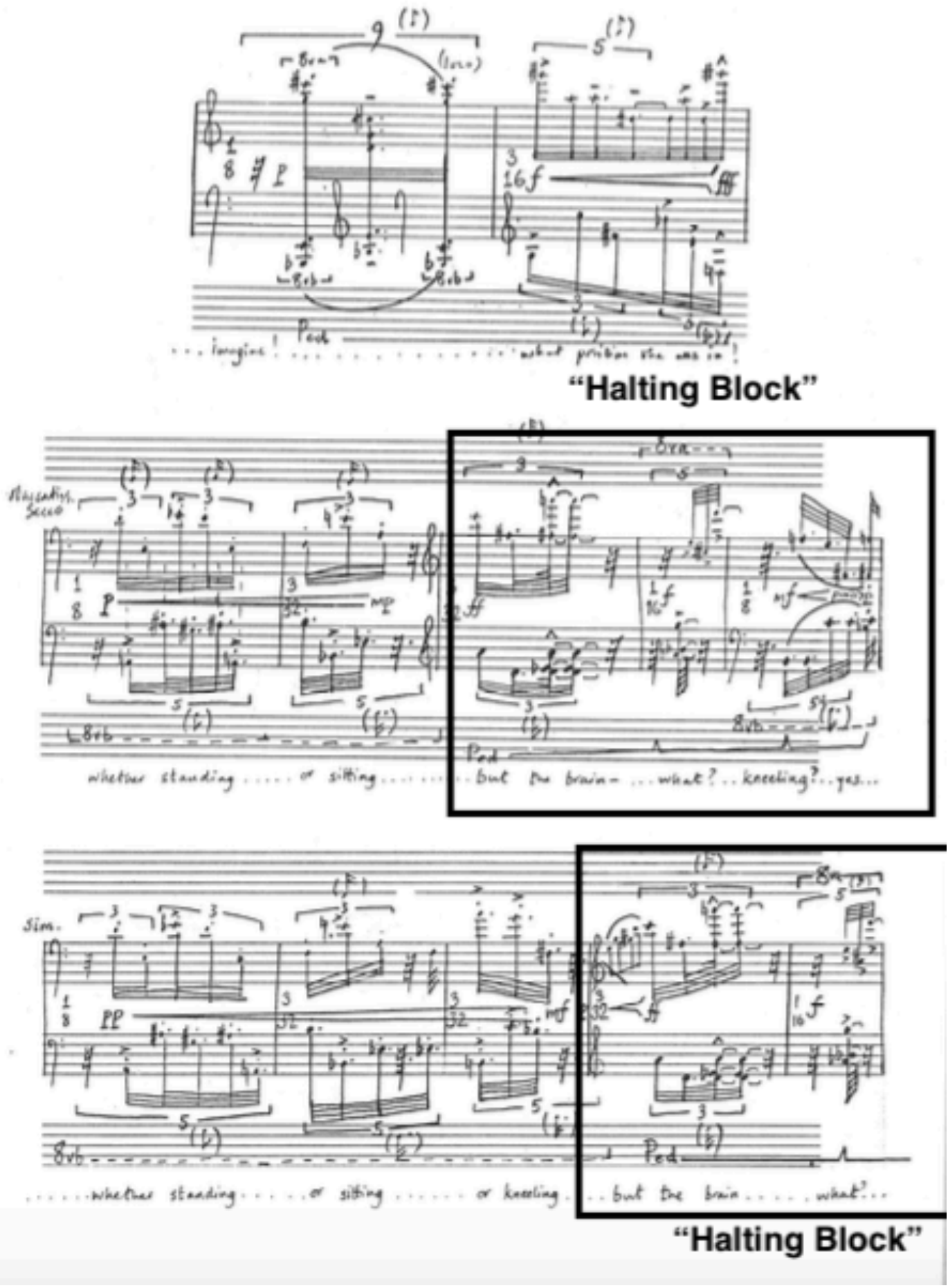

Example 2.3 (cont.) 
Paul Rhys, Not I, p. 9

(9)

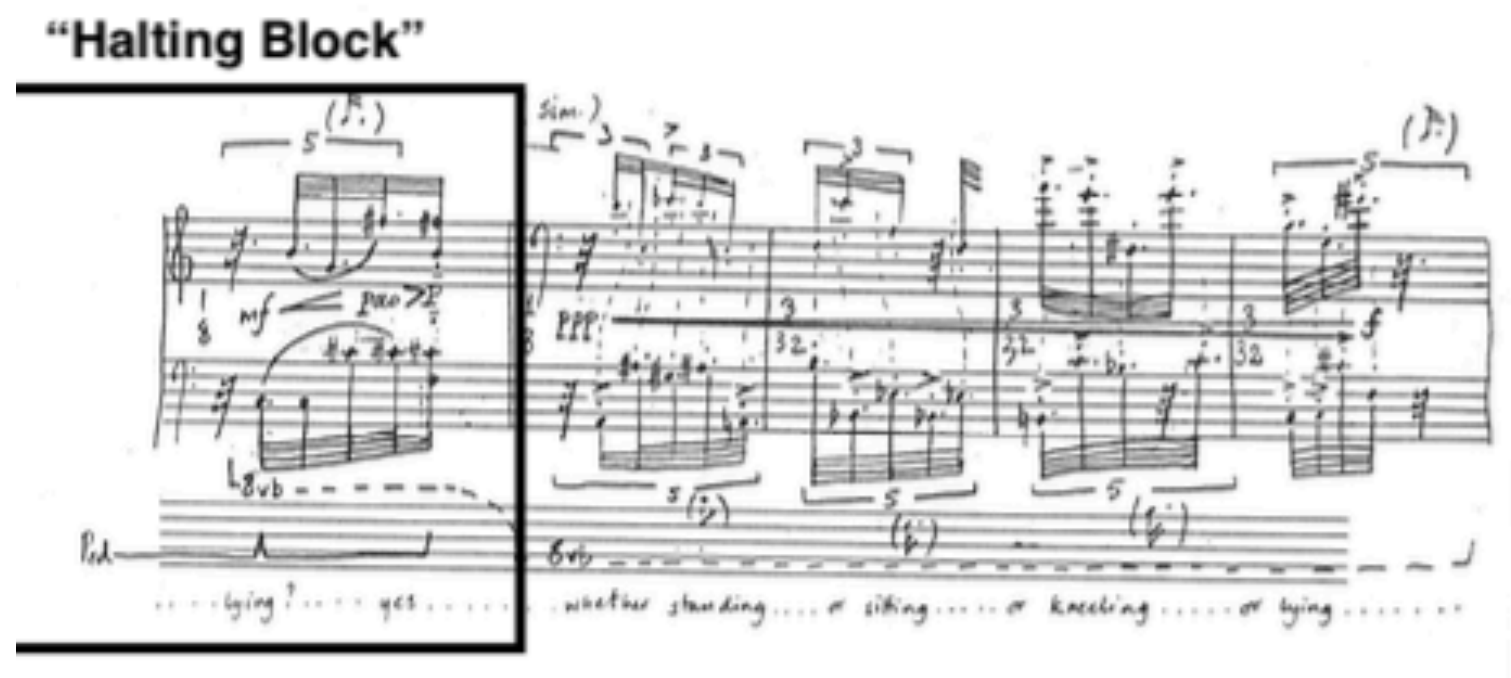

\section{"Halting Block"}

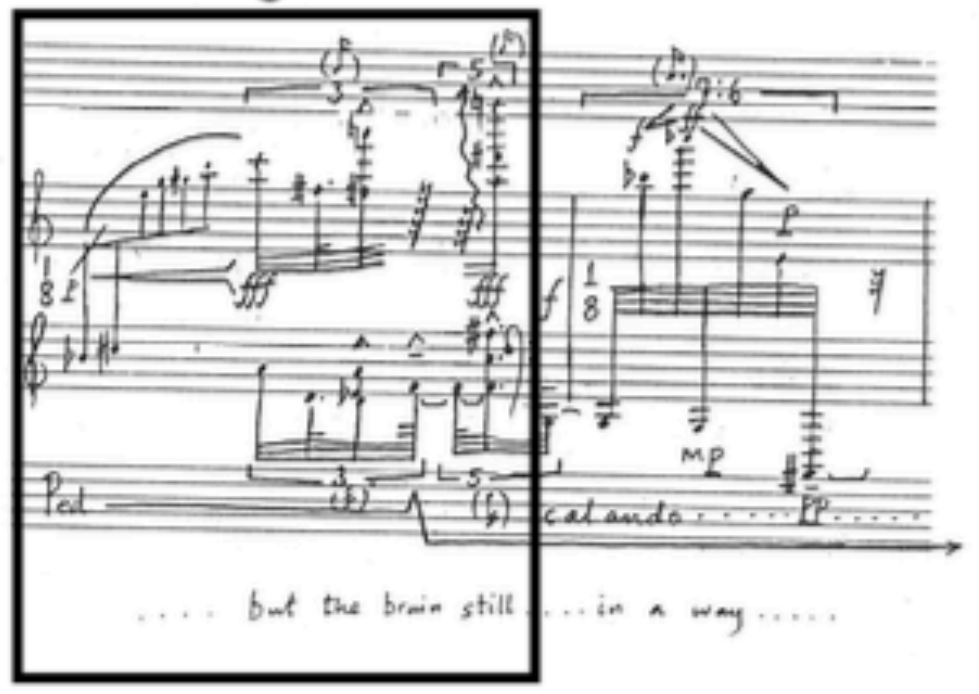

Example 2.4 
Paul Rhys, Not I, p. 45

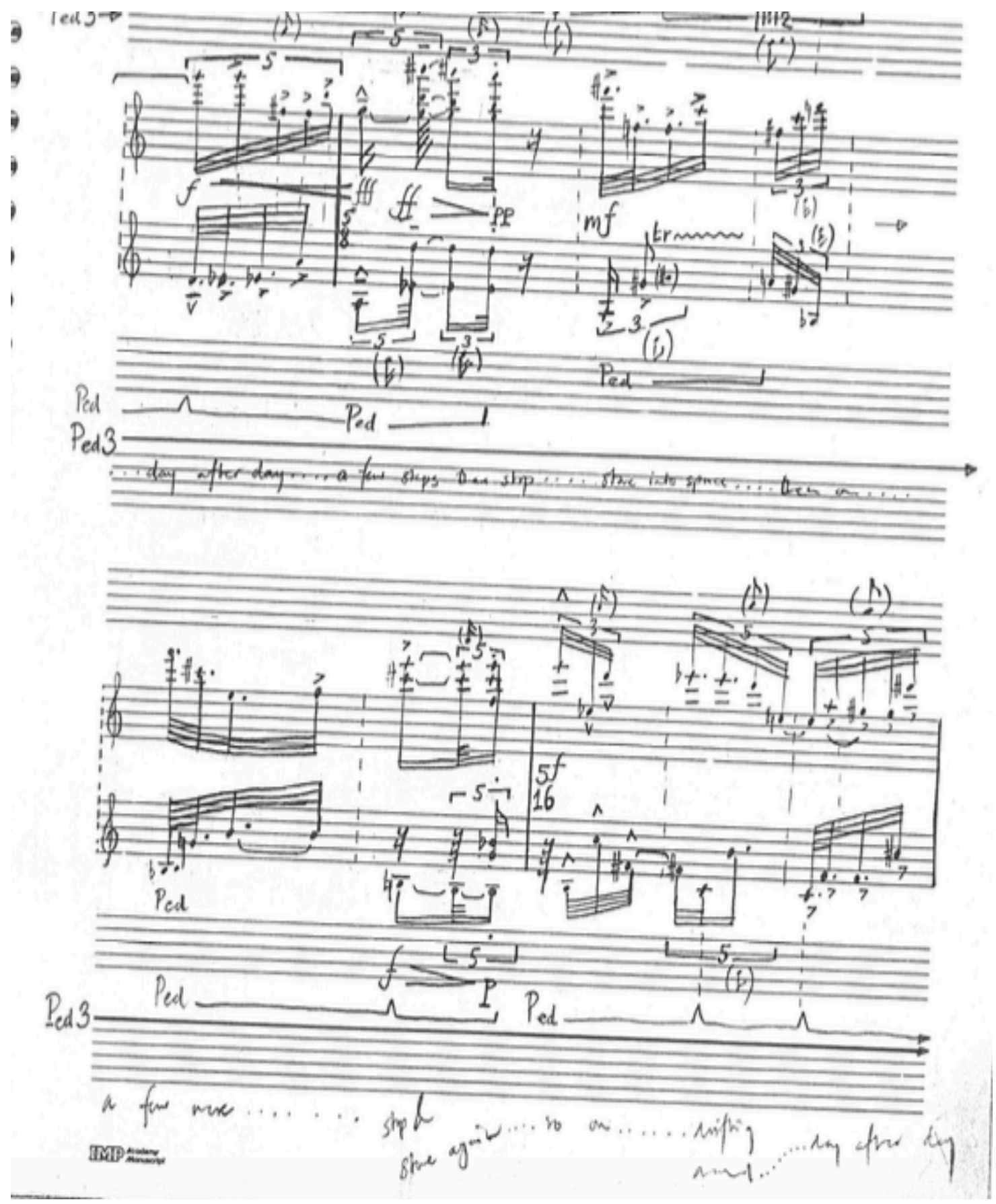

Example 2.5 


\section{Samuel Beckett, Not I, Annotated excerpt}

...tiny little thing...out before its time... godforsaken hole...no love...spared

that...speechless all her days... practically speechless...even to herself...never out loud...but not completely... sometimes sudden urge...once or twice a year...always winter some strange reason...the long evenings...hours of darkness...sudden urge to...tell...then rush out stop the first she saw...nearest lavatory.... start pouring it out...steady stream... mad stuff...half the vowels wrong...no one could follow...till she saw the stare she was getting...then die of shame...crawl back in...once or twice a year...always winter some strange reason...long hours of darkness...now this...this...quicker and quicker...the words...the brain...flickering away like mad...quick grab and on...nothing there...on somewhere else...try somewhere else... all the time something begging...something in her begging...begging it all to stop...unanswered...prayer unanswered...or unheard...too faint...so on...keep on...trying...not knowing what...what she was trying... what to try...whole body like gone...just the mouth...like maddened...so on...keep-... what?..the buzzing?..yes...all the time the buzzing...dull roar like falls...in the skull... and the beam...poking around...painless...so far...ha!..so far... all that...keep on...not knowing what... what she was-...what?..who?..no!...she!..[Pause.] 


\section{Example 3.1}

Heinz Holliger, Not I, p. 2, Systems 12-13

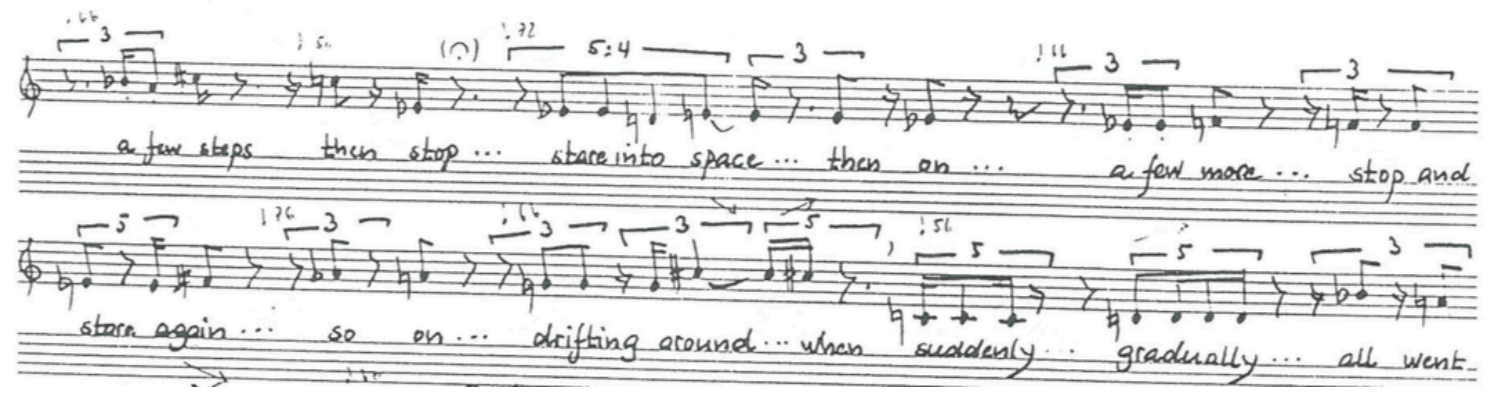




\section{Example 3.2}

Heinz Holliger, Not I, Page 2, Systems 20-21

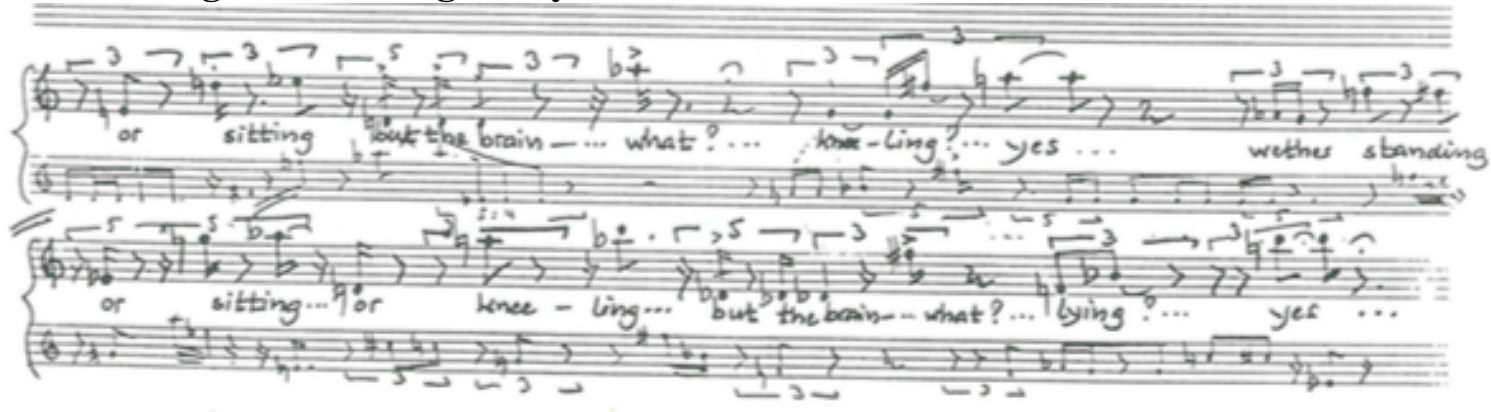




\section{Example 3.3}

Heinz Holliger, Not I, p. 2, System 15, Entrance of tape

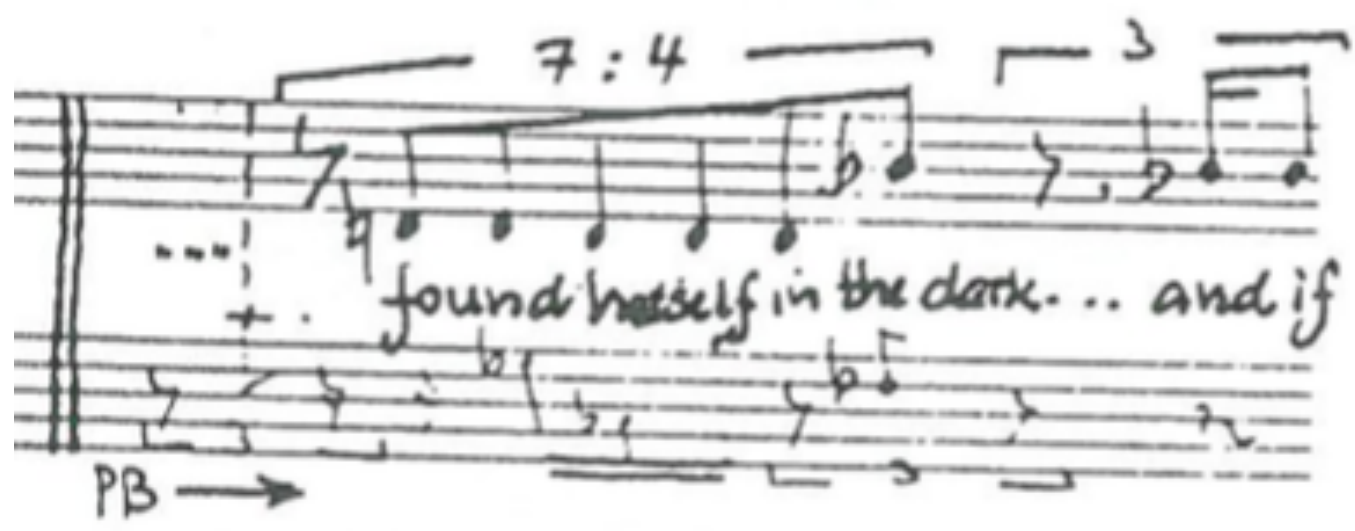




\section{Example 3.4}

\section{Heinz Holliger, Not I, Textual Refrains}

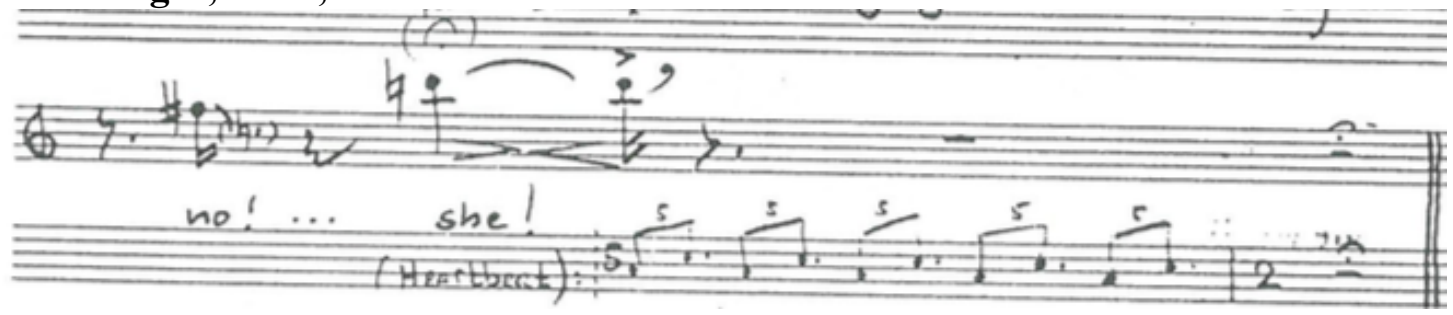

Page 2, System 15

First Textual Refrain: Solo Vocals, Heartbeat pulses on tape

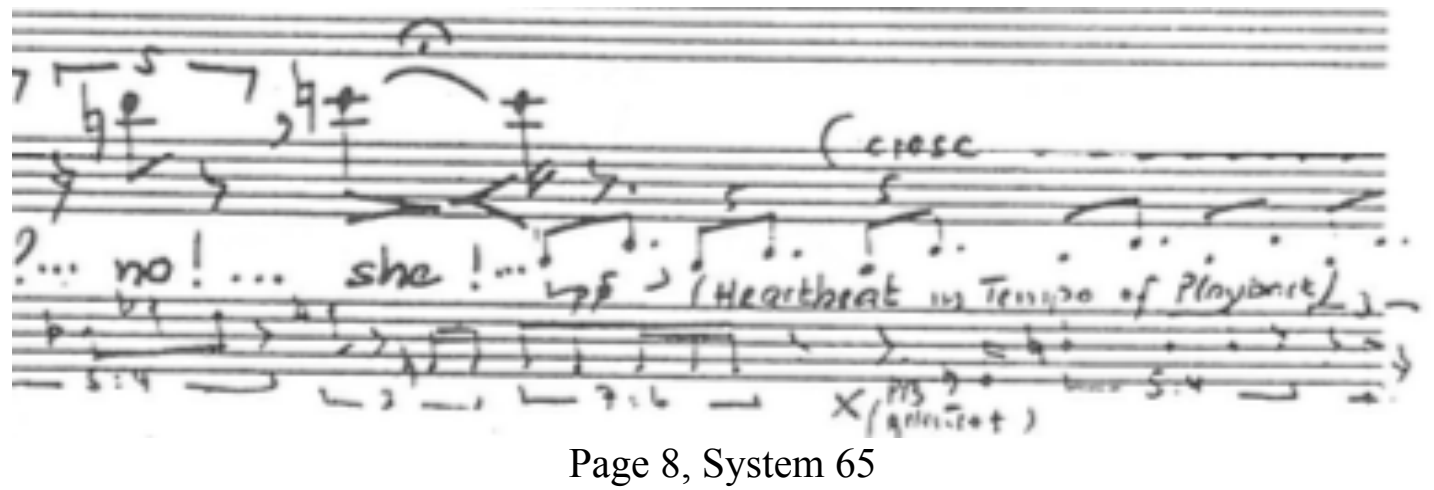

Second Textual Refrain: Tape continues playing while live voice pauses; tape features one musical line with heavily distorted voices in multiple octaves

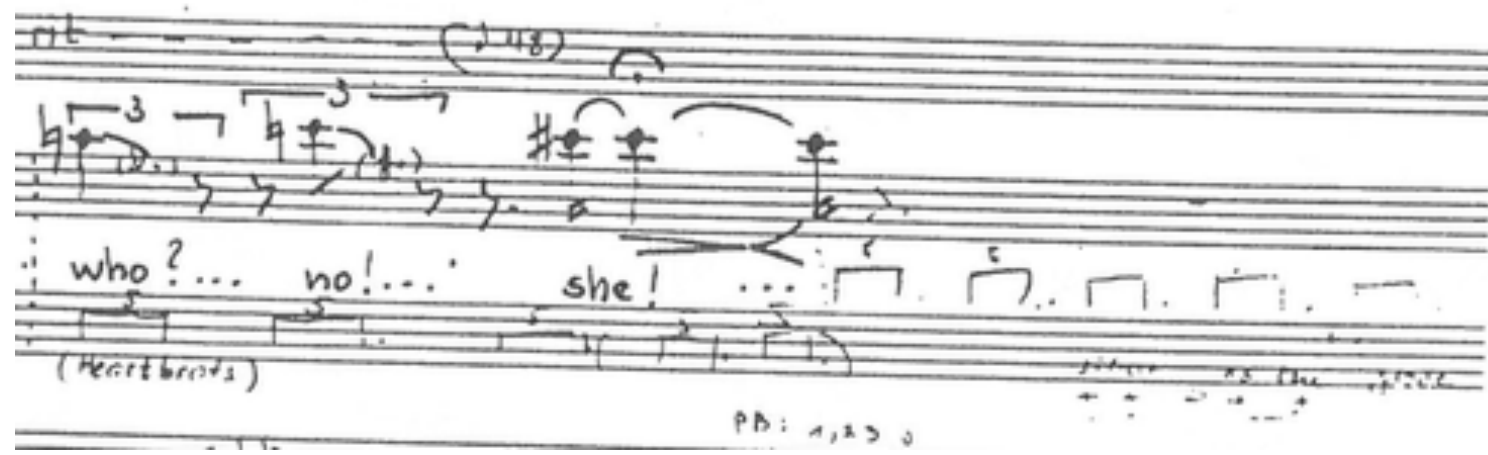

Page 14, System 116

Third Textual Refrain: Follows momentary silence from tape; last tone of live voice melds into a distortion on the tape 
Example 3.4 (cont.)

Heinz Holliger, Not I, Textual Refrains

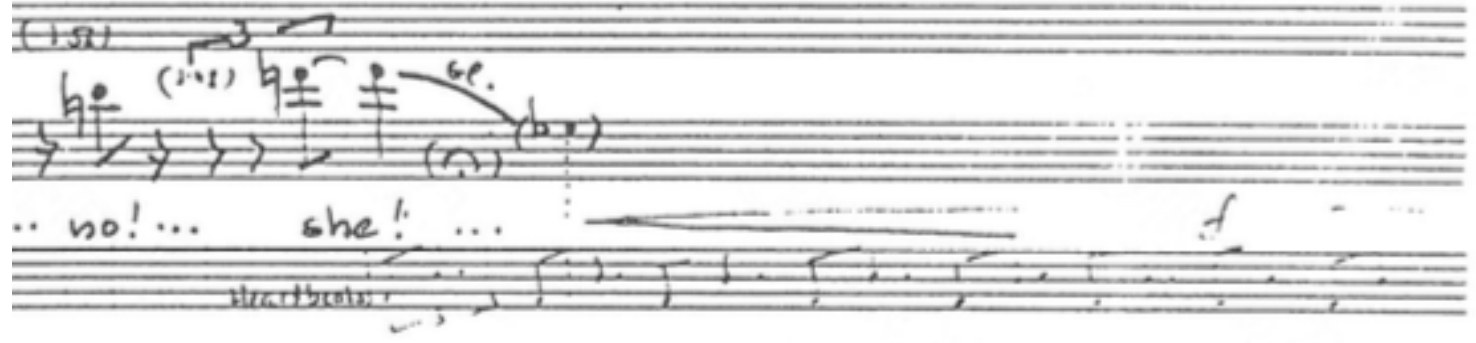

Page 17, System 136

Fourth Textual Refrain: Live voice's "she" is repeated in multiple distorted screams of the tape

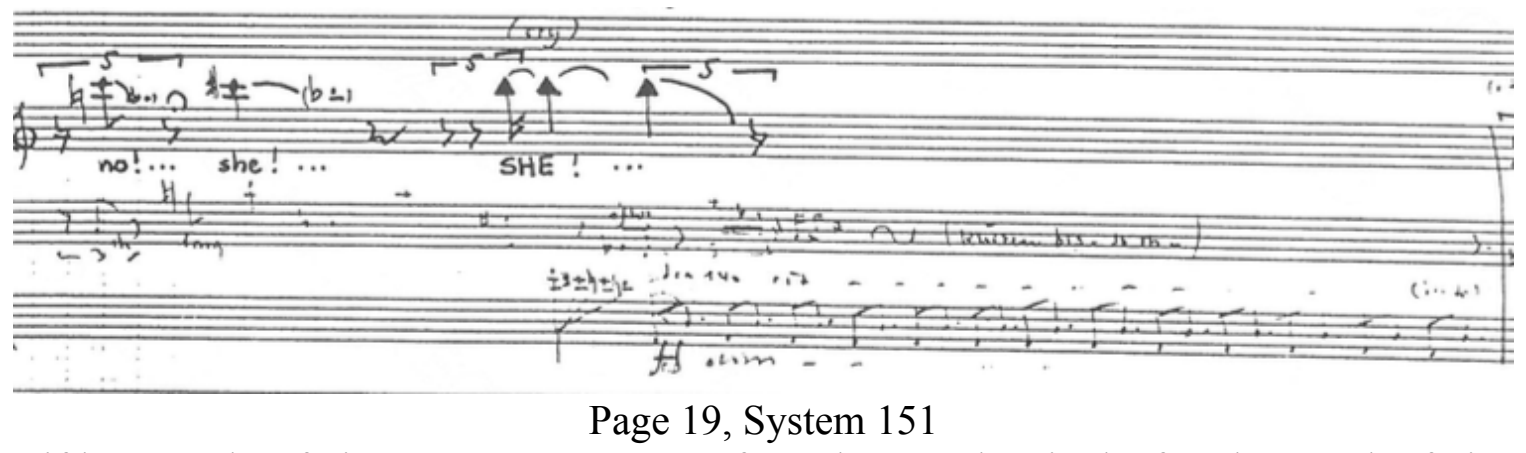

Fifth Textual Refrain: Even more screams from the tape than in the fourth textual refrain; multiple vocal lines continue sounding without pause 


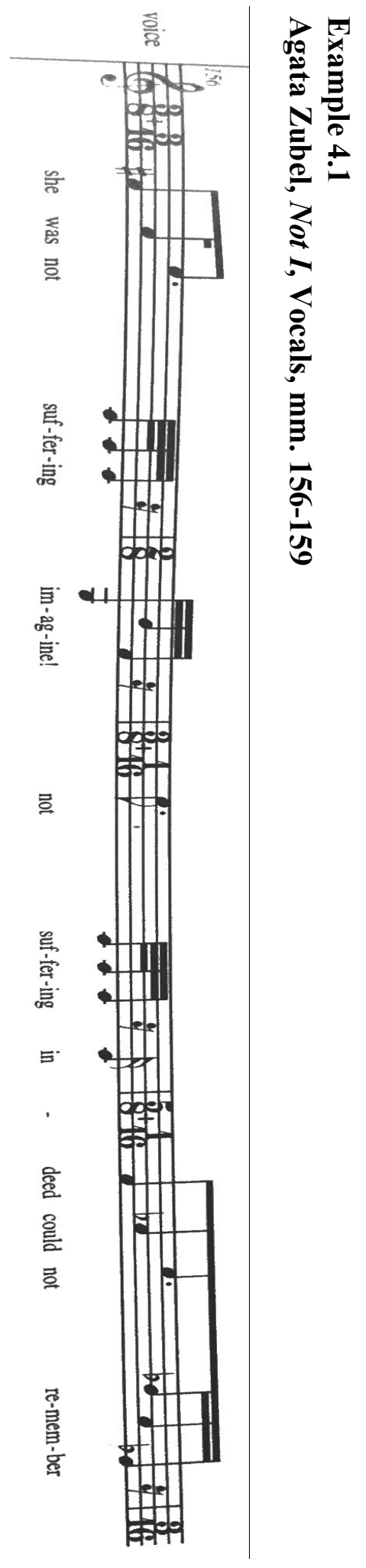



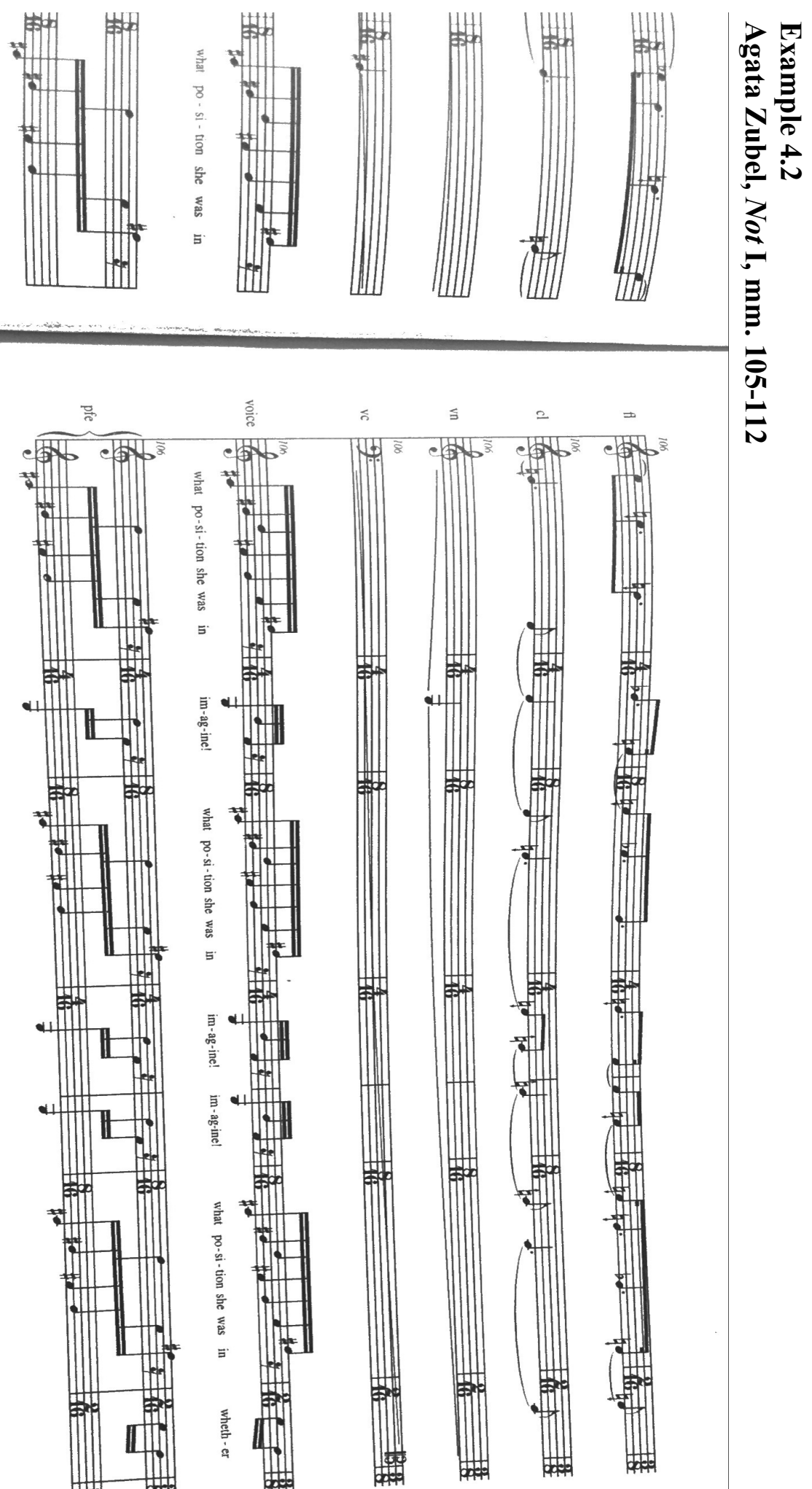


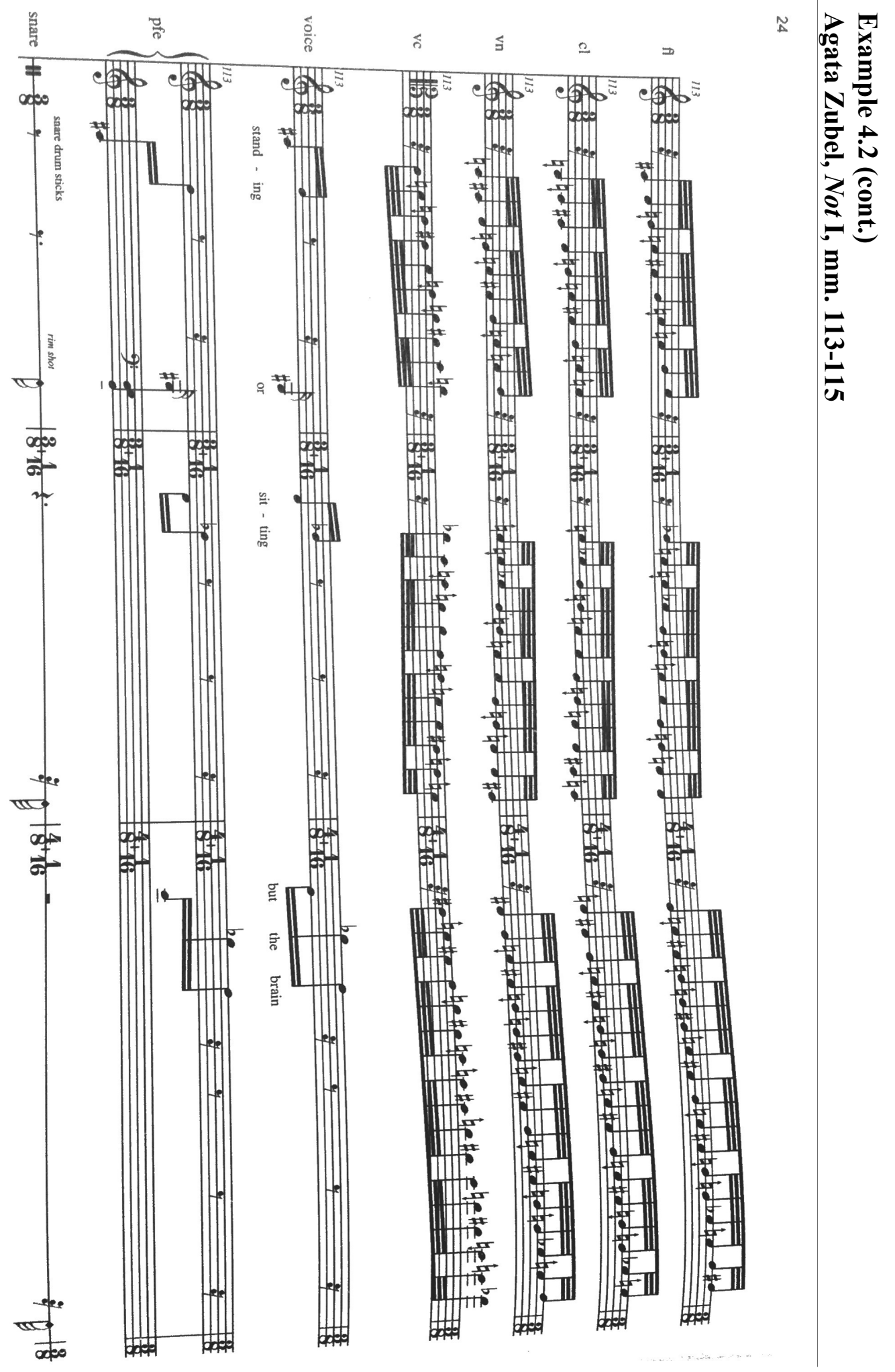


$y$
$\vdots$
$\vdots$
$\vdots$

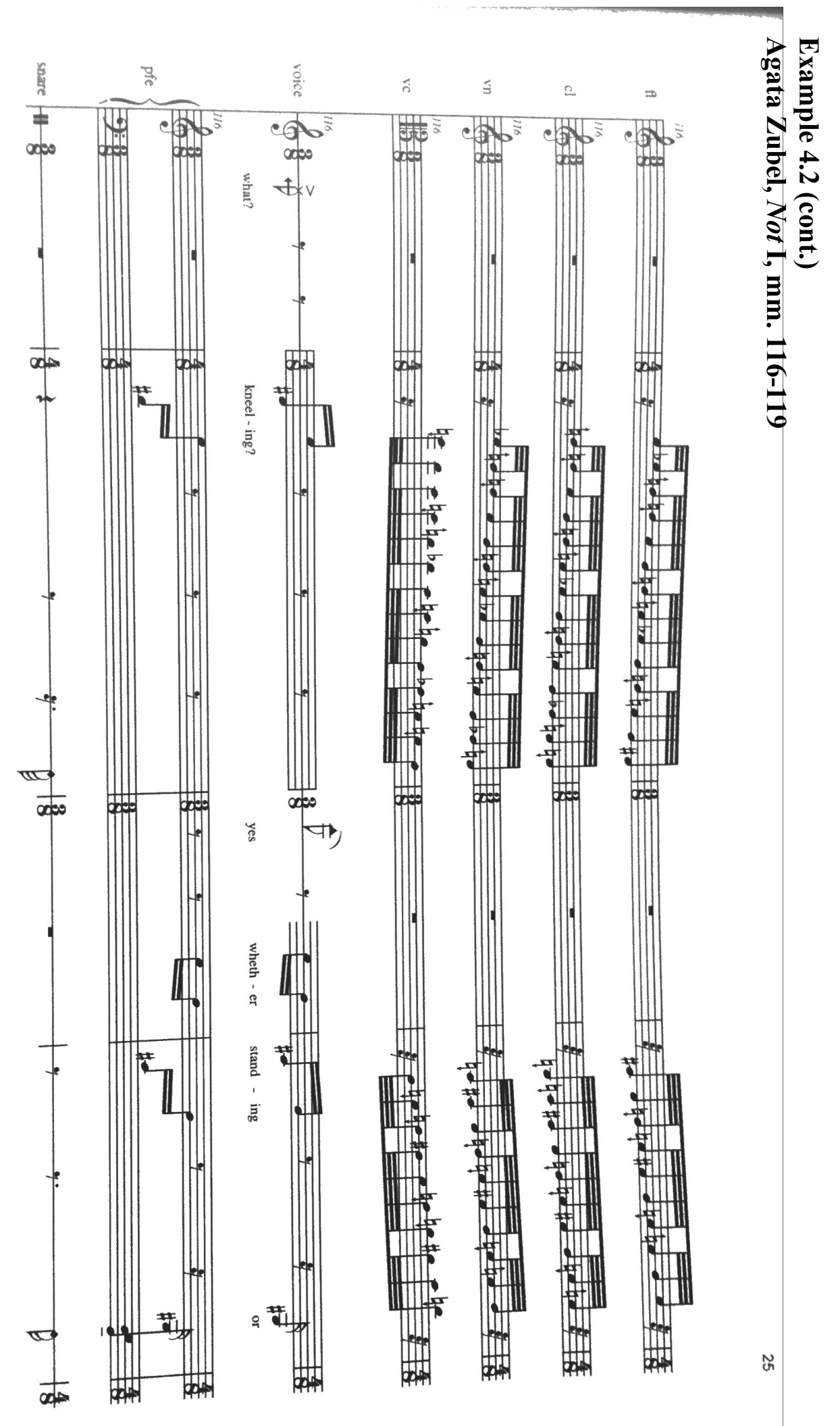




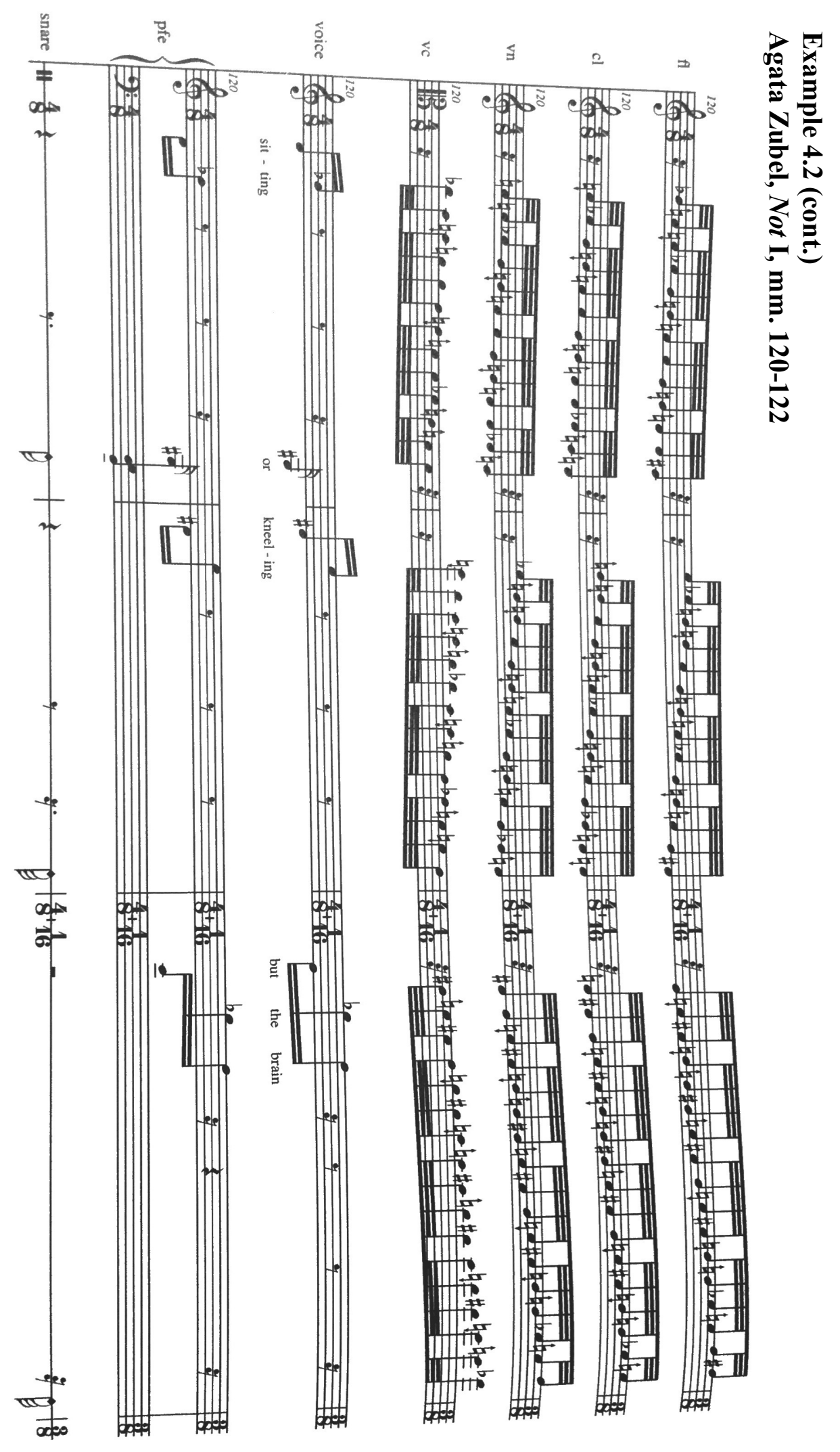




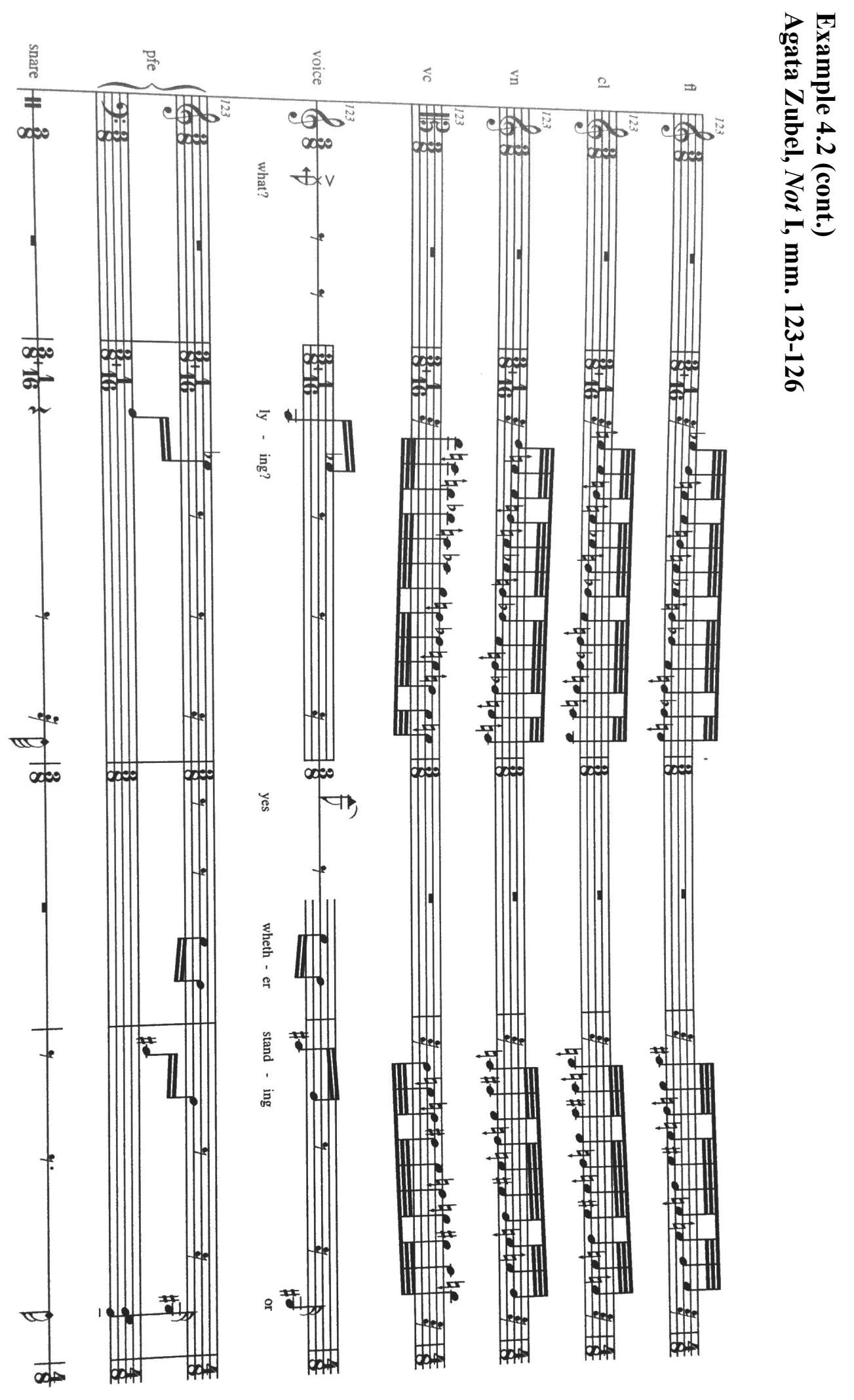




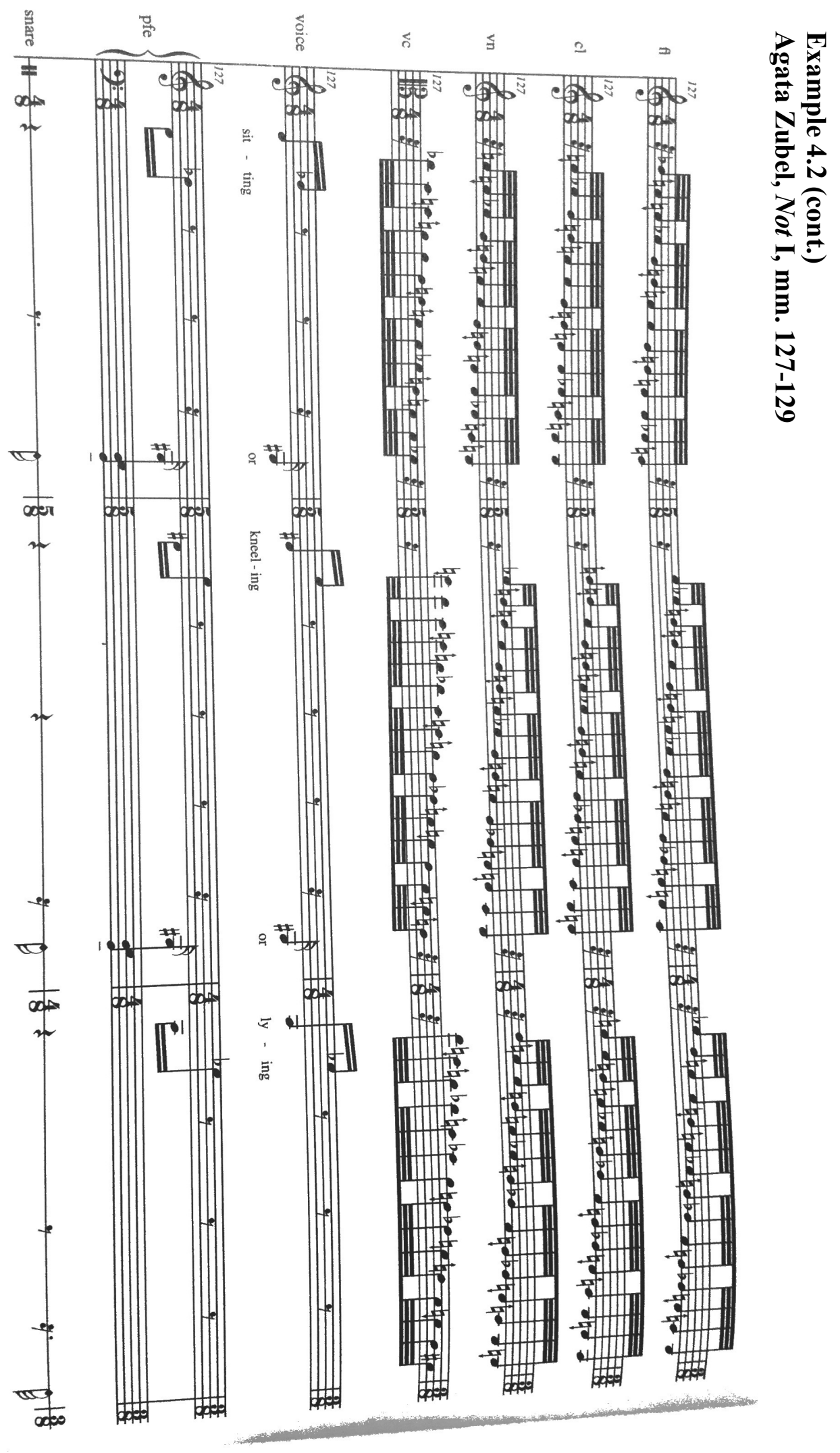




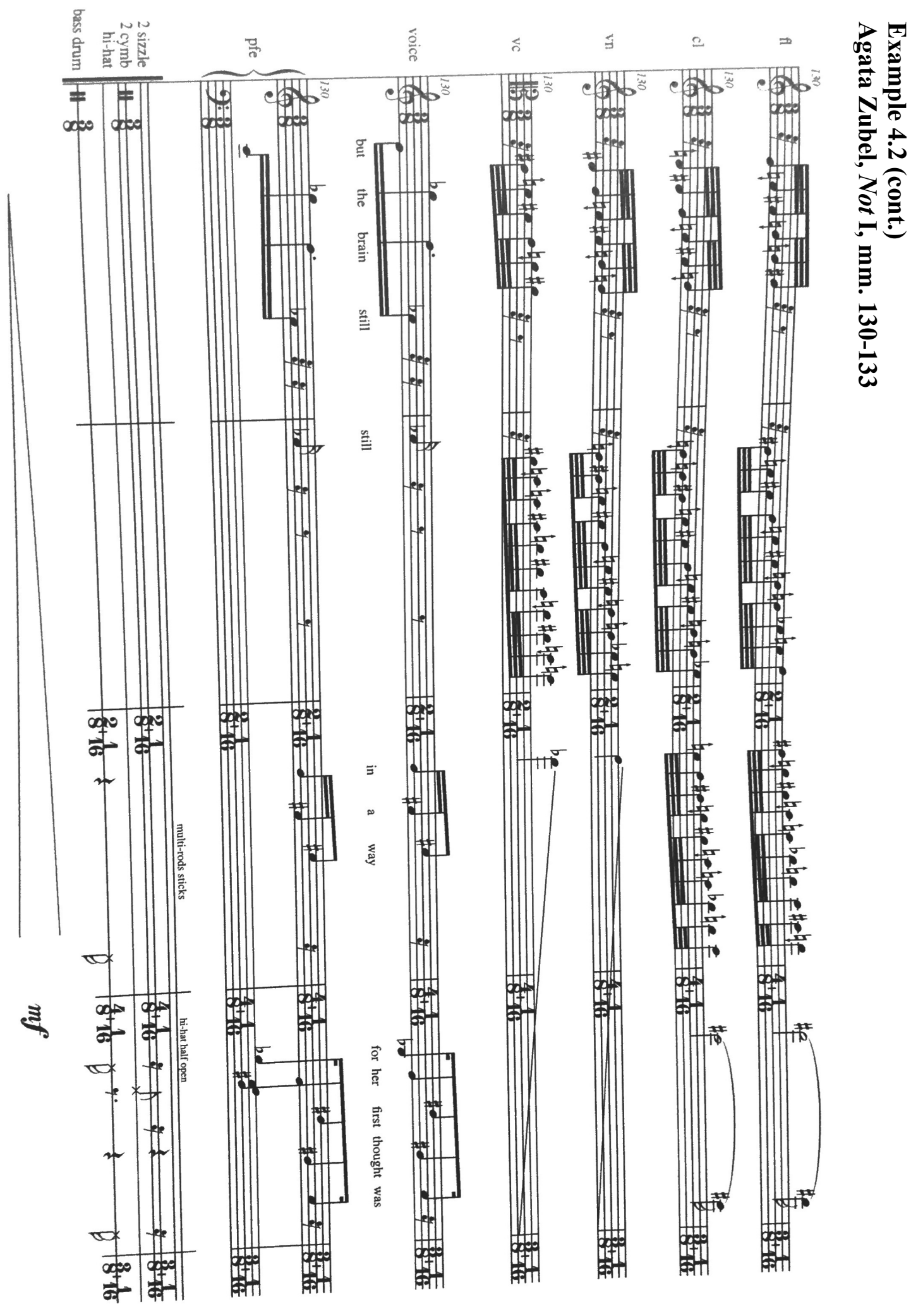




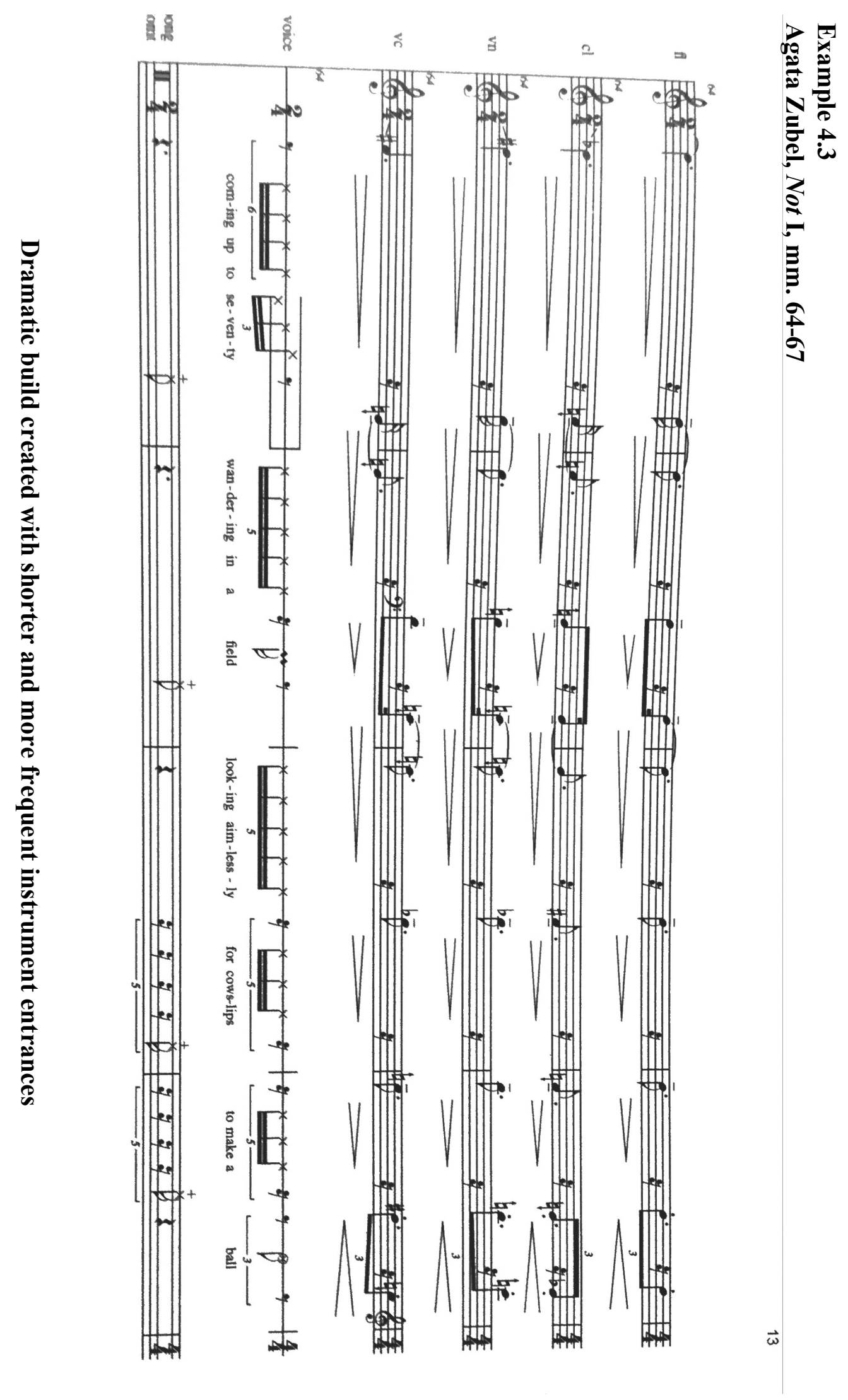




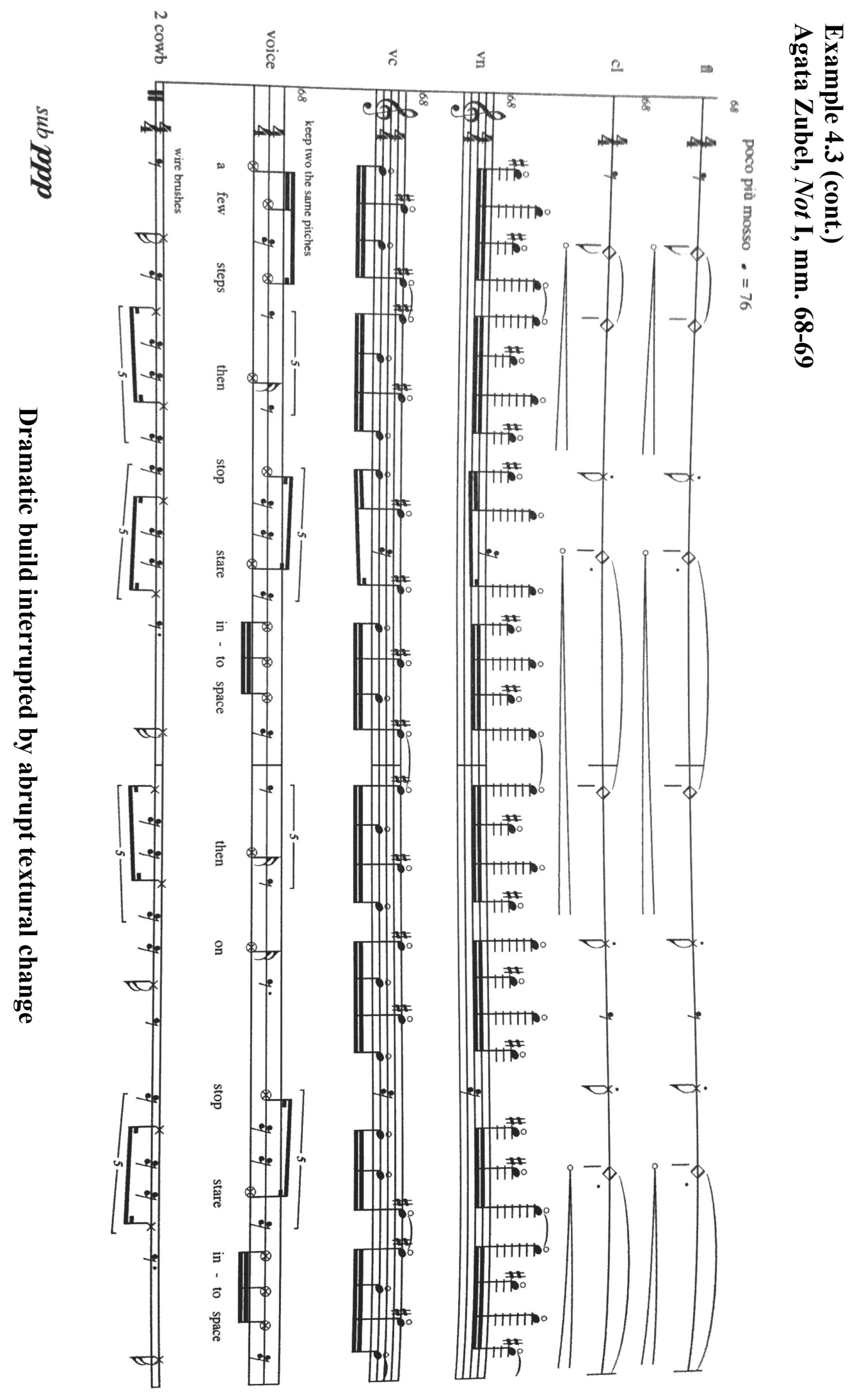




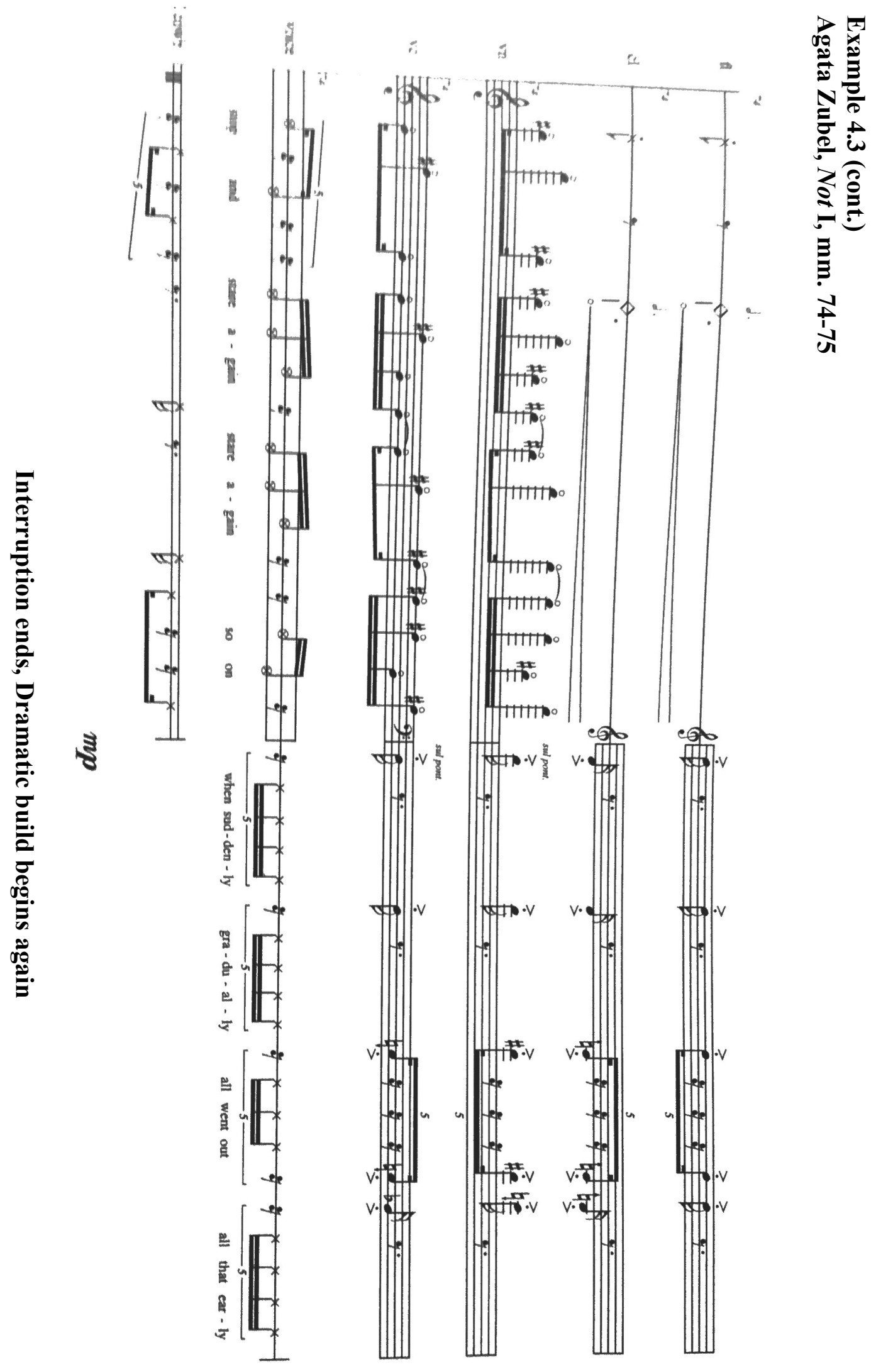




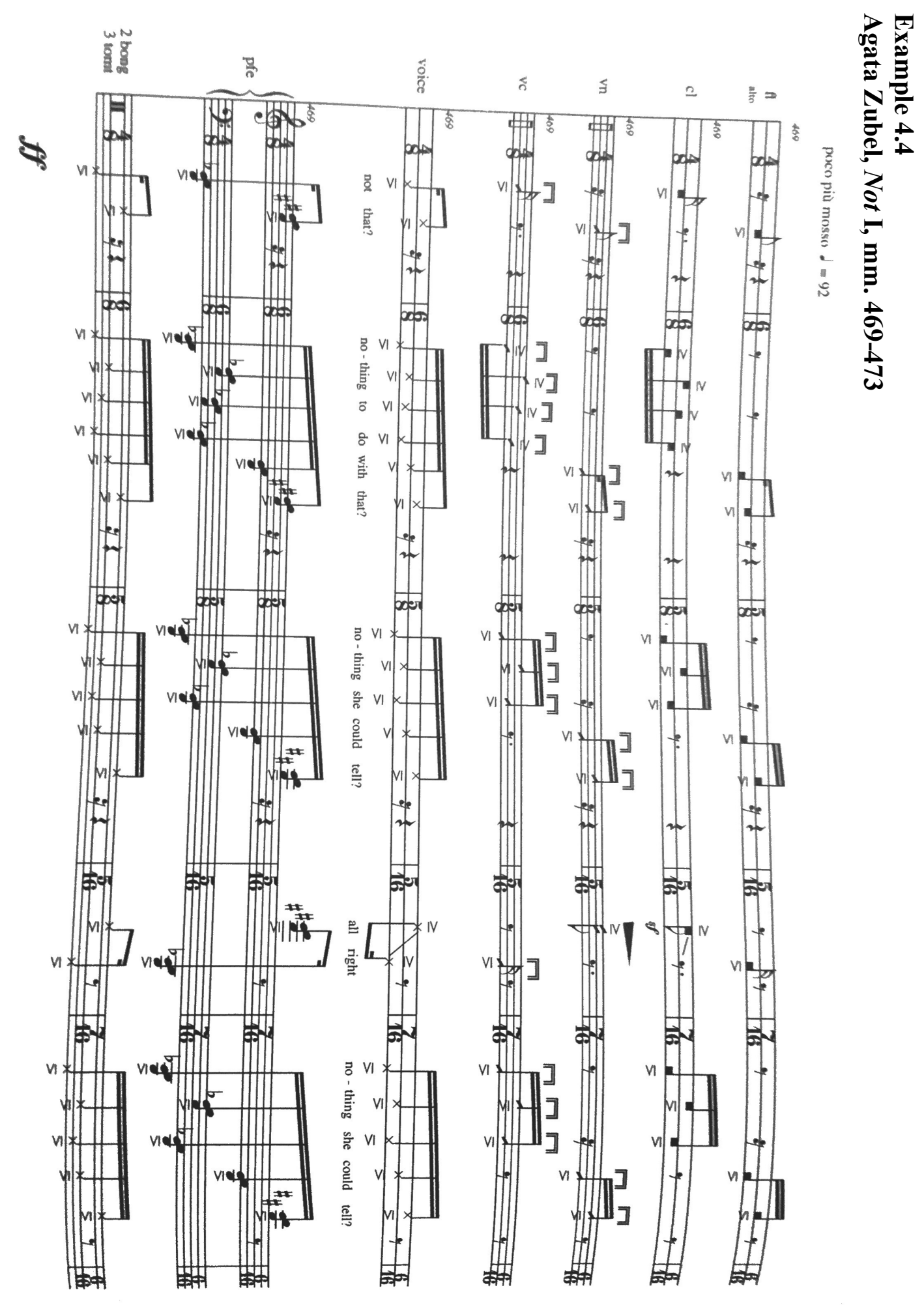




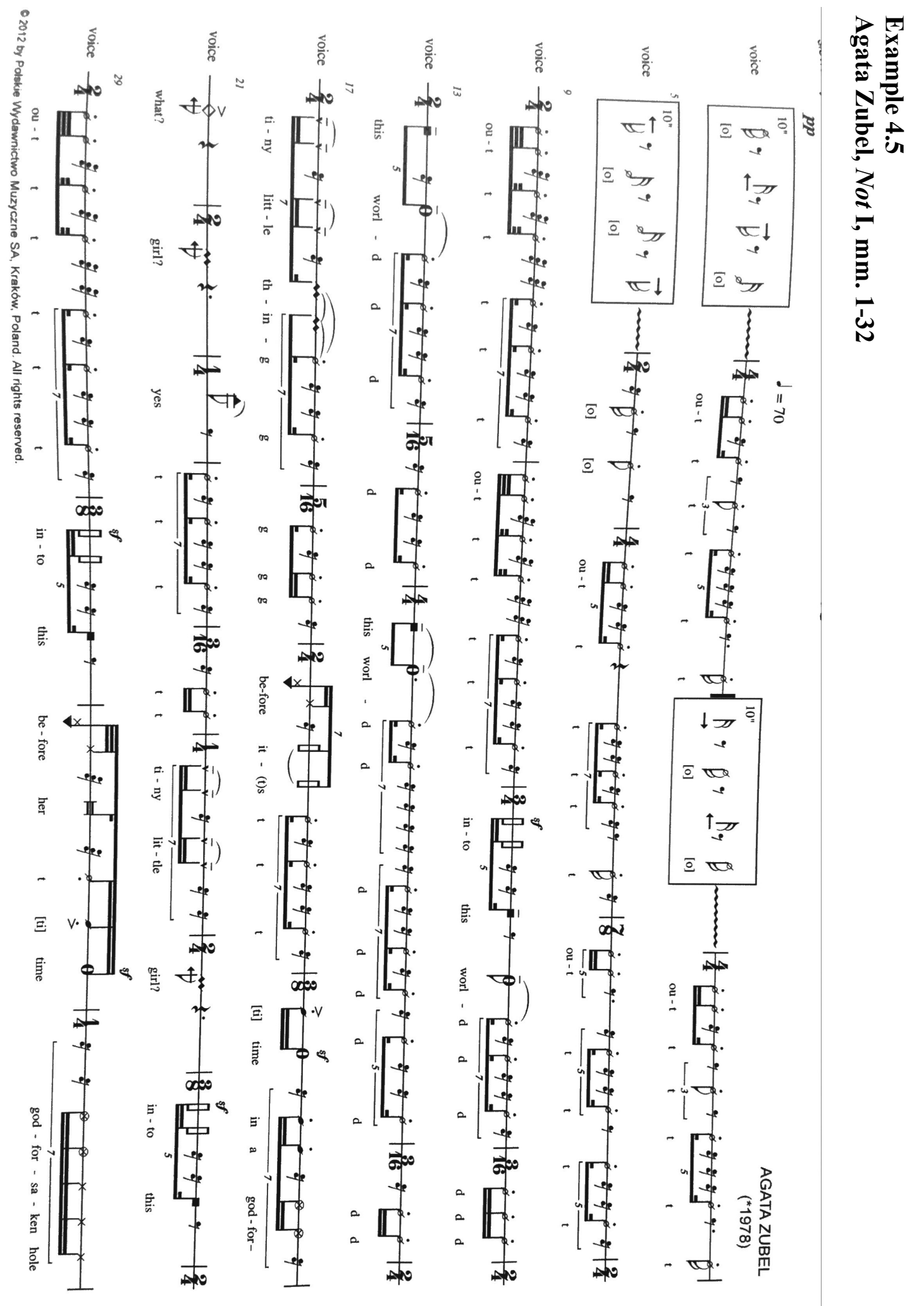




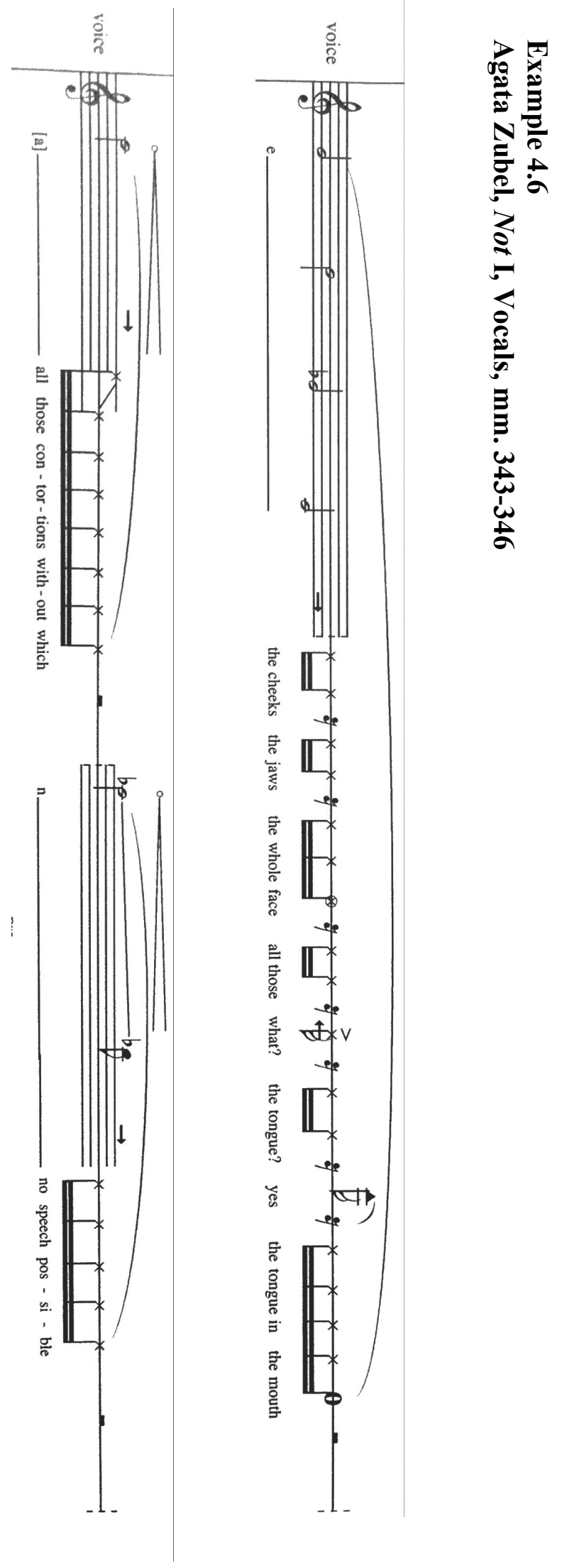




\section{Example 4.7}

Agata Zubel, Not I, Comparison of multiple vocal styles

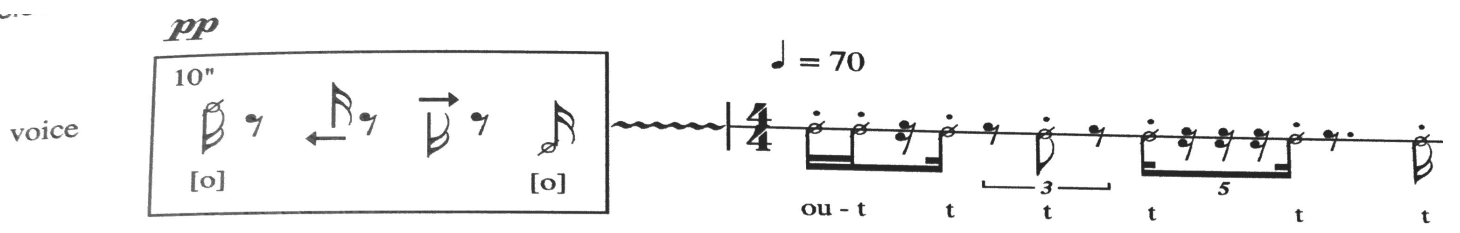

Opening, mm. 1-2, Stuttering gestures

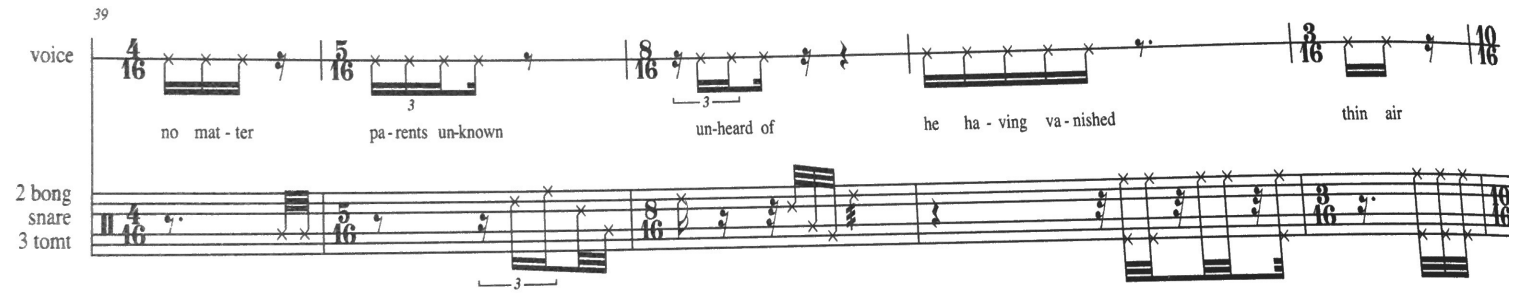

Rhythmic speech, mm. 39-43

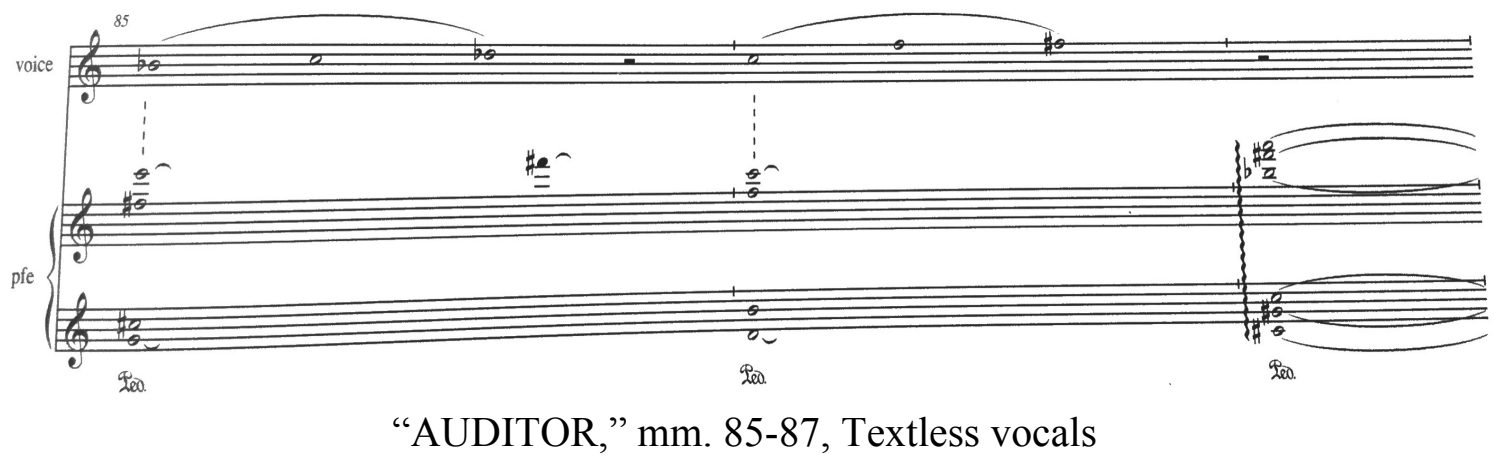




\section{Example 4.7 (cont.)}

Agata Zubel, Not I, Comparison of multiple vocal styles

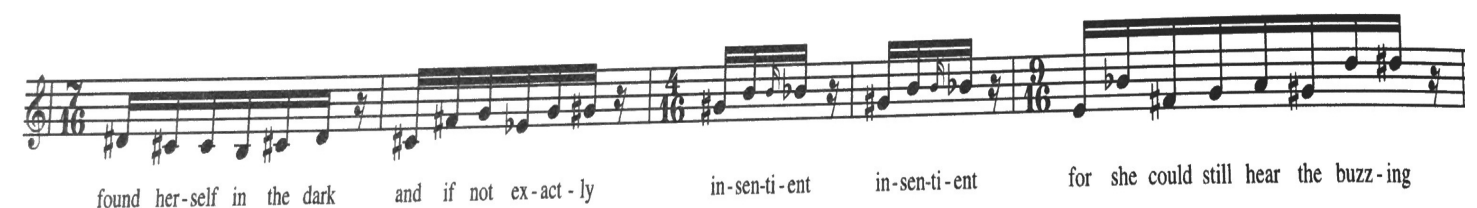

Opening of Pitched Outpouring, mm. 89-93

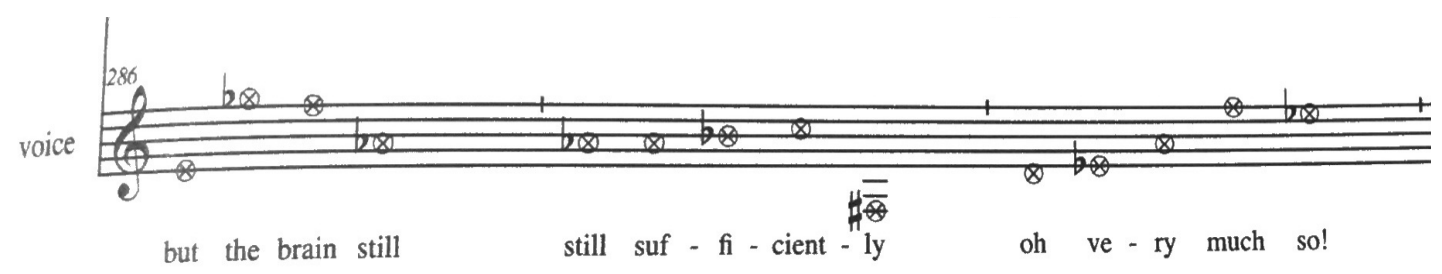

Pulseless Half-Whisper, mm. 286-288

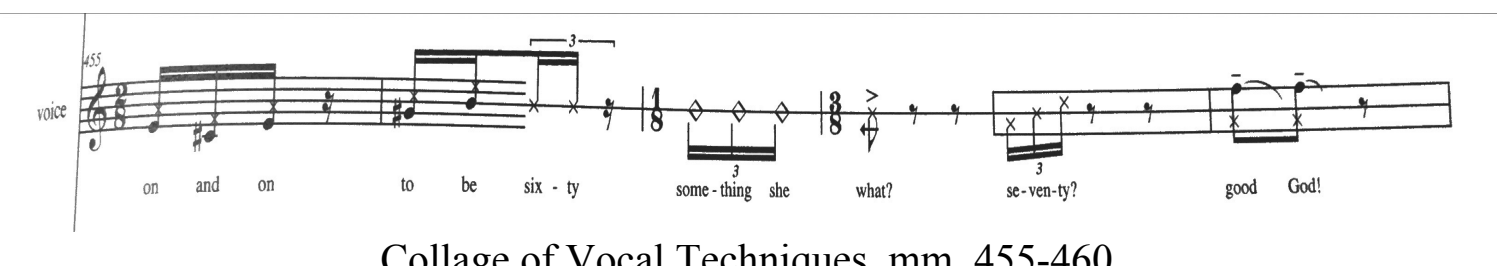

Collage of Vocal Techniques, mm. 455-460 


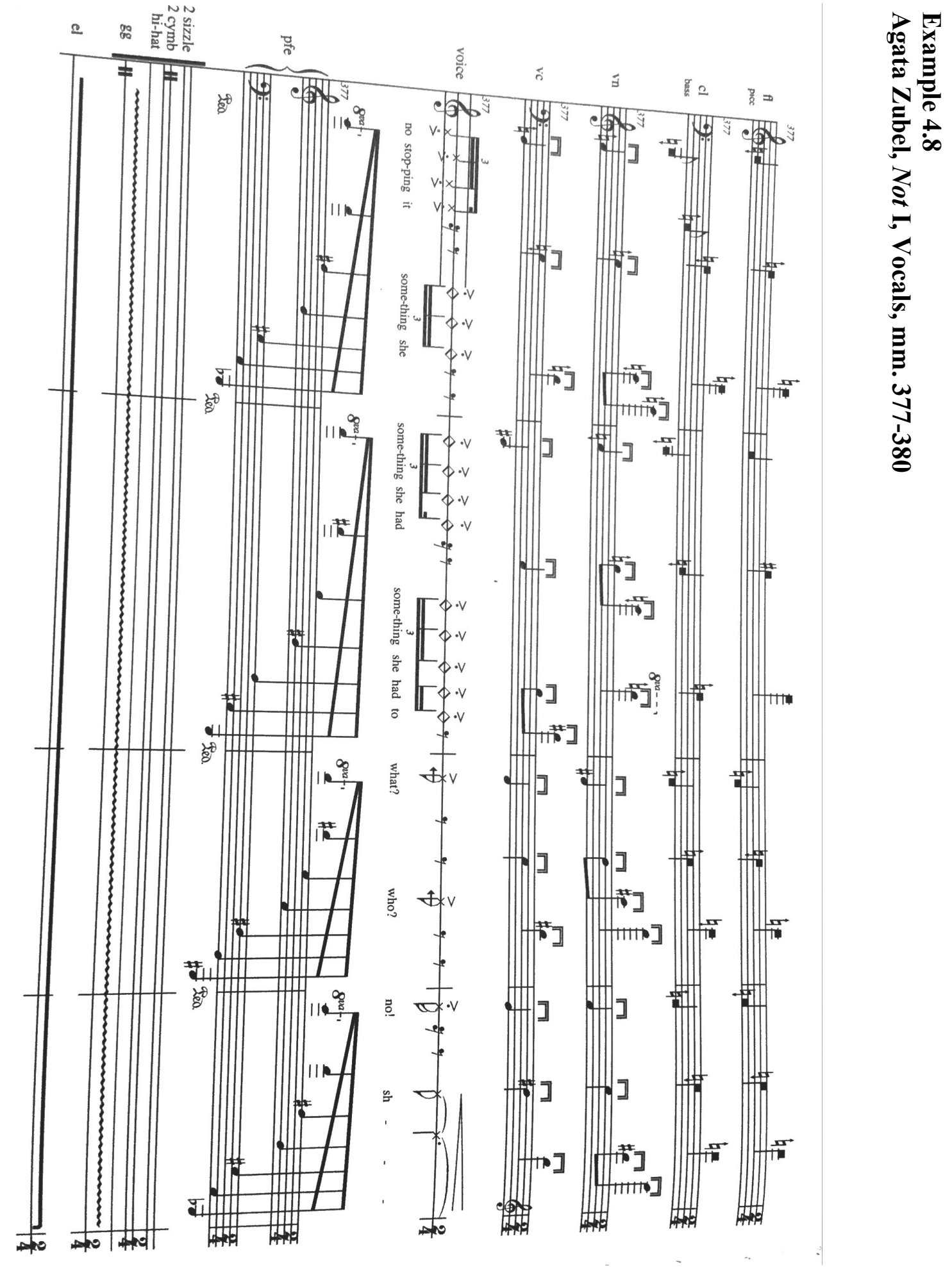




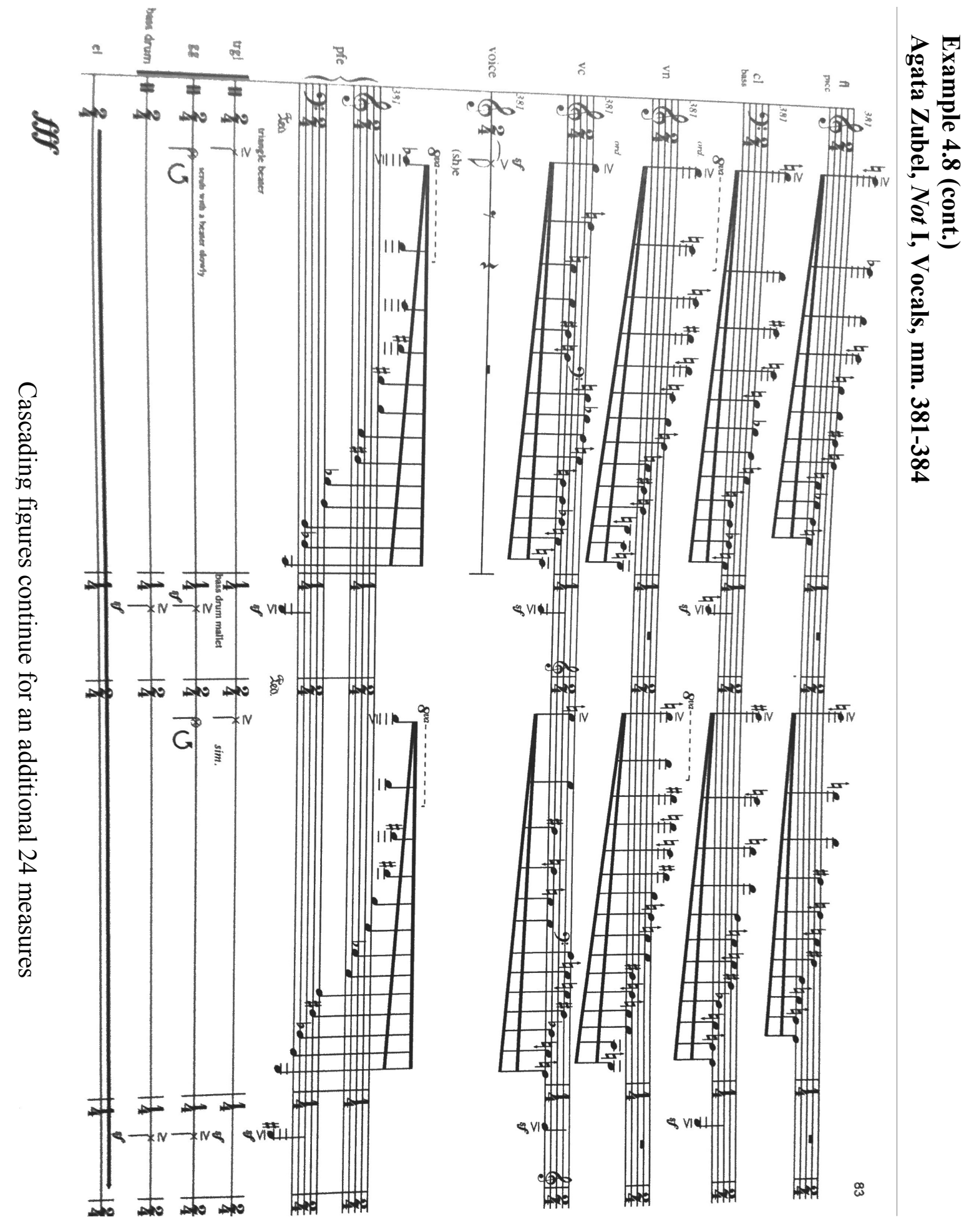




\section{CURRICULUM VITA}

NAME: $\quad$ Trevor Roy DeJarnett

ADDRESS: 1717 Washington Blvd

Louisville, KY 40242

DOB: $\quad$ Paducah, KY - November 13, 1989

EDUCATION

\& TRAINING: $\quad$ B.M.Ed., Music Education

University of Louisville

2008-2012

PROFESSIONAL

SOCIETIES: American Musicological Society

2016-PRESENT

Kentucky Music Education Association

2009-2015

Collegiate National Association for Music Education

2009-2012

ACADEMIC

PRESENTATIONS: Graduate Student Council Research Symposium

University of Louisville, 2016

"Interpreting Ligeti's Le Grande Macabre as Surrealist Collage"

AMS Southern-Central Chapter Meeting

University of Louisville, 2017

"Visceral Intensity: Exploring Samuel Beckett's late dramatic style in Paul Rhys's Not I for piano solo"

Graduate Student Council Research Symposium

University of Louisville, 2017

"Visceral Intensity: Exploring Samuel Beckett's late dramatic style in Paul Rhys's Not I for piano solo" 